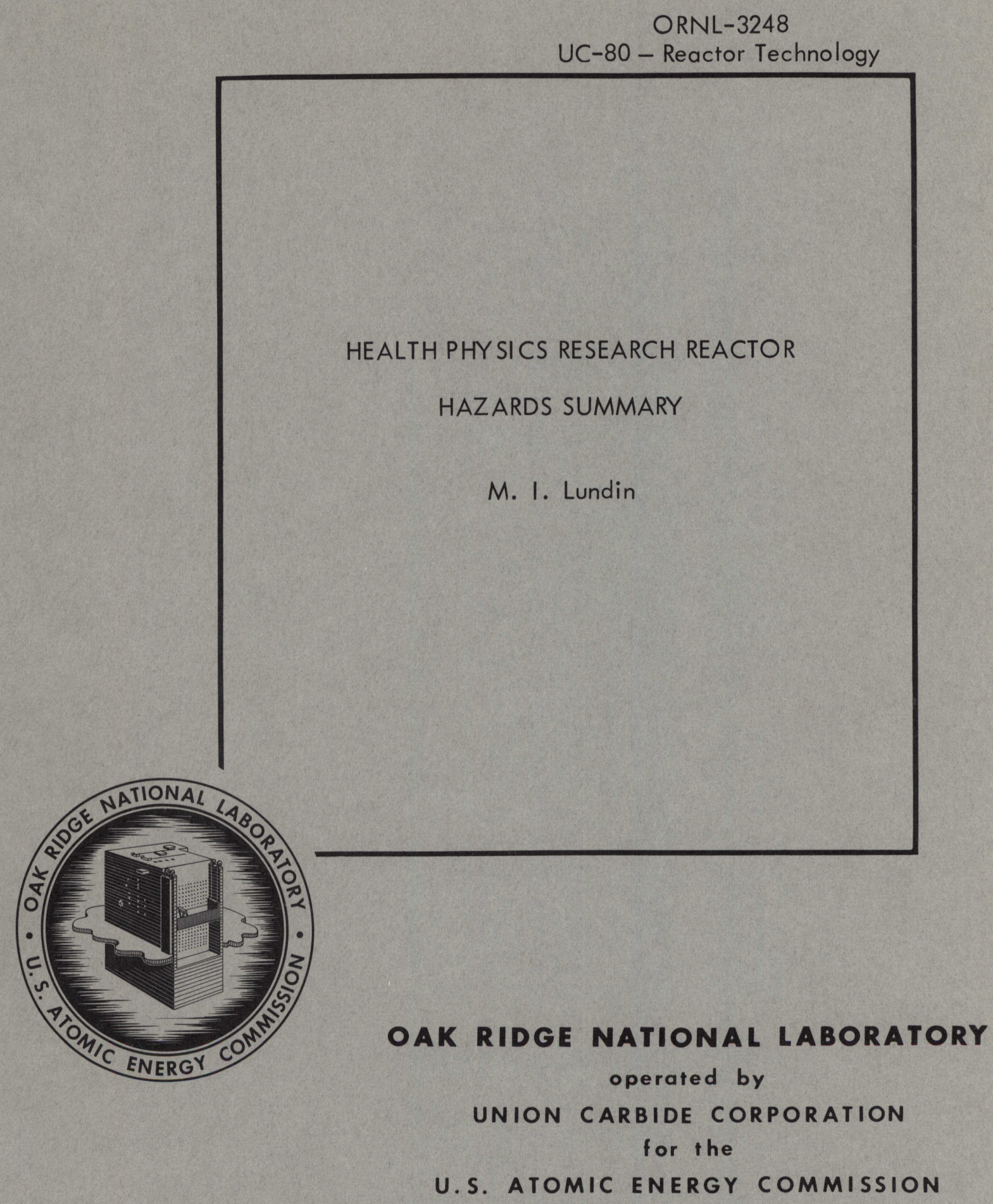




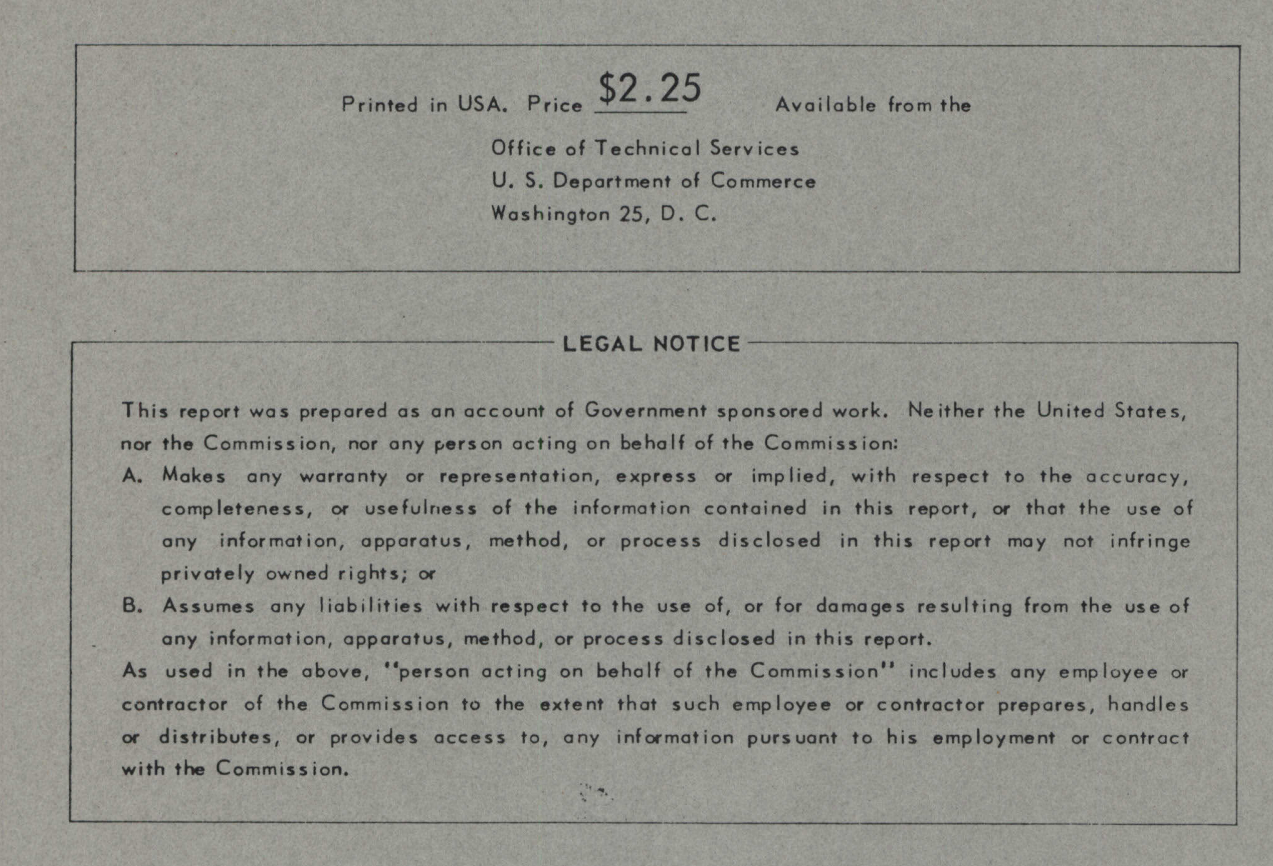




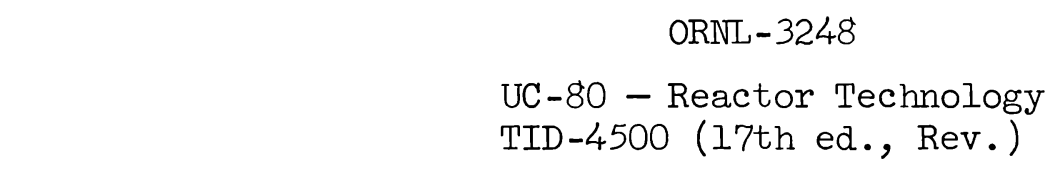

Contract No. W-7405-eng-26

Reactor Division

HEALTH PHYSICS RESEARCH REACTOR HAZARDS SUMMARY

M. I. Lundin

DATE ISSUED

SEP 101968

OAK RIDGE NATIONAL LABORATORY

Oak Ridge, Tennessee

operated by

UNION CARBIDE CORPORATION

for the

U. S. ATOMIC ENERGY COMMISSION 

CONTENTS

\section{Page}

1. INTRODUCTION $\ldots \ldots \ldots \ldots \ldots \ldots \ldots \ldots \ldots \ldots \ldots \ldots \ldots \ldots \ldots$

2. SUMMARY AND CONCLUSTONS $\ldots \ldots \ldots \ldots \ldots \ldots \ldots \ldots \ldots \ldots \ldots \ldots \ldots$

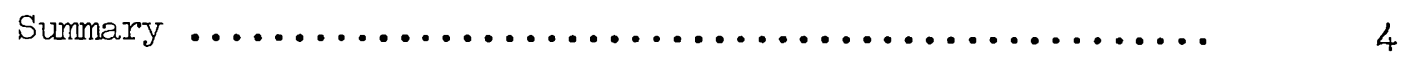

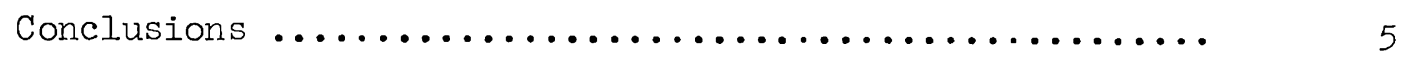

3. DESCRIPTION OF REACTOR AND REACTOR SYSTEMS ............ 6

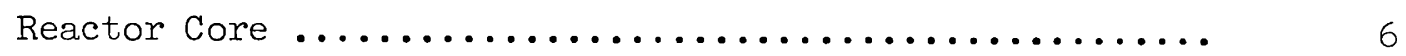

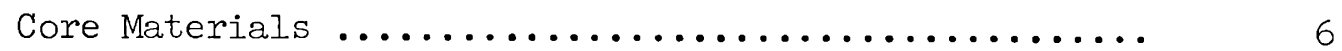

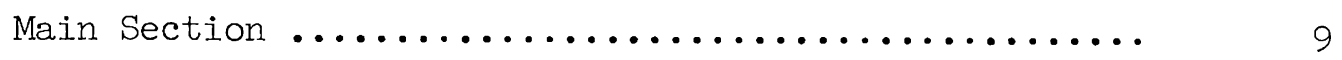

Safety Block ............................. 9

Control Rods $\ldots \ldots \ldots \ldots \ldots \ldots \ldots \ldots \ldots \ldots \ldots \ldots \ldots \ldots$

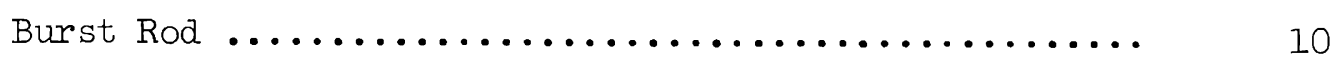

Shim Mass Adjustments $\ldots \ldots \ldots \ldots \ldots \ldots \ldots \ldots \ldots \ldots \ldots$

Reactor Support Structure $\ldots \ldots \ldots \ldots \ldots \ldots \ldots \ldots \ldots \ldots \ldots$

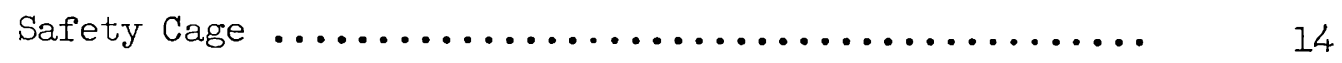

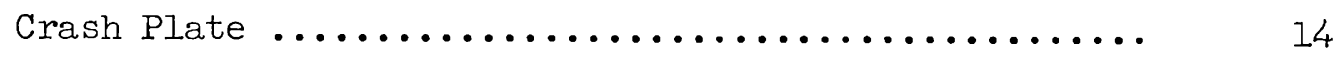

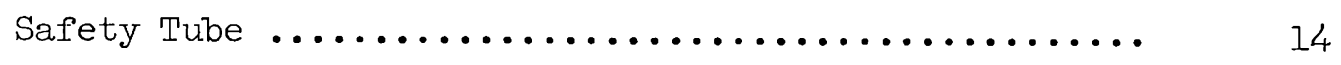

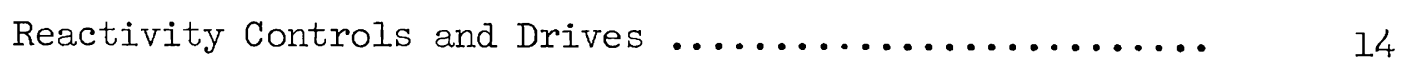

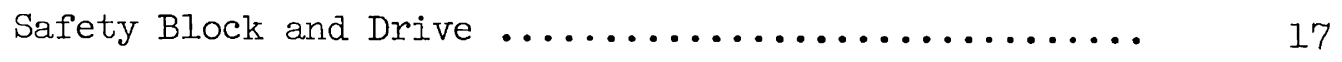

Control Rods and Drives ..................... 19

Burst Rod and Drive ....................... 20

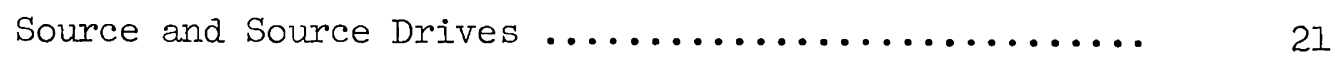

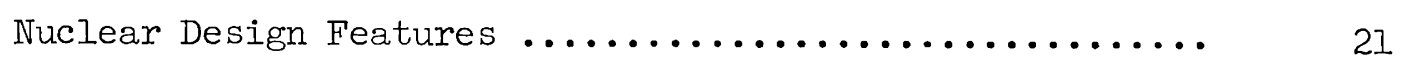

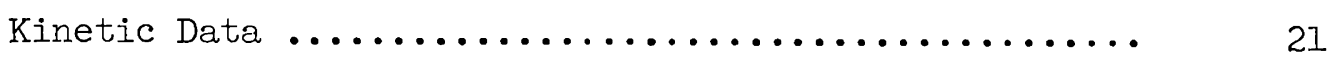

Fission-Rate Distribution ................... 24

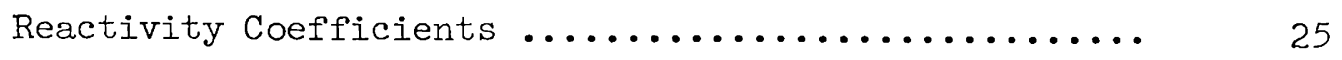

Critical Parameters Under Various Conditions of Reflection ........................... 27

Core Lifetime .......................... 30

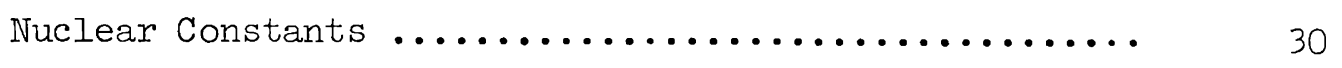


Thermal Design Features ..................... 30

Natural-Convection Cooling ................. 31

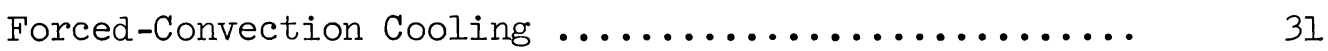

Core Temperature Distributions ............... 32

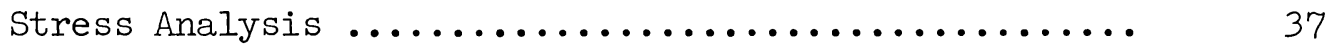

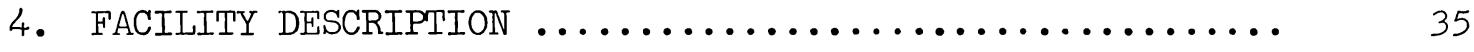

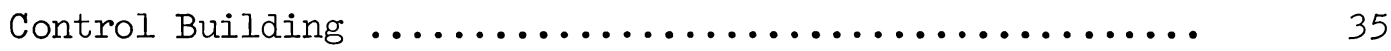

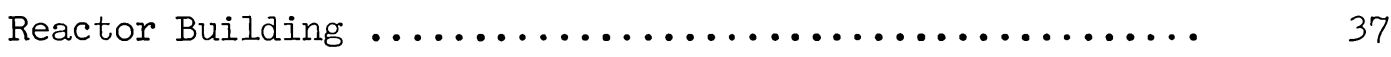

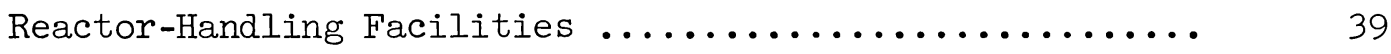

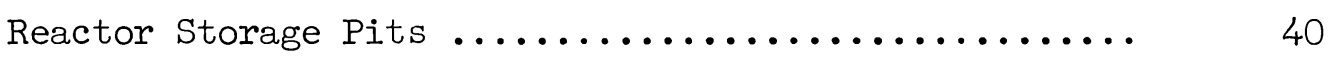

Reactor-Positioning Device .................. 40

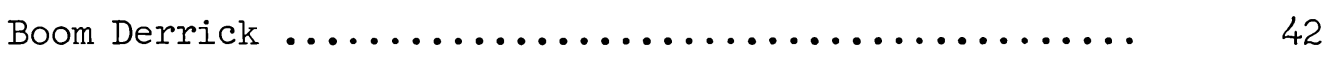

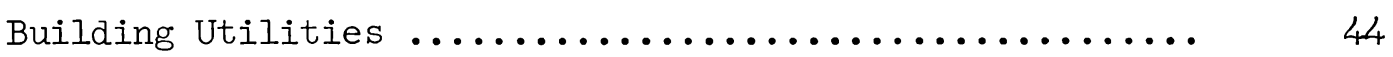

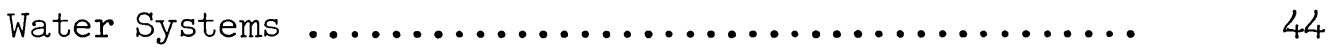

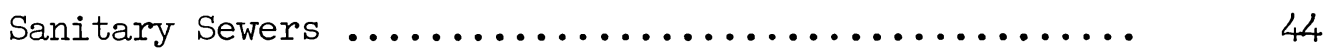

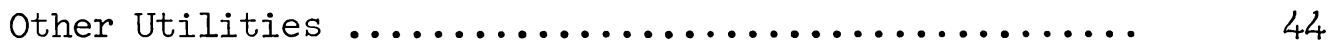

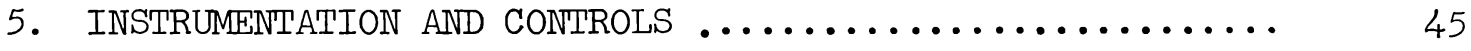

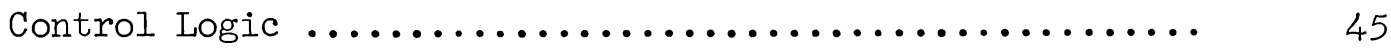

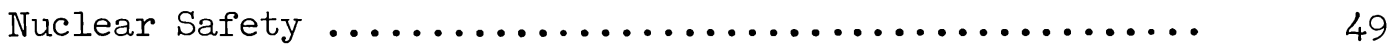

Non-Nuclear Instrumentation $\ldots \ldots \ldots \ldots \ldots \ldots \ldots \ldots \ldots \ldots$

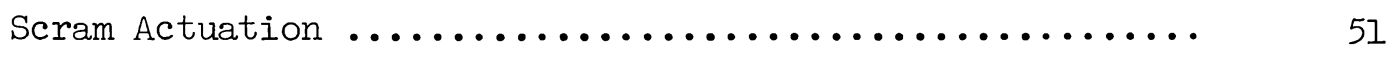

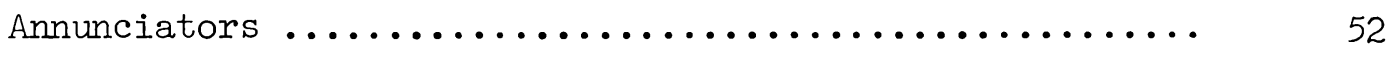

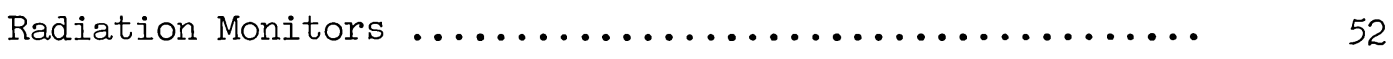

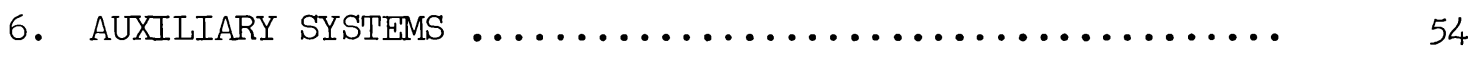

Control Building Ventilation Systems ............... 54

Reactor Building Ventilation Systems ............... 54

Television Monitors ........................ 56

Communications Systems ...................... 56

Intercommunication System $\ldots \ldots \ldots \ldots \ldots \ldots \ldots \ldots \ldots \ldots \ldots \ldots \ldots \ldots$

Public Address System ...................... 56

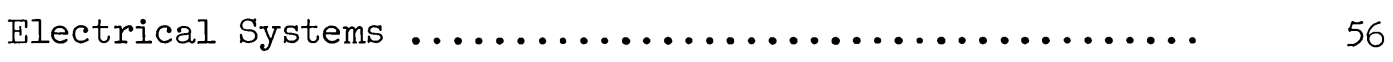

Waste-Disposal System $\ldots \ldots \ldots \ldots \ldots \ldots \ldots \ldots \ldots \ldots \ldots \ldots$ 
7. SITE DESCRIPTION $\ldots \ldots \ldots \ldots \ldots \ldots \ldots \ldots \ldots \ldots \ldots \ldots \ldots \ldots \ldots \ldots \ldots \ldots$

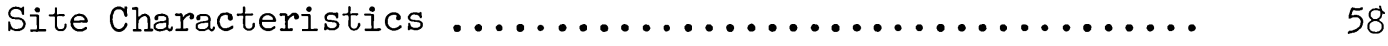

Restricted Areas ............................ 58

Nearby Installations ......................... 60

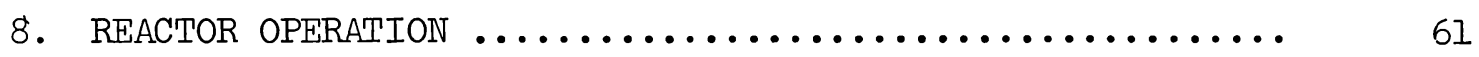

Operating Staff $\ldots \ldots \ldots \ldots \ldots \ldots \ldots \ldots \ldots \ldots \ldots \ldots \ldots \ldots \ldots \ldots$

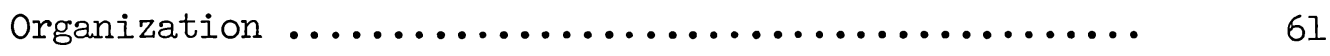

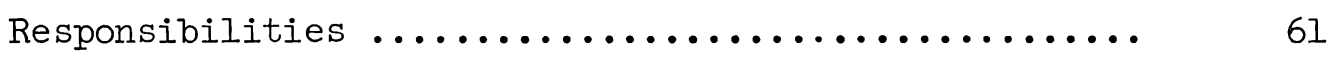

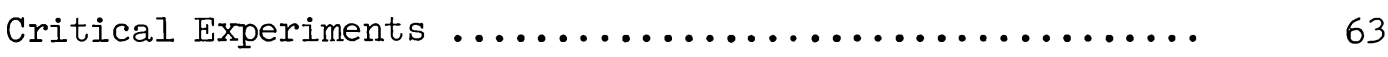

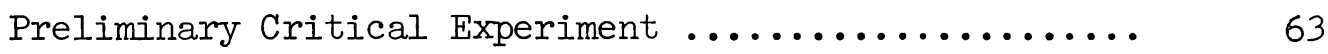

Critical Experiment with Machined Assembly .......... 64

Calibration Experiments for Reflectors ............ 64

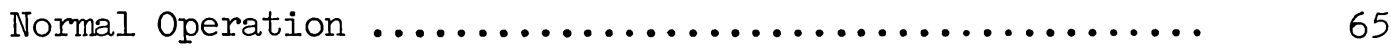

Reactor and Experimental Assembly Positioning ....... 65

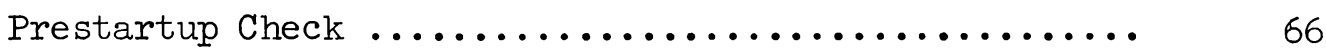

Personnel Check ........................... 66

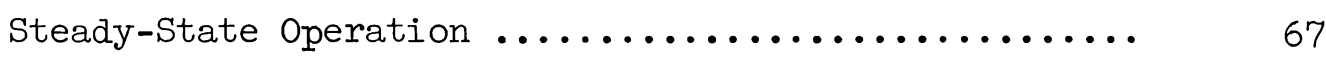

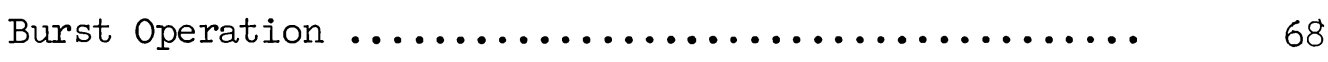

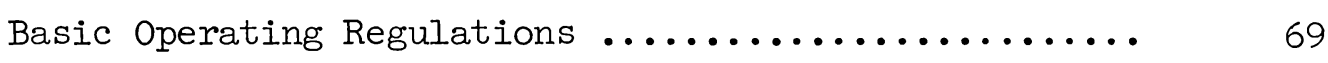

Special Operations .......................... 69

Reactor Handling and Transportation ............. 70

Inspection Procedures ..................... 70

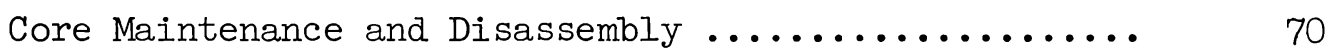

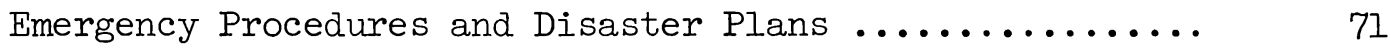

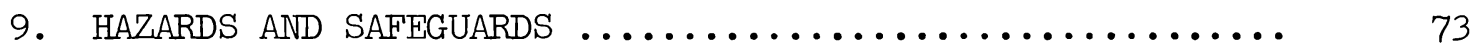

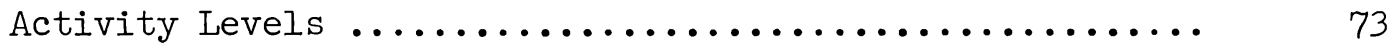

Fission-Product Inventory and Exposure Doses ........ 73

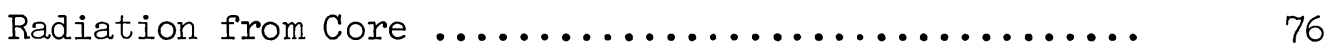

Radiation from Activated Materials .............. 78

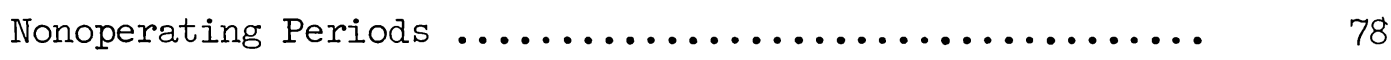

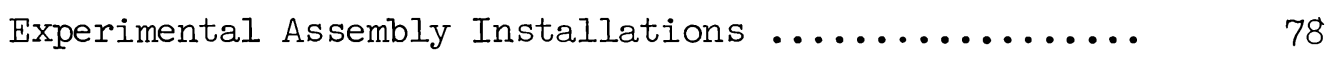

Maintenance and Inspection .................. 79

Reactor Movement ........................ 80

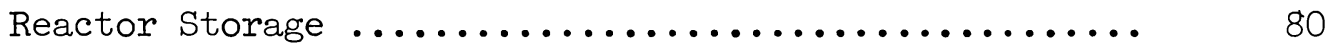


Abnormal Operation $\ldots \ldots \ldots \ldots \ldots \ldots \ldots \ldots \ldots \ldots \ldots \ldots \ldots$

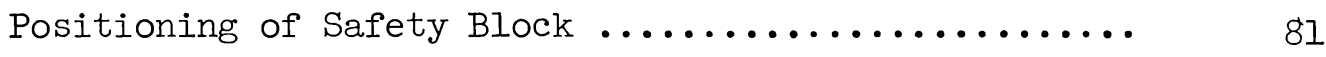

Jamming of Movable Fissionable Materials ........... 82

Control System Failures ..................... 82

Steady-State Mode ....................... 82

Burst Mode ............................ 83

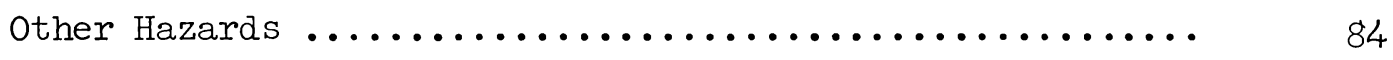

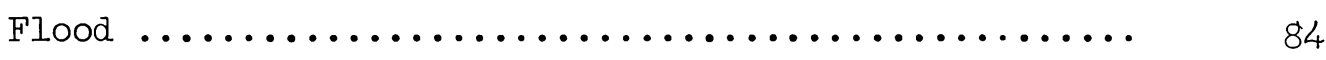

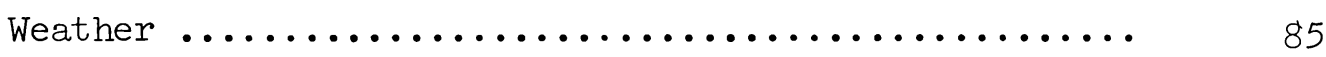

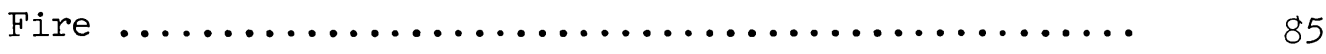

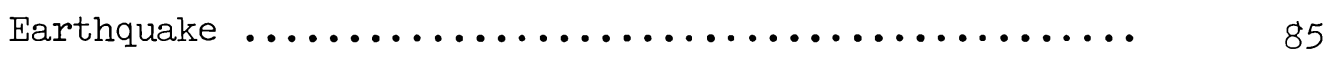

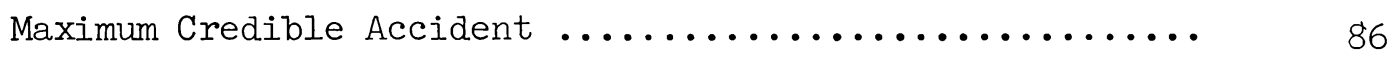

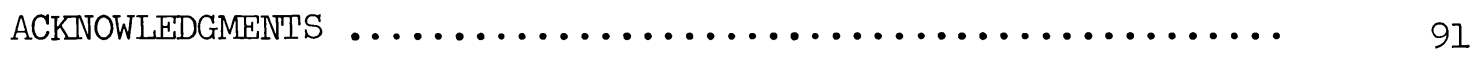

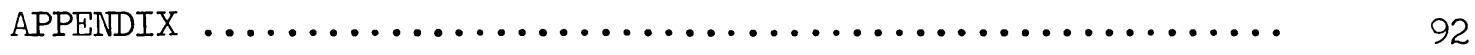

Shielding Considerations $\ldots \ldots \ldots \ldots \ldots \ldots \ldots \ldots \ldots \ldots . \ldots \ldots$ 
The Health Physics Research Reactor is an essentially unmoderated, unreflected, uranium-molybdenum alloy assembly that is capable of producing self-limiting prompt-critical bursts with yields of the order of $10^{17}$ fissions. The design, and performance characteristics, although similar to those of the Los Alamos Scientific Laboratory's Godiva assemblies, are improved by the use of the alloyed fuel material for the core assembly. The reactor will be utilized in the Dosimetry Applications Research Facility (DOSAR) constructed at the Oak Ridge National Laboratory for the furtherance of the health physics and biomedical research programs of the Laboratory.

The design of the reactor and its controls and the siting of the facility are such that normal operation of the reactor, as proposed, will not involve radiation levels that are hazardous to either operating personnel or to the general public. The facility will safely handle the postulated maximum credible accident of $10^{19}$ fissions. 

HEALTH PHYSICS RESEARCH REACTOR HAZARDS SUMMARY

M. I. Lundin

\section{INTRODUCTION}

The Oak Ridge National Laboratory has designed and constructed a Dosimetry Applications Research Facility ("DOSAR") for use in furtherance of its programs in health physics and biomedical research. The bare, unmoderated, reactor assembly, described here, will be used to obtain a high-energy neutron spectrum from pulses of up to $10^{17}$ fissions and, during routine operation at steady-state power, to provide a constant flux for experimental work. Some of the applications presently being considered are discussed below.

1. Radiation Dosimetry. The reactor will be used for the development of instrumentation and techniques for the use of threshold detectors and counters in neutron dosimetry, counting methods in gamma ray dosimetry, and spectrometers in gamma ray and neutron dosimetry.

2. Interaction of Radiation with Matter. Fundamental investigations of the interaction of radiation with matter, such as studies of local energy absorption and linear energy transfer, can be conducted to obtain a better understanding of the effects of radiation on biological systems.

3. Reactor Accidents. Chemicals found in body fluids and tissues, such as sodium, chlorine, and phosphorus, can be activated and studied to obtain critically needed data on doses received in reactor accidents.

4. Ichiban Program. Studies now under way for estimating the doses received by the Hiroshima and Nagasaki survivors can be completed in this facility.

5. Radiobiology. Research on life shortening and the late effects of radiation and leukemia can be accomplished with this reactor, since it will be possible to work with neutron irradiation fields of up to 38,000 $\mathrm{rad} / \mathrm{hr}$ or single burst doses of up to 2,100 rad at $5 \mathrm{ft}$.

6. Medical Research. The reactor will make available a wide beam of neutrons of sufficient intensity for a study of the relative importance of ionization produced in man by secondary electrons, protons, and heavy 
ions. It could provide a facility for treating leukemia patients with total-body neutron irradiation which may offer advantages over treatment by gamma irradiation. Information concerning effects of total-body irradiation on normal human hematopoietic tissue will be attainable under controlled conditions. Such data may be of value in treating victims of future reactor accidents.

The details of the design and analyses of the associated hazards and safeguards are presented here in sufficient scope to provide substantial assurance that this reactor can be safely operated in the Oak Ridge area. The reactor, now designated the Health Physics Research Reactor (HPRR) and formerly called the ORNL Fast Burst Reactor (FBR), is similar to the Los Alamos Godiva II. ${ }^{1}$. The HPRR consists of an essentially unmoderated, cylindrical assembly fabricated from highly enriched uranium-molybdenum alloy. Characteristic operations are quite similar to those of Godiva II and other pulsed reactor assemblies, such as the University of California Lawrence Radiation Laboratory's "Kukla" and the Sandia Pulsed Reactor, for which hazards analyses have been reported. 2,3

The ORNL site report ${ }^{4}$ on the DOSAR Facility was submitted to the SiteEnvironmental Branch of the Division of Licensing and Regulation for review on August 29, 1960, and site approval was received on December 2, $1960 . .^{5}$ In addition the reactor was operated at the Nevada Test Site under the designation Operation BREN. The "Operation Plan and Hazards Report" for Operation BREN was submitted in draft form to the Albuquerque Operations Office of the USAEC on October 16, 1961.6 The conditions of the USAEC

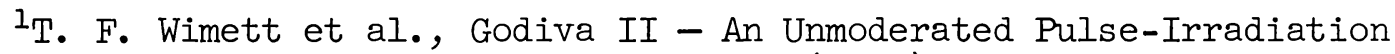
Reactor, Nuclear Sci. and Eng., 8, 691-708 (1960).

${ }^{2}$ F. R. Christie and B. W. Mar, Hazards Summary Report - The Kukla Prompt Critical Assembly, UCRL-6105, Feb. 24, 1960.

${ }^{3}$ R. D. O'Brien, Hazards Evaluation of the Sandia Pulsed Reactor Facility (SPRF), SC-4375A(RR), February 1961.

${ }^{4}$ M. I. Lundin, ORNL Fast Burst Reactor and Facilities, ORNL CF-60-8116, August 29, 1960 .

${ }^{5}$ Letter from H. M. Roth to J. A. Swartout, subject: ORNL Fast Burst Reactor and Laboratories, Project 624-61-1, December 2, 1960.

${ }^{6}$ F. W. Sanders et al., Operation Plan and Hazards Report - Operation BREN, CEX-62.02 (January 1962).
} 
authorization for the Nevada operation were summarized in a letter of February 21, 1962.7 The HPRR was operated safely in the burst mode at the ORNL Critical Facility and it will have been operated in Nevada prior to its installation in the DOSAR Facility at the Oak Ridge National Laboratory.

${ }^{7}$ Letter from S. R. Sapirie to C. E. Larson, subject: Operation of the Health Physics Research Reactor, February 21, 1962. 


\title{
2. SUMMARY AND CONCLUSIONS
}

\author{
Summary
}

The DOSAR Facility will include the bare critical assembly that has been designated the Health Physics Research Reactor (HPRR). The reactor core consists of enriched uranium-molybdenum alloy in a configuration designed to produce self-limiting prompt critical bursts of the order of $1 \times 10^{17}$ fissions. The reactor is similar to the Los Alamos Godiva II, which served as a basis for the design, but it differs in certain significant aspects.

The core material is a uranium-10 wt $\%$ molybdenum alloy rather than unalloyed $\mathrm{U}^{235}$ metal. The addition of molybdenum improves the high-temperature strength of the fuel material, provides increased dimensional stability under thermal cycling, and reduces the thermal-expansion stresses because of its lower modulus of elasticity. As anticipated, this alloy has permitted a significantly larger burst yield than is possible with unalloyed $\mathrm{U}^{235}$ metal. The use of the alloy results in a larger critical mass.

The central 2-in.-diam section of the core is stainless steel. This central section permits a slightly larger burst yield by reducing the peakto-average flux and thus decreasing the local hot-spot temperature. The use of the central stainless steel section also results in a larger core mass.

The supporting structure for the drives and other mechanisms associated with the HPRR is located above rather than below the core as in Godiva II. The ORNL HPRR is operated with the support structure and core suspended from a positioning device so that the areas underneath and to the sides of the core are available for experiments.

Safety devices are available for installation as required during certain types of experiments. A crash plate can be suspended beneath the reactor, and a safety tube is attached to the bottom section of the core to prevent the addition of significant reactivity in case of an accident in which the reactor assembly would fall to the ground. These features are intended to minimize the potential yields from a fall. 
The HPRR will be housed within a structural-steel-framed, insulated, aluminum-sided building specifically designed for this purpose and located in a small valley on Copper Ridge about $13 / 8$ miles east of the Tower Shielding Facility. An antipersonnel chain-link fence surrounds this area at a radius of about $1000 \mathrm{ft}$ to limit access. A posted perimeter fence will be installed ${ }^{1}$ to provide access restriction of the general public. The control building is a reinforced concrete structure located behind an intervening hill. It is approximately $800 \mathrm{ft}$ from the reactor operating site.

The design of the reactor and its controls and the site of the facility are such that normal operation of the reactor, as proposed, does not involve radiation levels that are hazardous to either operating personnel or to the general public. There are no normal processes or operations contemplated that would produce radioactive wastes or result in dissemination of contaminated materials.

The existence of potential hazards is recognized. These hazards are associated with uncontrollable power excursions resulting from the accidental assembly into highly supercritical reactor configurations. The probability of such an event is greatly minimized by the design of the reactor support and safety structures and will be ensured by rigid administrative control of experiments and operating procedures.

The facility is designed and sited to safely handle the maximum credible accident which would produce an excursion of $10^{19}$ fissions. In order to obtain a burst yield of $10^{19}$ fissions, the undetected addition of over 50 cents worth of reactivity would be required.

\section{Conclusions}

The information presented in this report indicates that the maximum credible burst of $10^{19}$ fissions would result in exposure doses at $3000 \mathrm{ft}$ of no greater than $25 \mathrm{mrad}$. This limitation is contingent upon the effectiveness of administrative controls and procedures inherent to the safe operation of this type of reactor.

${ }^{1}$ This fence is scheduled for installation by the Tennessee Valley Authority in Fiscal Year 1963. 


\section{DESCRIPTION OF REACTOR AND REACTOR SYSTEMS}

The ORNL Health Physics Research Reactor consists of an essentially unmoderated, cylindrical, critical assembly fabricated from approximately $115 \mathrm{~kg}$ of $93.17 \%$ enriched uranium-10 wt \% molybdenum alloy. A sketch of the components of the reactor core is presented in Fig. 3.1. The assembly is designed for burst operation with yields up to $1 \times 10^{17}$ fissions and can achieve continuous steady-state operation at powers up to $1 \mathrm{kw}$, utilizing natural-convection air cooling. It is also estimated that a power of approximately $10 \mathrm{kw}$ can be maintained for more than $10 \mathrm{~min}$ with forcedconvection air cooling.

\section{$\underline{\text { Reactor Core }}$}

The fissionable components of the HPRR are fabricated of cast and homogenized enriched uranium-10 wt \% molybdenum alloy having an average density of $17.1 \mathrm{~g} / \mathrm{cm}^{3}$. The uranium is enriched to $93.17 \% \mathrm{U}^{235}$. The core of the reactor is a cylinder 8 in. in diameter and approximately 9 in. long. The cylinder consists essentially of two parts, an outer shell and a movable inner shell or safety block. In addition, three movable rods pass through stainless steel-lined openings in the outer shell. Two of these rods, the mass adjustment and regulating rods, are used to adjust the reactivity to compensate for the reflection of experimental equipment placed near the reactor. The third rod, the burst rod, contains the required reactivity for rapid insertion to produce fission bursts.

The uranium contents of the pieces that make up the first assembly are listed in Table 3.1.

All surfaces of the fissionable components are nickel plated to a thickness of 3 to 5 mils for oxidation protection. In addition the outer surfaces of the burst, mass adjustment, and regulating rods are chromium plated over the nickel plating to reduce sliding friction. Core Materials

In efforts to improve the performance characteristics of the Godiva type of reactor, two major drawbacks to the use of unalloyed uranium 


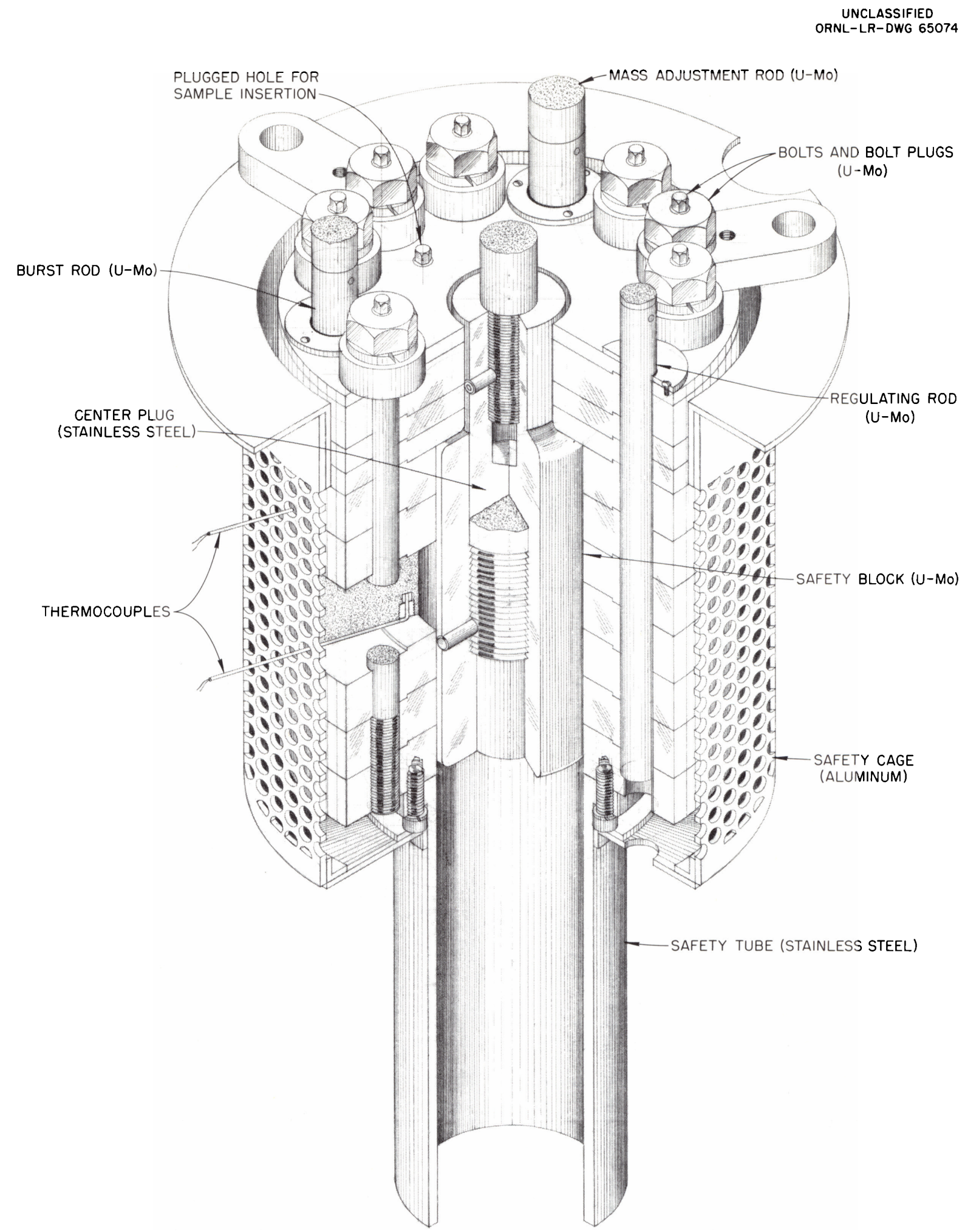

Fig. 3.1. Health Physics Research Reactor Core. 
Table 3.1. Uranium Content of Alloy in Core

\begin{tabular}{|c|c|c|}
\hline Component & $\underset{(\mathrm{k}}{\text { Uranium }}$ & ontent \\
\hline \multicolumn{3}{|l|}{ Outer shell } \\
\hline $\begin{array}{l}3.5-i n \cdot-i \cdot d . \text { annulus } \\
2 \text { 5/32-in.-i.d. annulus }\end{array}$ & & $\begin{array}{l}55.8 \\
23.9\end{array}$ \\
\hline Bolts and plugs & & 10.3 \\
\hline $\begin{array}{l}\text { Bolts (total of 9) } \\
\text { Bolt plugs (total of } 8 \text { ) } \\
\text { Glory-hole plug }\end{array}$ & $\begin{array}{l}9.2 \\
0.98 \\
0.13\end{array}$ & \\
\hline \multicolumn{2}{|l|}{ Movable sections } & 12.5 \\
\hline $\begin{array}{l}\text { Mass adjustment rod } \\
\text { Regulating rod } \\
\text { Safety block }\end{array}$ & $\begin{array}{r}1.7 \\
0.7 \\
10.1\end{array}$ & \\
\hline $\begin{array}{l}\text { Total core uranium, } \\
\text { burst rod }\end{array}$ & exclusive of & 102.5 \\
\hline \multirow[t]{2}{*}{ Burst rod } & & 0.96 \\
\hline & Total & 103.46 \\
\hline
\end{tabular}

became apparent. These drawbacks are the low strength and the growth and distortion of uranium when subjected to thermal cycling. Thus the prime requirements for the fuel material were that it be dimensionally stable under thermal cycling, possess high strength with reasonable ductility at elevated temperatures, and be within the scope of existing technology to permit its use with a minimum of developmental effort. Careful study of the available literature indicated that uranium-10 wt \% molybdenum alloy in the gamma-stabilized condition would meet the design requirements. Experiments have shown that this uranium-molybdenum alloy does not exhibit the pyrophoric properties that are characteristic of unalloyed uranium.

An extensive summary of the available information on the alloy and a discussion of the properties and technology of the material as they affect and limit the design of the reactor was presented in the preliminary 
design report. ${ }^{1}$ Results of tests to determine whether distortion or transformation would occur during cycling within the temperature range anticipated for the reactor fuel were also reported. ${ }^{2}$

Main Section

The outer shell of the core consists of a stack of stepped, annular disks made of the enriched uranium-molybdenum alloy. This stack is supported from the reactor structure by three steel mounting lugs attached at the top. This method of support permits thermal expansion of the core in all directions with a minimum of restraint. The stepped disks of the outer shell are held together by nine 3/4-in.-diam uranium-molybdenum fuel alloy bolts, which thread into the bottom disk. The outer shell is penetrated by lined holes for (1) the regulating rod, (2) the mass adjustment rod, and (3) the burst rod and an unlined hole for experimental exposures. Slots pass through the outer shell for the installation of two thermocouples near the center of the assembly. The thermocouple junctions are imbedded near the inner surfaces of two of the fuel disks, as shown in Fig. 3.1.

\section{Safety Block}

The large central cavity in the outer shell accommodates the safety block, which is $33 / 8 \mathrm{in}$. in diameter and $6 \mathrm{l} / 2 \mathrm{in}$. long. It is made of the uranium-molybdenum fuel alloy and has a central stainless steel plug approximately 2 in. in diameter. The safety block is supported by being threaded and pinned onto the steel plug, which, in turn, is connected to the drive shaft by a threaded and pinned connection. Because reliable shutdown of the reactor depends largely upon the easy withdrawal of the safety block, a clearance of approximately l/l6 in. is provided between the safety block and the outer shell to minimize the possibility of jamming. This clearance also provides a gap for cooling-air flow. The

\footnotetext{
${ }^{1}$ Preliminary Design of the ORNL Fast Burst Reactor, NDA-2136-1, July 30, 1960.

${ }^{2}$ Thermal Cycling Tests on U-10 w/O Mo for the ORNL Fast Burst Reactor, NDA-2136-2, July 30, 1960.
} 
safety block is normally either fully in or fully out of the reactor. In its out position, its bottom protrudes 7.5 in. below the core, as shown in Fig. 3.2.

Control Rods

Two control rods (the regulating rod and the mass adjustment rod) enter the outer shell from the top. These rods are 5/8 and 1 in. in diameter, respectively, and run essentially the full length of the core. The reactivity worth of these two rods is used to compensate for reflection from experimental equipment placed near the reactor. These rods are attached to their drives by threaded and pinned connections.

Burst Rod

The burst rod is $3 / 4$ in. in diameter and provides an incremental change in reactivity worth of approximately $\$ 1$ when fully inserted in the reactor from its partially withdrawn position. This rod is rapidly inserted in the reactor to initiate a burst. It is threaded and pinned to its drive.

Shim Mass Adjustments

Shim mass adjustments can be made by means of plugs located within the nine bolts that clamp the core sections together. These bolts have central holes in their shanks to increase their energy-absorption capacity. The holes may be filled with fuel or steel plugs, depending on reactivity requirements. In addition the plug used to fill the experiment hole during the period when it is not in use may be either fuel or steel, again depending on reactivity requirements. A total adjustment of $1.1 \mathrm{~kg}$ of uranium is thus available.

\section{$\underline{\text { Reactor Support Structure }}$}

The structural arrangement of the reactor holding and assembling device is shown in Figs. 3.3 and 3.4. All structural members are stainless steel. The drive-mounting plate located approximately $83 / 4$ in. 


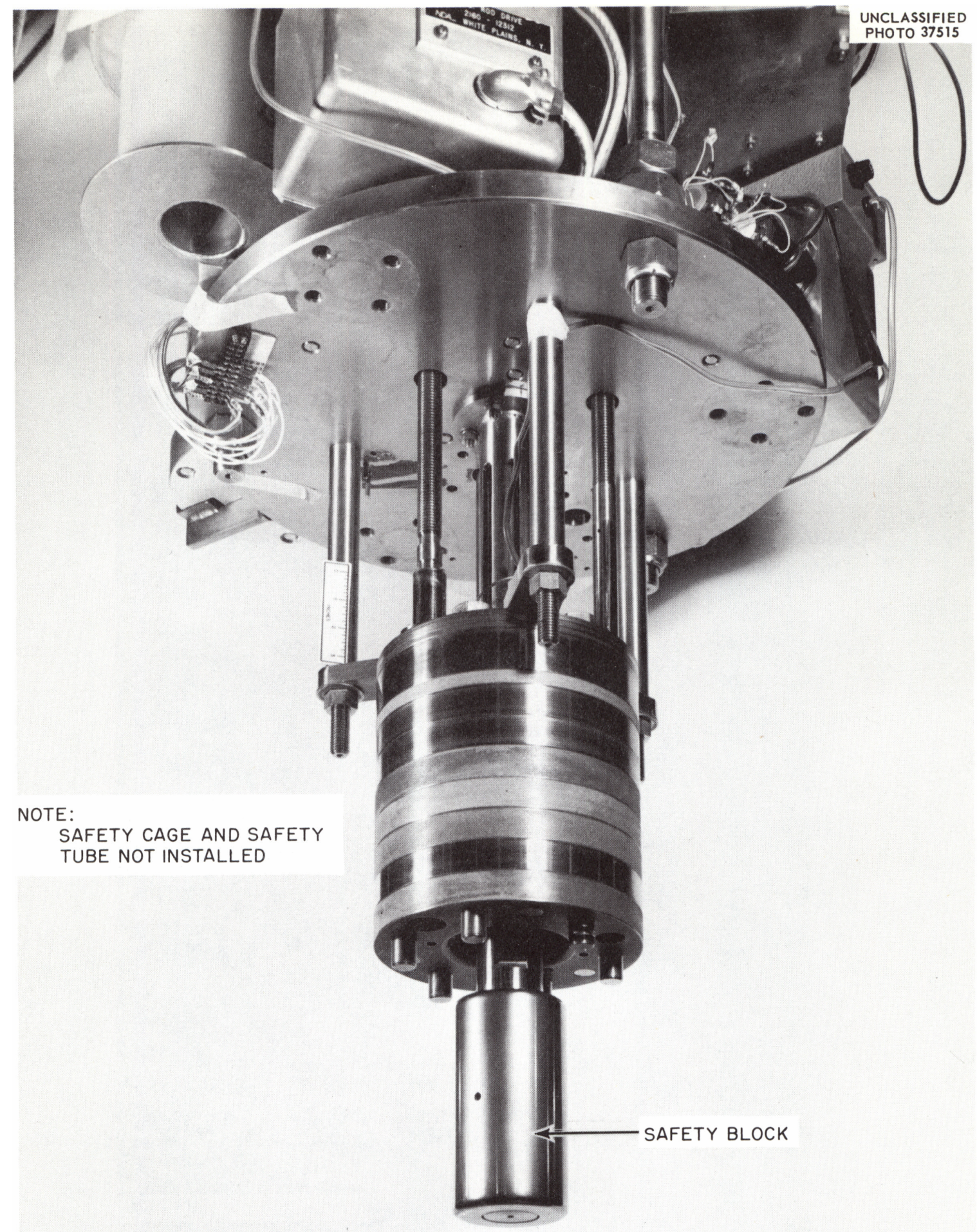

Fig. 3.2. Core During Critical Experiments with Safety Block Withdrawn. 


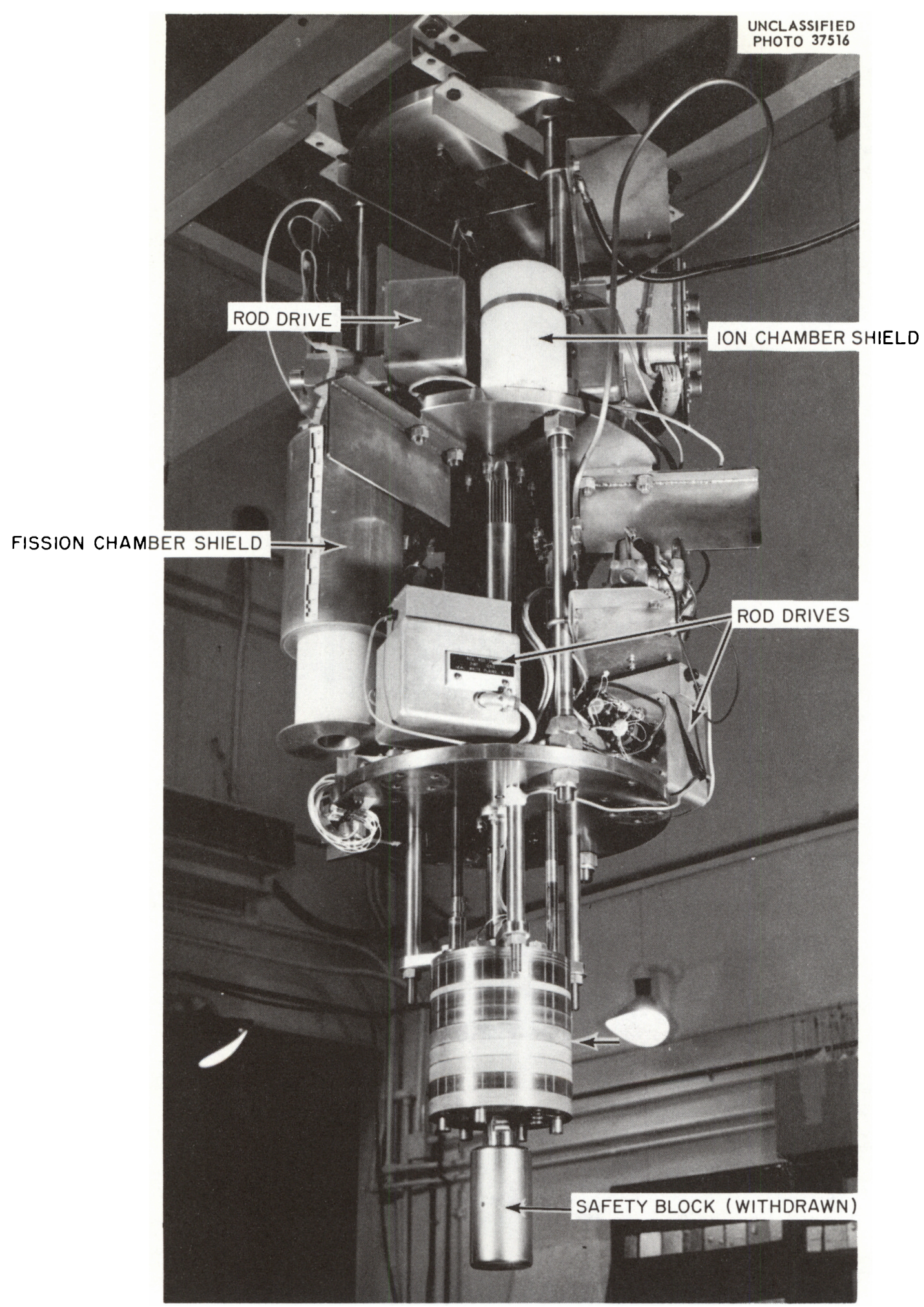

Fig. 3.3. Core Attached to Reactor Support Structure During Critical Experiments. 


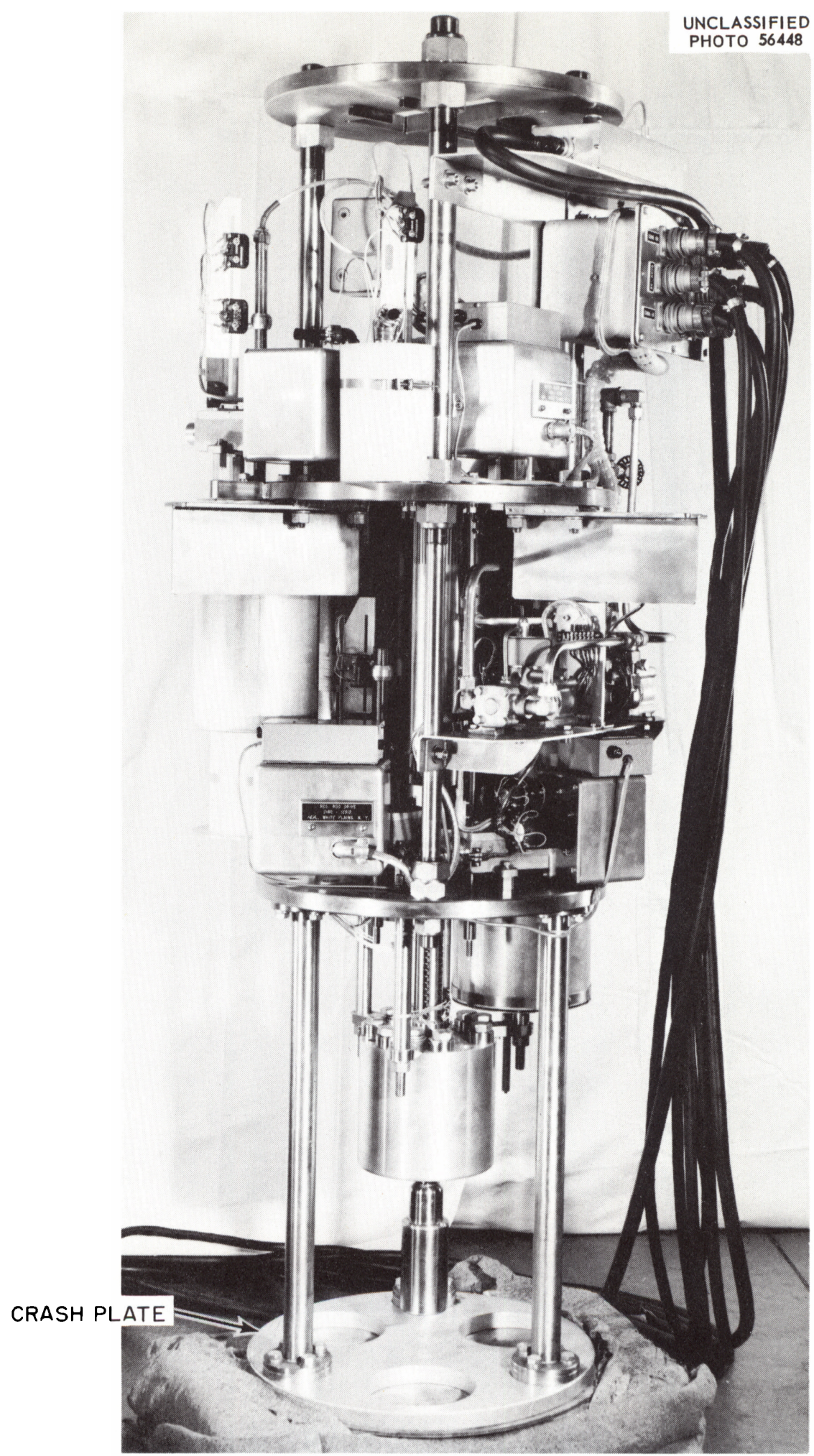

Fig. 3.4. Reactor Support Structure Shown with Dummy Core During Mechanical Checkout. 
from the top of the reactor core supports the drives for the burst, regulating, and mass adjustment rods. This steel plate is attached to the top plate by means of three steel rods. An intermediate plate serves to make the structure more rigid and supports the drives for the safety block, fission chamber, and source. The top plate has provision for engagement of the reactor-positioning device from which the reactor is normally suspended during operation. The structure around the sides and bottom of the core has been minimized in order to leave space for irradiation experiments. The total weight of the structure, including the reactor core, is approximately $1000 \mathrm{lb}$.

Safety Cage

An aluminum safety cage, supported by the core mounting lugs and 1ocated approximately $\mathrm{l} / 2 \mathrm{in}$. from the core surface, is available for use when required to prevent the placement of experimental assemblies at locations too close to the reactor. The cage can be seen in Fig. 3.1.

\section{Crash Plate}

A crash plate (see Fig. 3.4) supported from the drive-mounting plate by three pipe columns can be installed approximately 9 in. below the bottom of the core when required. This assembly would transmit the shock to the reactor holding structure rather than directly to the core if the assembly fell. It would also minimize the possibility of the core falling into intimate contact with a reflector.

\section{Safety Tube}

A steel safety tube (see Fig. 3.5) that encircles the volume into which the safety block scrams is attached to the bottom plate of the core. This tube will prevent driving the safety block into the core in case the reactor is accidentally dropped.

\section{$\underline{\text { Reactivity Controls and Drives }}$}

Reactivity is controlled by the accurate positioning of four movable pieces of fuel in the core. The movement of these pieces of fuel, namely, 


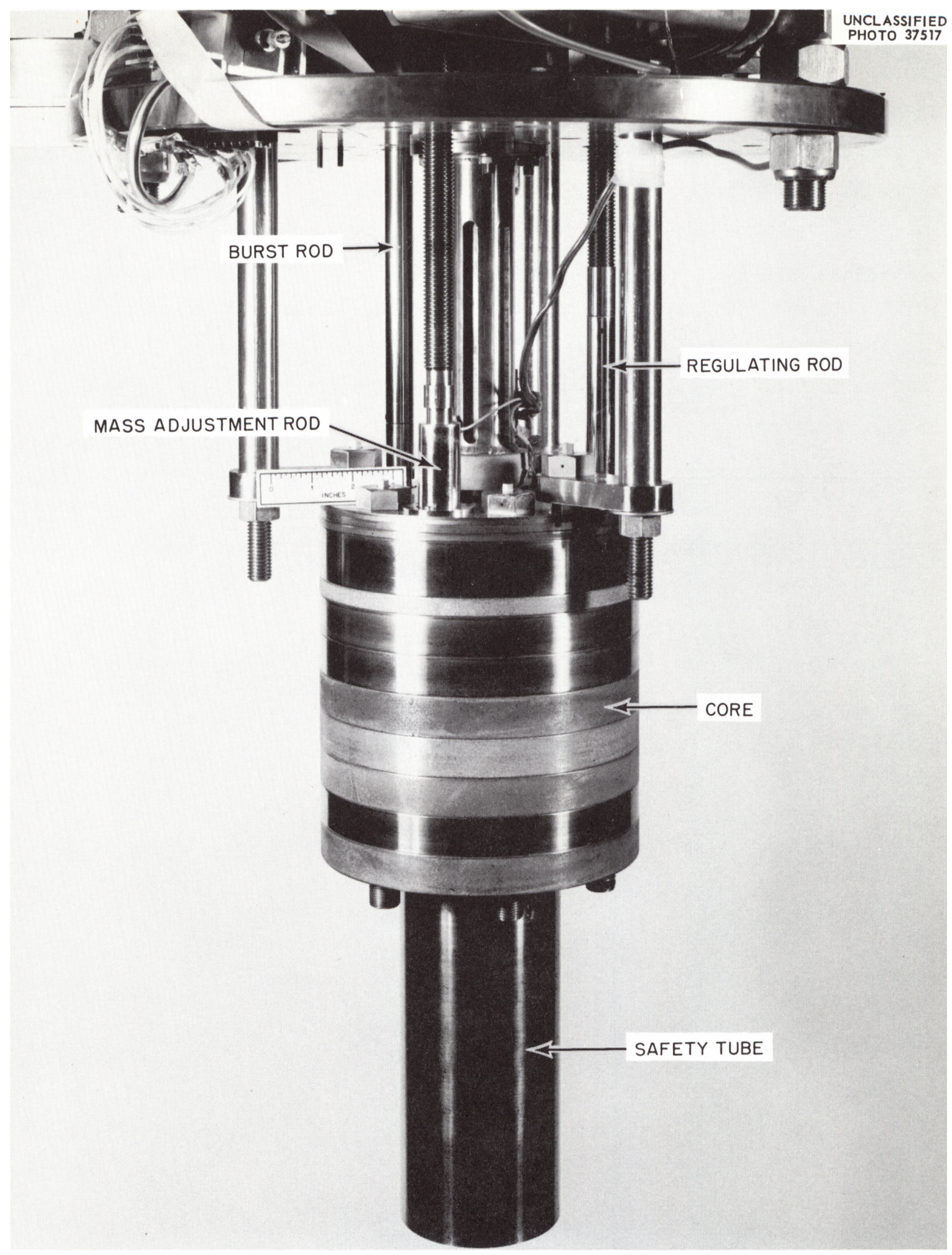

Fig. 3.5. Core with Safety Tube Attached. 
the mass adjustment rod, the regulating rod, the burst rod, and the safety block, is discussed in detail below. The controls are interlocked so that at any given time the addition of reactivity may be safely controlled. The sequence of operation is likewise interlocked and combined with safety instrumentation to require that a safe assembly procedure is followed. The safety philosophy and instrumentation are discussed in Section 5 and the operating procedures are outlined in Section 8. The reactivity and drive characteristics are discussed in detail below and are summarized in Table 3.2. The reactivity worth of the mass adjustment, regulating, and burst rods as a function of position was experimentally determined in the preliminary critical experiments ${ }^{3}$ and is shown in Fig. 3.6.

${ }^{3}$ J. T. Michalczo, Reactivity Calibrations and Fission Rate Distributions in an Unmoderated, Unreflected Uranium-Molybdenum Alloy Research Reactor, ORNL-TM-189 (in press).

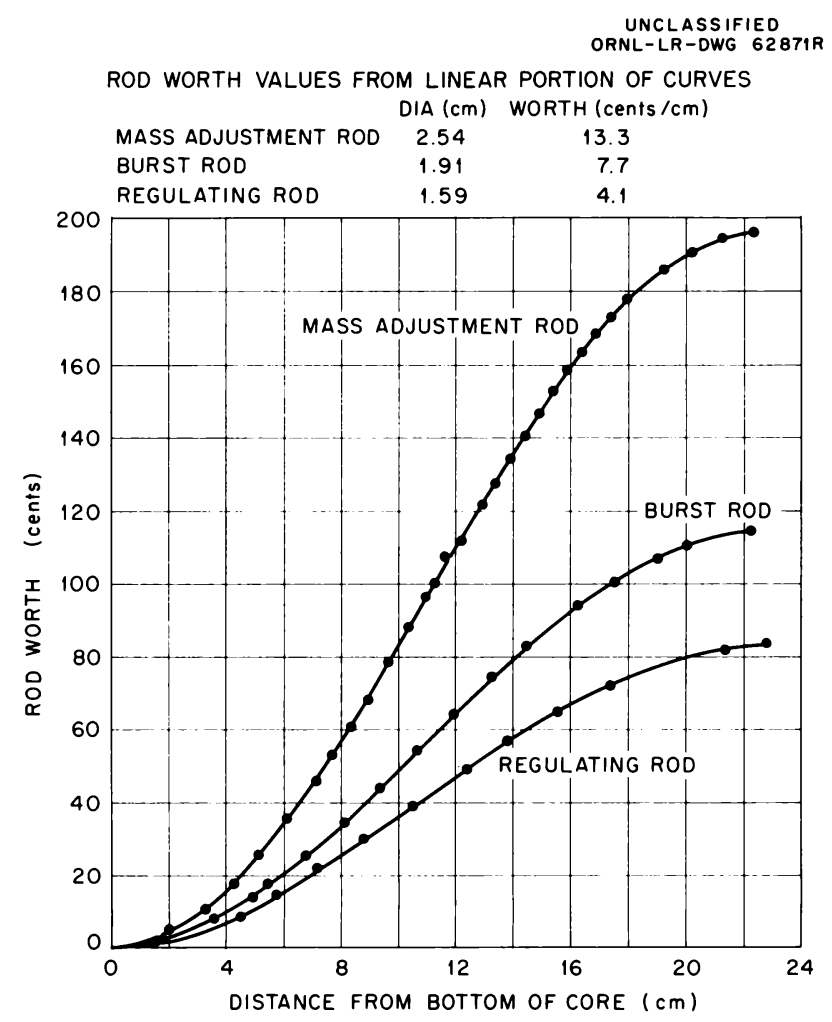

Fig. 3.6. Reactivity vs Position for HPRR Burst and Control Rods. 
Table 3.2. Reactivity and Drive Characteristics of HPRR

\begin{tabular}{lccll}
\hline \multicolumn{1}{c}{ Item } & $\begin{array}{c}\text { Uranium } \\
\text { Content } \\
(\mathrm{kg})\end{array}$ & $\begin{array}{c}\text { Total } \\
\text { Reactivity } \\
(\$)\end{array}$ & Type of Drive & $\begin{array}{c}\text { Drive } \\
\text { Speed }\end{array}$ \\
\hline Safety block & 10.1 & 20 & Electromechanical & $1.9 \mathrm{in.} / \mathrm{min}$ \\
Mass adjustment rod & 1.7 & 1.95 & Electromechanical & $2.5 \mathrm{in.} / \mathrm{min}$ \\
Regulating rod & 0.7 & 0.83 & Electromechanical & $2.5 \mathrm{in.} / \mathrm{min}$ \\
Burst rod & $0.96^{\mathrm{a}}$ & $1.15^{\mathrm{a}}$ & Pneumatic & $7.5 \mathrm{in}$. in \\
& & & & $\sim 40 \mathrm{msec}$ \\
\hline
\end{tabular}

$a_{\text {The }}$ values are based on the total length of the burst rod and its complete removal from the core. The actual stroke of $7.5 \mathrm{in}$. results in a $\delta \mathrm{k}$ of approximately $\$ 1$.

\section{Safety Block and Drive}

Safety-block movement is accomplished by means of an electric-motor driven $^{4}$ worm-and-screw-type linear actuator capable of instantaneous reversal of direction of motion. This drive limits the safety-block insertion speed to approximately $1.9 \mathrm{in./min}$. The safety block has a central stainless steel plug that is connected to the drive shaft. The block is supported from above and inserted into the core from below. Withdrawal is accomplished by vertical movement downward. The total travel distance of the safety block is $7.5 \mathrm{in}$.

The safety block is scrammed in the downward direction by de-energizing the holding electromagnet that couples the safety block drive shaft to the electromechanical drive. A spring is provided around the drive shaft to decrease the scram time and to provide the capability of partially expelling the safety block from the core if the reactor should accidentally become inverted. To ensure that the safety block is always inserted to the same position, a positive stop in the form of a rigidly supported cylinder with three electrical contacts is used to provide a signal when two out of three of the contacts have made up on safety block insertion.

\footnotetext{
4The motors are the shaded-pole type and thus their direction of rotation is unaffected by external changes in phase of the a-c power supply.
} 
This signal is interlocked into the operating sequence. Tests have shown that the drive system can reposition the safety block to \pm 0.0001 in. if no scram has taken place and to 0.001 in. after release by the electromagnet. An overtravel spring in the drive circuit provides positive seating. The force required to compress the overtravel spring will not result in holding-magnet disengagement.

The safety block controls the major portion of the shutdown reactivity change. It contains $10.1 \mathrm{~kg}$ of uranium and has a total reactivity worth of approximately $\$ 20$. The safety block is inserted twice in the procedure leading up to burst production. Electrical interlocks prevent the initial insertion unless the neutron source is in the insert position. The safety block is normally either fully in or fully out and is used as the primary mechanical shutdown device to bring the reactor to below delayed critical following burst or steady-state operations. It provides fast scram capability for the reactor to limit the reactor temperature rise following a burst. The fast scram is accomplished by electronic signal from the safety instruments during the initial rise of the burst spike. Tests have indicated that the electromagnet release time is approximately $0.004 \mathrm{sec}$. An effective scram, defined as the time at which the reactor is taken below delayed critical, is completed in approximately $40 \mathrm{msec}$ after start of movement of the safety block. Characteristics of the safety block as a function

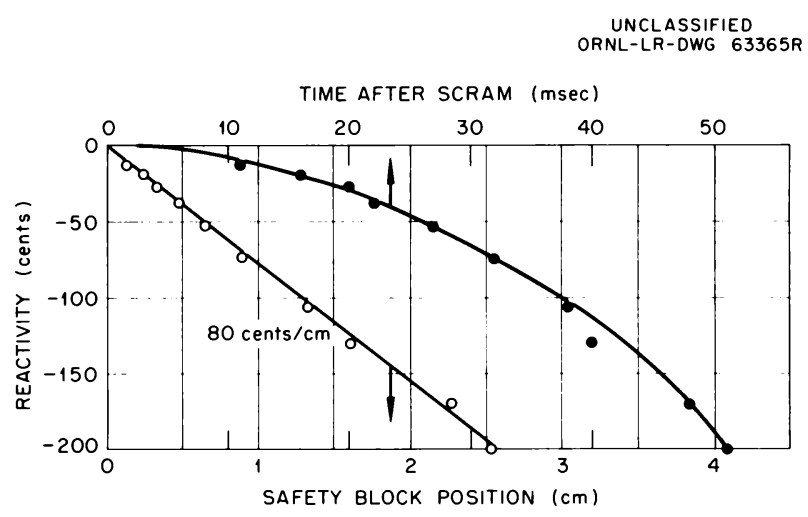

Fig. 3.7. Reactivity Worth of the HPRR Safety Block as a Function of Its Position and Time After Scram. of position and time have been determined ${ }^{3}$ experimentally and are shown in Fig. 3.7.

The safety block drive is provided with the following position switches: (1) upper limit switch, (2) lower limit switch, (3) clutch switch, showing the aspect of the release magnet, (4) seat switch, showing whether the rod reached the fully out 
position when released, and (5) three contact switches to show that the block is fully inserted. The position of the safety-block drive is constantly indicated on the reactor control console by a dual synchro system. The coarse synchro indicates full travel in 270 degrees of rotation, while the fine synchro indicates $0.5 \mathrm{in}$. per revolution. In actual use the magnet will be driven down against the pole face to prevent accidental insertion of the safety block.

\section{Control Rods and Drives}

The drive mechanisms for the control rods, that is, the regulating and mass adjustment rods, are electric-motor-driven worm-and-screw-type linear actuators that are capable of instantaneous reversal of direction of motion (similar to the safety block drive) and are operated individually. The drives for the two rods are identical except that the regulating rod may be servo-operated for automatic power level control. The rods run the full length of the core and are driven from above at the rate of approximately $2.5 \mathrm{in.} / \mathrm{min}$. These rods do not have scram capabilities but are automatically withdrawn at normal speed on a reactor scram signal.

The positions of both rods may be read directly on synchro indicators on the control console. The mass adjustment rod has a dual synchro system calibrated similarly to that for the safety block. The regulating rod utilizes a single synchro calibrated to show full stroke in less than 270 degrees of rotation. Using this instrumentation, the positioning of the regulating rod has been found to be reproducible to $\pm 0.005 \mathrm{in}$. and that of the mass adjustment rod to \pm 0.001 in. Upper and lower limit position switches are provided on both rod drives.

Interlocks prevent the initial insertion of the rods unless the neutron source is inserted and the safety block is seated in the fully in position. Following establishment of a satisfactory reactivity configuration with the rods, further inward movement is prevented by interlocks after the safety block has left its seat. Withdrawal of the rods is permitted to compensate for slight core temperature changes as a result of cooling that may occur before the final steps of the burst-generation 
procedure. During steady-state operation, the smaller of the two rods, the regulating rod, may be servo-operated for automatic power control. A tachometer on the rod drive provides derivative control for the servo system.

Burst Rod and Drive

The brust rod is driven by a pneumatically operated cylinder. It is inserted into the core from above and is withdrawn vertically upward. The 2-in.-bore drive cylinder is capable of inserting the burst rod in approximately $0.040 \mathrm{sec}$ so that a prompt-critical configuration can be achieved before an appreciable neutron population builds up.

The pneumatic system used to supply air to the drive cylinder is shown in Fig. 3.8. The gas supply for the drive is located in two tanks

UNCLASSIFIED
ORNL-LR-DWG 65075

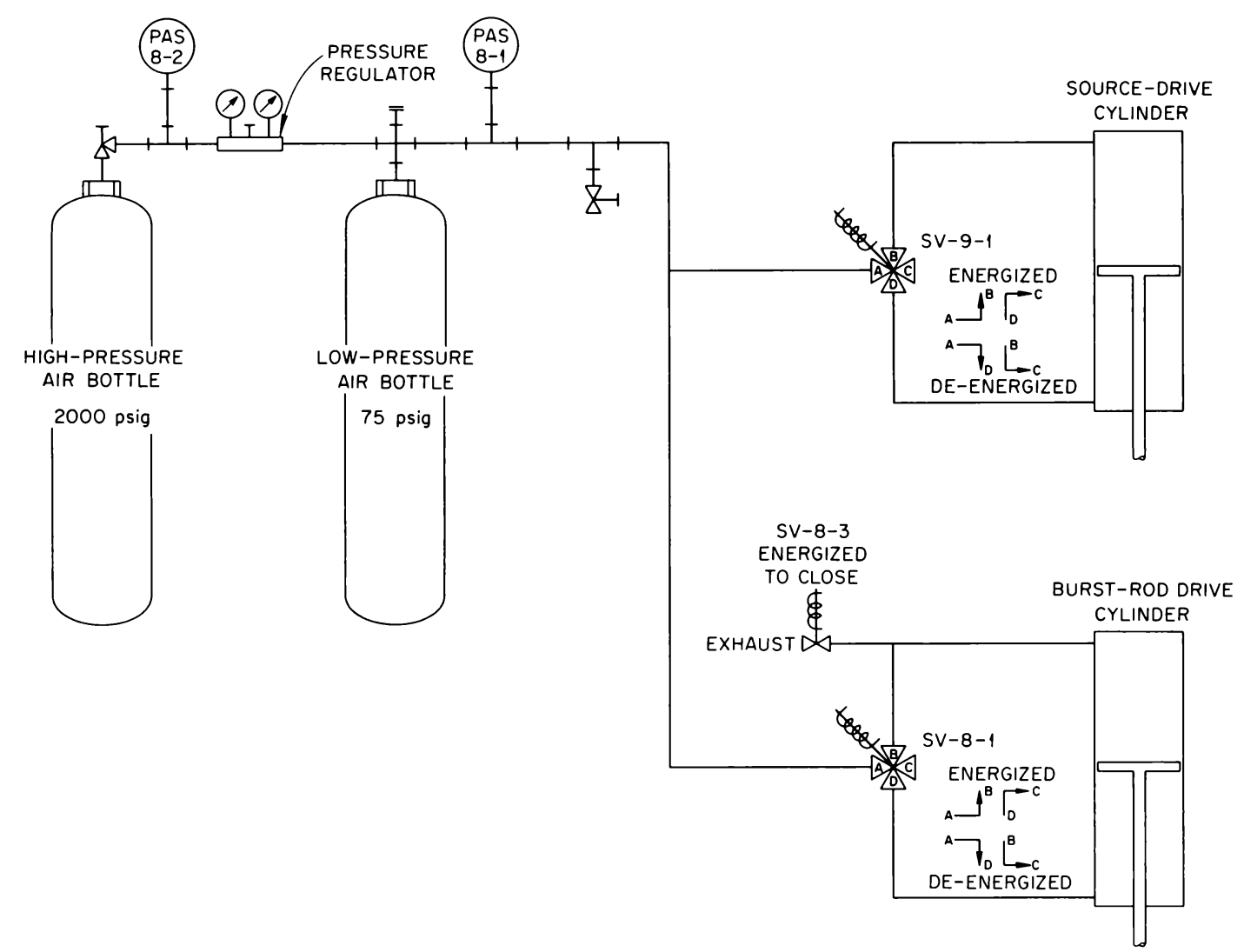

Fig. 3.8. Pneumatic Circuits for Burst Rod and Source Drives. 
on the reactor holding structure. One is a high-pressure ( 2000 psi) reservoir that feeds into the second tank which is maintained at operating pressure (60 to $75 \mathrm{psi}$ ). The capacity of the tanks is sufficient to permit about 100 bursts before a recharged high-pressure tank is needed. Electrical interlocks are provided to prevent accidental firing of the burst rod unless the proper preburst assembly procedures have been followed. An additional, electrical-solenoid-operated latch interlock ensures that the burst rod cannot be inadvertently inserted in the event the air valves leak. After a burst, the burst rod is withdrawn, in the upward direction, by reversing the air pressure on the piston in the pneumatic cylinder. A spring is provided around the upper extension shaft to expel the rod from the core in case of loss of air pressure. The burst rod is automatically withdrawn on actuation of any scram circuit. The burst-rod drive is equipped with position-indicating switches to show when it is fully withdrawn or fully inserted and when its locking latch is engaged or disengaged.

\section{Source and Source Drives}

A neutron source is used during the start of each delayed-critical determination. The source is actuated by a 1 1/2-in.-bore penumatic cylinder. During startup the source is positioned about 2 in. away from the core surface. The source can be withdrawn into a neutron shield when not in use. Electrical interlocks are provided to ensure that the source is in the insert position during the initial insertion (delayed critical) of the safety block to minimize the possibility of assembling a supercritical geometry before a chain reaction is initiated. Failure of the pneumatic system would result in slow movement of the source to its insert position. Position switches show whether the source is in the fully in (withdrawn) or fully out (inserted) position.

\section{Nuclear Design Features}

\section{$\underline{\text { Kinetic Data }}$}

Reactor performance characteristics were calculated for a reference core design as part of the preliminary design study. ${ }^{1}$ The data for the 
reference core are compared in Table 3.3 with those obtained for the first core during the critical experiments. ${ }^{5}$ The calculated burst yield and burst width are shown for the reference core in Fig. 3.9 as a function of the initial reactivity addition both with and without consideration of inertial effects. It may be seen that inertial effects (i.e., the reactor core cannot expand in equilibrium with heat input) result in burst enhancement at greater yields than approximately $10^{16}$ fissions.

${ }^{5}$ J. T. Mihalczo, Superprompt Critical Behavior of an Unreflected, Unmoderated Uranium-Molybdenum Alloy Assembly, ORNL-TM-230 (in press).

Table 3.3. Reactor Performance Characteristics

\begin{tabular}{|c|c|c|c|}
\hline & Calculated ${ }^{\mathrm{a}}$ & Exper & ental \\
\hline \multicolumn{4}{|l|}{ Burst performance characteristics } \\
\hline Burst yield, fissions & $1 \times 10^{17}$ & $\sim 1.8 \times 10^{17}$ & $1.05 \times 10^{17}$ \\
\hline Total temperature coefficient, cents $/{ }^{\circ} \mathrm{C}$ & -0.20 & -0.30 & -0.30 \\
\hline $\begin{array}{l}\text { Initial reactivity insertion above prompt } \\
\text { critical, cents }\end{array}$ & 7.6 & $\sim 11$ & $\sim 9$ \\
\hline $\begin{array}{l}\text { Integrated neutron current } 1 \text { in. from the } \\
\text { reactor surface, neutrons } / \mathrm{cm}^{2}\end{array}$ & $2 \times 10^{13}$ & & \\
\hline Total leakage neutrons & $1.3 \times 10^{17}$ & & \\
\hline Peak power, Mw & 63,000 & 100,000 & 42,000 \\
\hline Initial reactor period, $\mu \mathrm{sec}$ & 13 & $\sim 16$ & 20 \\
\hline Burst half-width, $\mu$ sec & 38 & $\sim 48$ & 63 \\
\hline Maximum temperature rise, ${ }^{\circ} \mathrm{F}$ & 740 & $\sim 720$ & 415 \\
\hline Average temperature rise, ${ }^{\circ} \mathrm{F}$ & 360 & $\sim 380$ & 220 \\
\hline Cooling time (forced convection), min & $\sim 30$ & & \\
\hline Cooling air required, $\mathrm{ft}^{3} / \mathrm{min}$ & $1500-2000$ & & \\
\hline \multicolumn{4}{|l|}{ Steady-state performance characteristics } \\
\hline \multicolumn{4}{|l|}{ Natural-convection cooling } \\
\hline Maximum power, watts & 1000 & & \\
\hline Maximum reactor temperature, ${ }^{\circ} \mathrm{F}$ & 600 & & \\
\hline Reactor surface temperature, ${ }^{\circ} \mathrm{F}$ & 480 & & \\
\hline \multicolumn{4}{|l|}{ Forced-convection cooling } \\
\hline $\begin{array}{l}\text { Cooling air required for steady-state } \\
\text { operation at } 10 \mathrm{kw} \text { for } 10 \mathrm{~min}, \mathrm{ft}^{3} / \mathrm{min}\end{array}$ & $1500-2000$ & & \\
\hline $\begin{array}{l}\text { Maximum allowable reactor temperature, } \\
{ }^{\circ} \mathrm{F}\end{array}$ & 600 & & \\
\hline
\end{tabular}

${ }^{a}$ Calculations are for reference design (see ref. 1). 


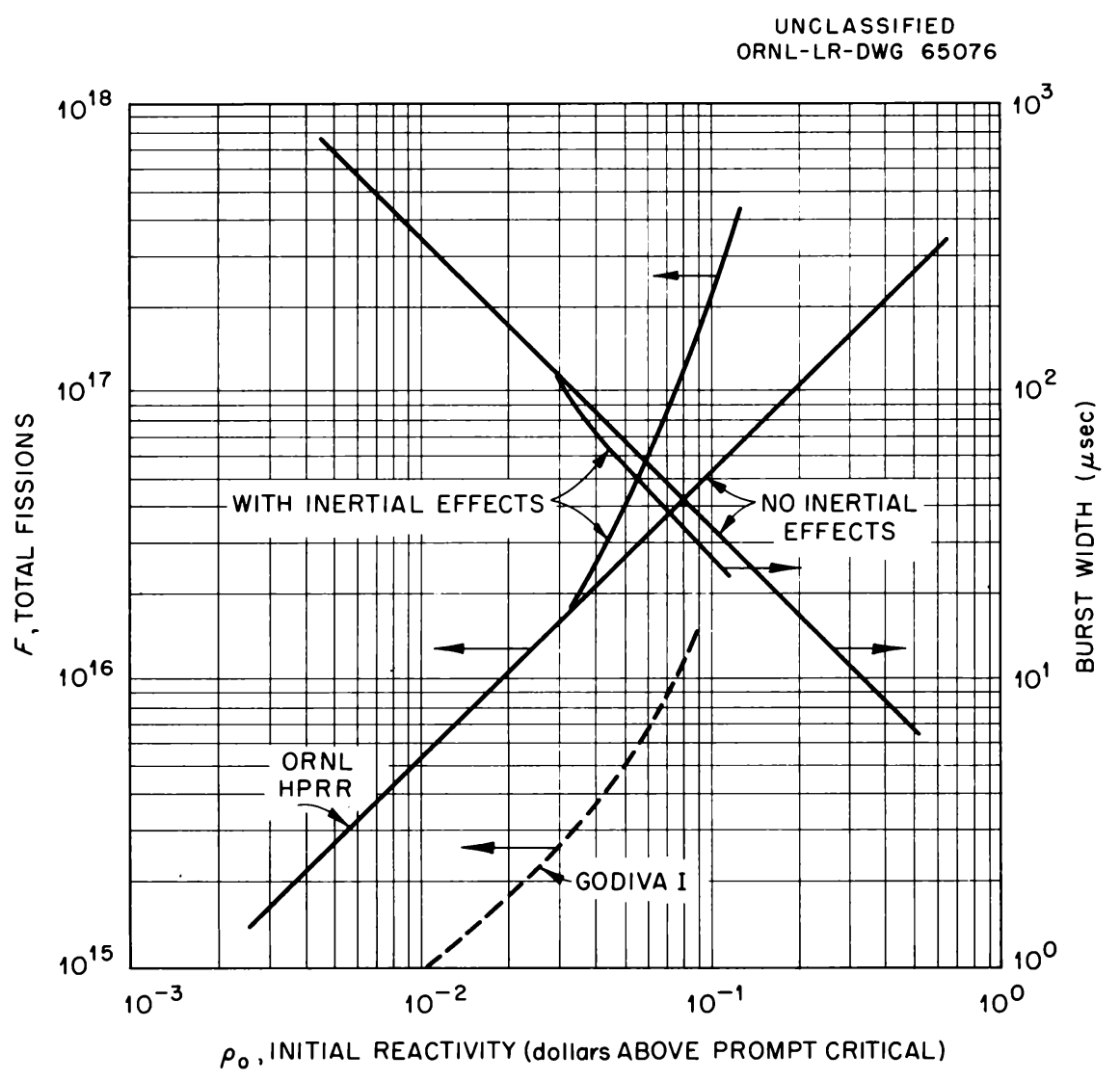

Fig. 3.9. Calculated Burst Yield and Half Width vs Initial Reactivity. (Based on data from NDA Report 2136-1.)

Experimentally determined characteristics are illustrated in Figs. 3.10 through 3.15. Figure 3.10 shows both the total yield and "spike" yield as a function of the reciprocal period. It should be noted that in the higher yield bursts about 90\% of the fissions occur in the "spike." The peak fission rate is plotted against the reciprocal period in Fig. 3.1l. The deviation caused by inertial effects at periods shorter than $30 \mu \mathrm{sec}$ can be seen.

Typical burst performance is shown in Figs. 3.12, 3.13, and 3.14. The low yield burst of Fig. 3.12 shows the afterburst plateau. Also shown is the reactivity removal associated with the displacement of the safety block as a function of time after scram. The instruments used for this test did not have a $4 \mathrm{msec}$ response time. 


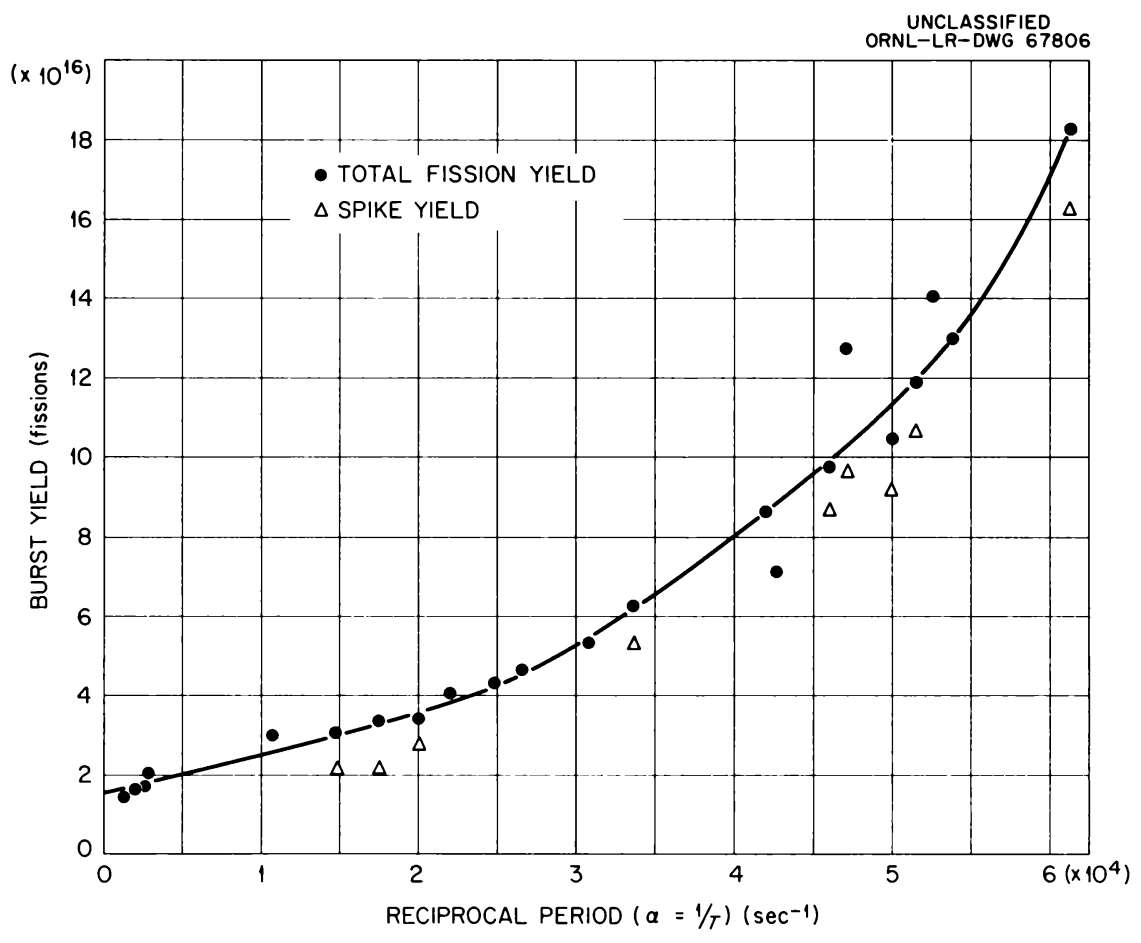

Fig. 3.10. Burst Yield as a Function of Reciprocal Period.

Figure 3.13 illustrates a burst during which the inertial or pressure wave effects initiated safety-block motion and resulted in a cutoff of the afterburst plateau at approximately $225 \mu \mathrm{sec}$ after the peak. This pressure-wave induced separation of the safety block from its magnet occurs at yields greater than approximately $6 \times 10^{16}$ fissions. Also shown on this figure is a theoretical burst shape. The burst decays faster than predicted by simple theory. Figures 3.14 and 3.15 show the characteristics of bursts with yields of $1.05 \times 10^{17}$ and $1.8 \times 10^{17}$ fissions, respectively.

\section{Fission-Rate Distribution}

The approximate fission-rate distribution in the reactor core can be predicted from the information obtained during the critical experiments. The relative fission-density distribution within the sample irradiation hole is shown on Fig. 3.16, and the experimental results are 


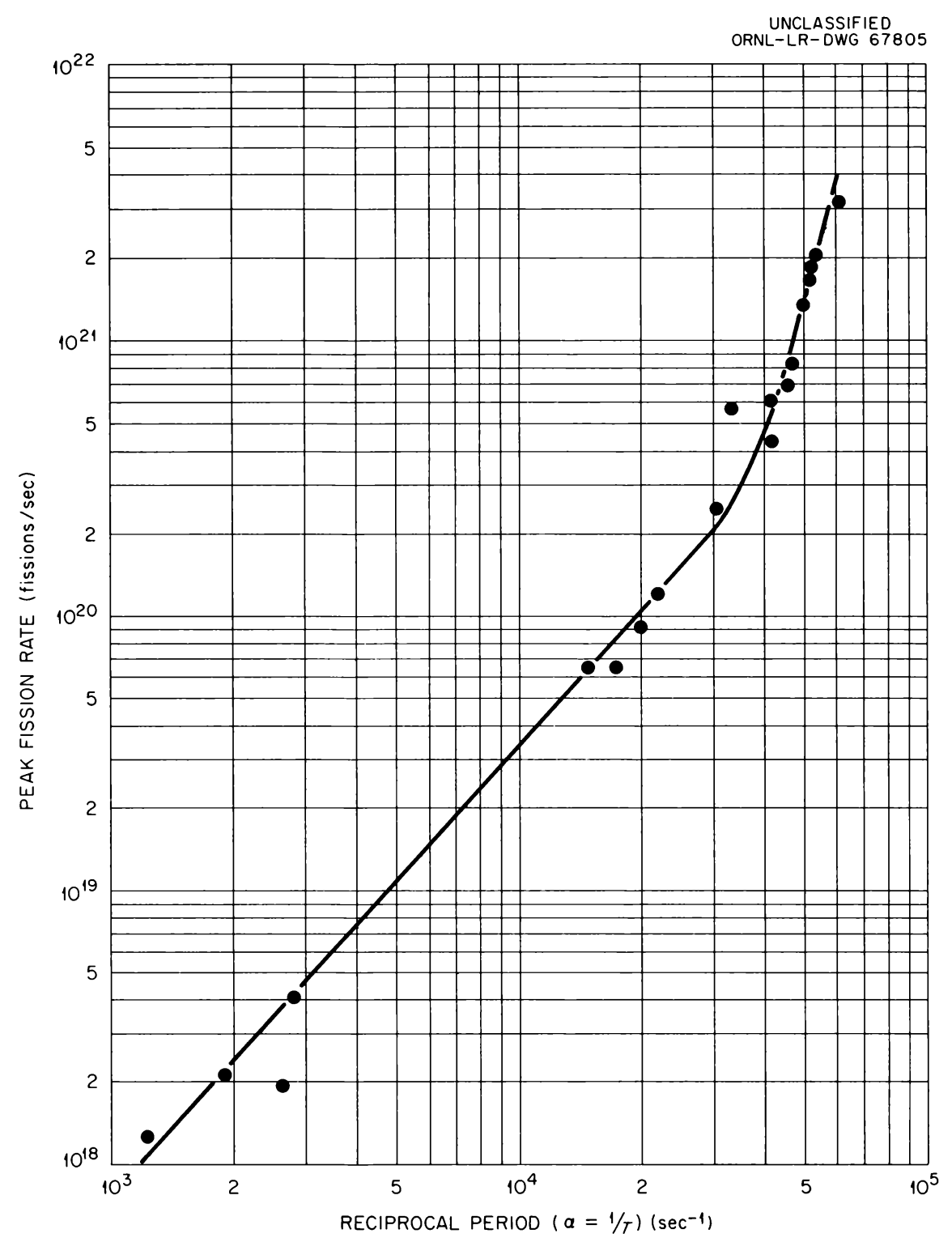

Fig. 3.11. Peak Fission Rate as a Function of Reciprocal Period.

compared with $\mathrm{S}_{4}$ transport theory calculations. The comparative experimental and calculated relative radial fission density in the safety block is shown in Fig. 3.17.

\section{$\underline{\text { Reactivity Coefficients }}$}

The critical experiments gave a negative temperature coefficient of 0.3 cents $/{ }^{\circ} \mathrm{C}$ rather than the originally calculated ${ }^{1} 0.2$ cents $/{ }^{\circ} \mathrm{C}$. A dynamic coefficient of 0.3 cents $/{ }^{\circ} \mathrm{C}$ was calculated ${ }^{5}$ for the burst of 


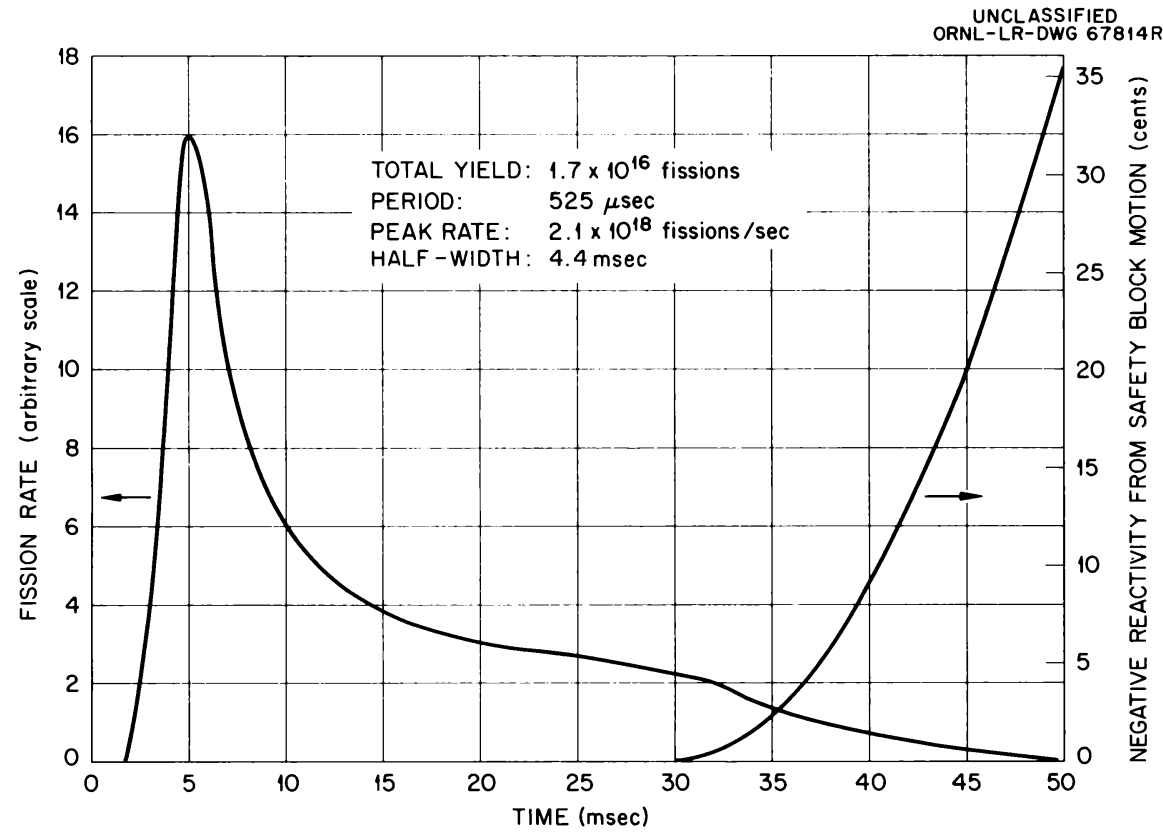

Fig. 3.12. Burst Shape for Yield of $1.7 \times 10^{16}$ Fissions.

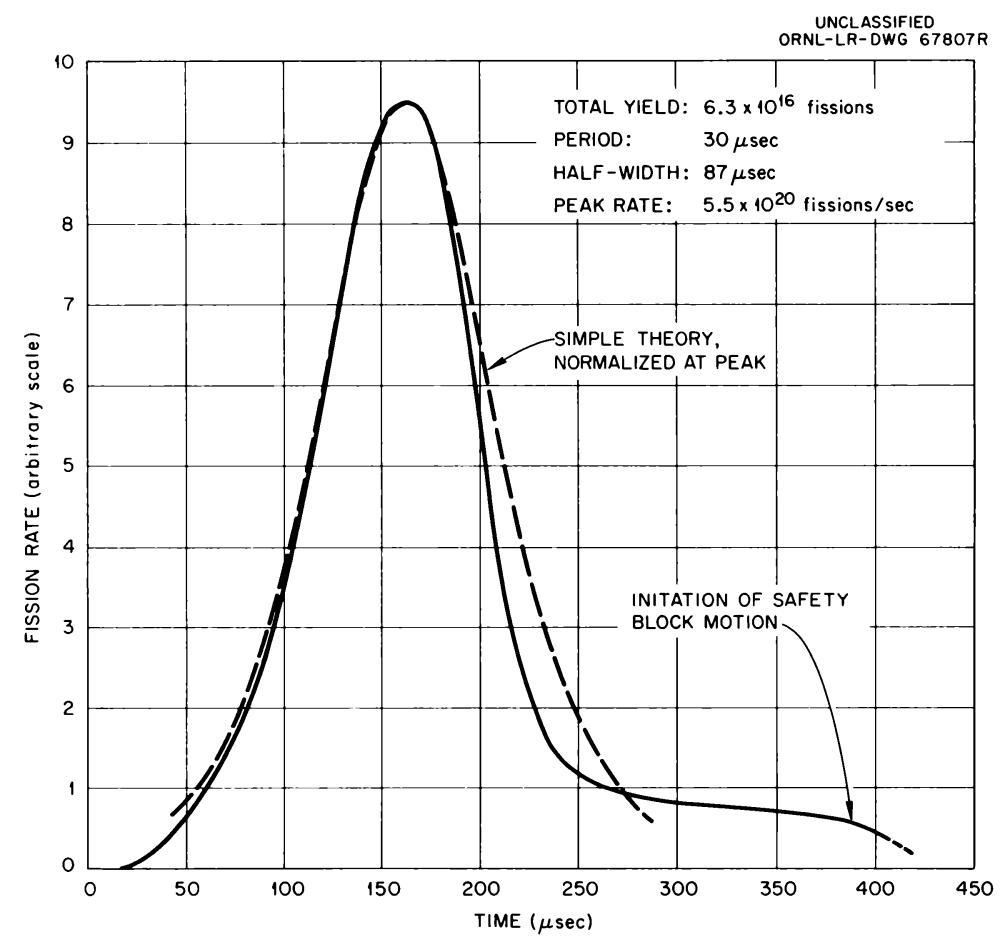

Fig. 3.13. Burst Shape for Yield of $6.3 \times 10^{16}$ Fissions. 


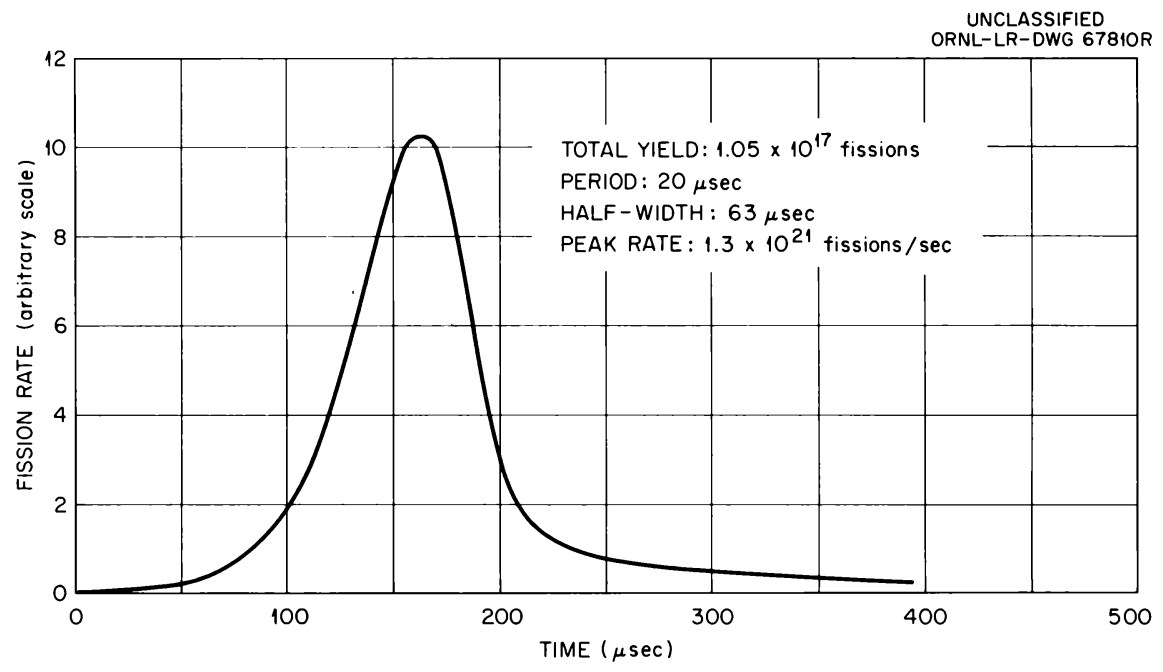

Fig. 3.14. Burst Shape for Yield of $1.05 \times 10^{17}$ Fissions.

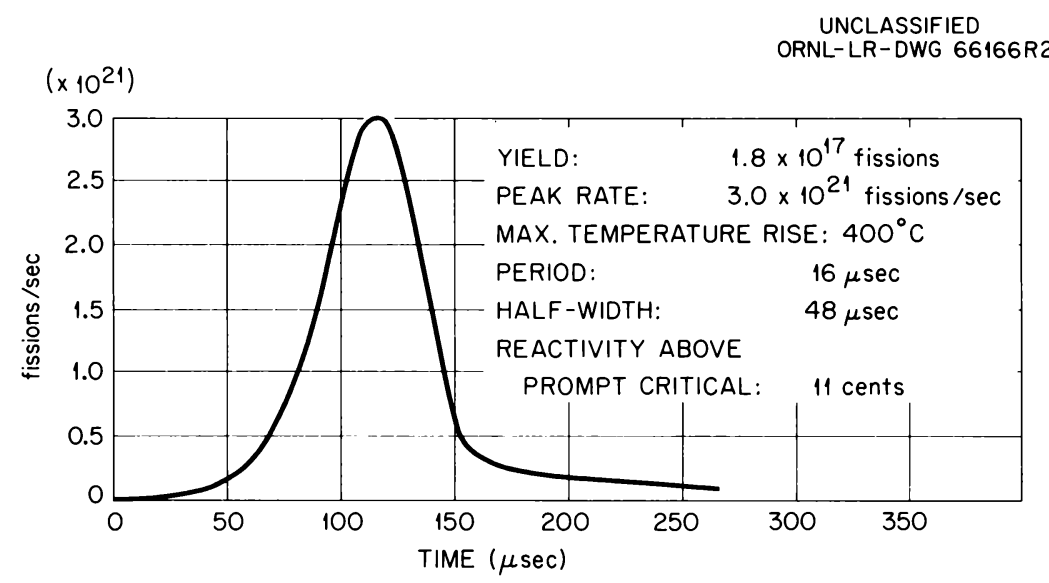

Fig. 3.15. Burst Shape for Yield of $1.8 \times 10^{17}$ Fissions.

Fig. 3.12. The final core turned out to contain 5\% voids rather than the anticipated 3\%. Approximately 1.2\% of these "voids" are formed by nickel plating.

Critical Parameters Under Various Conditions of Reflection

A series of experiments ${ }^{6}$ was performed during the preliminary critical experiments to estimate the amount of hydrogenous reflector that

${ }^{6}$ W. E. Kinney and J. T. Mihalczo, ORNL Fast Buirst Reactor: Critical Experiments and Calculations, ORNL CF 61-8-71 (August 24, 1961). 


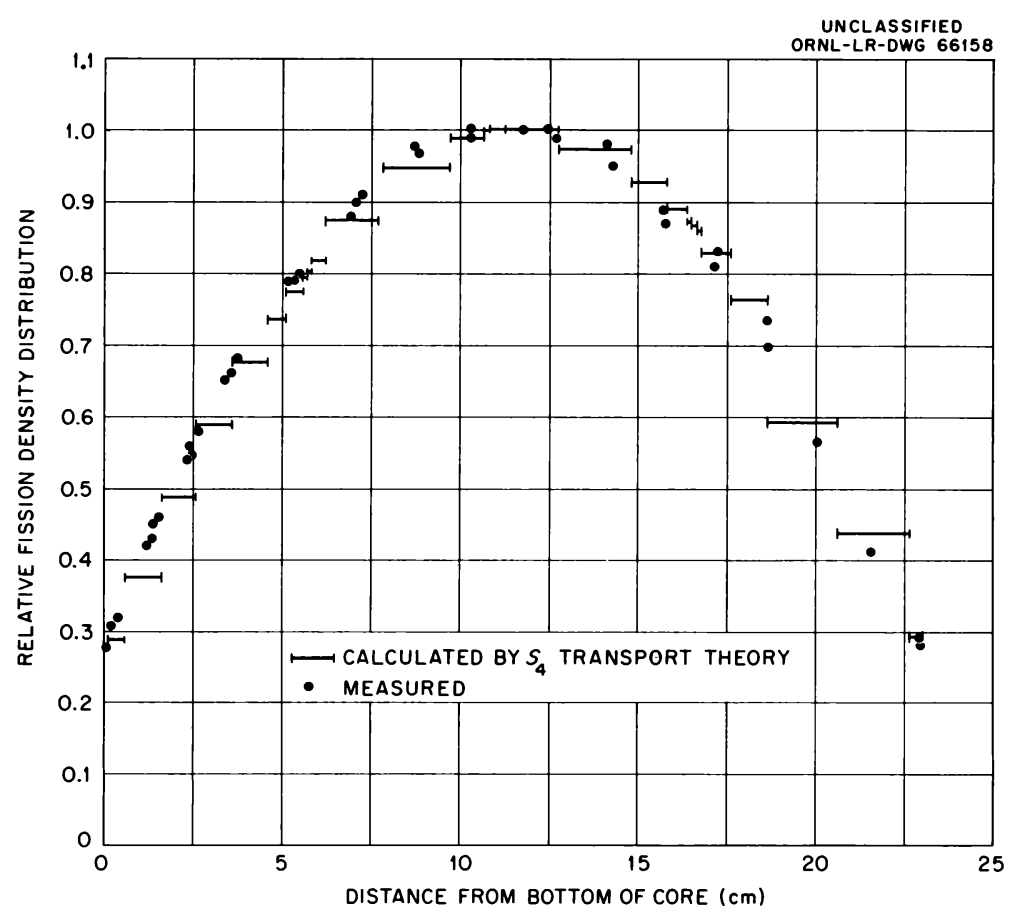

Fig. 3.16. Vertical Fission-Density Distribution in Irradiation Hole of HPRR.

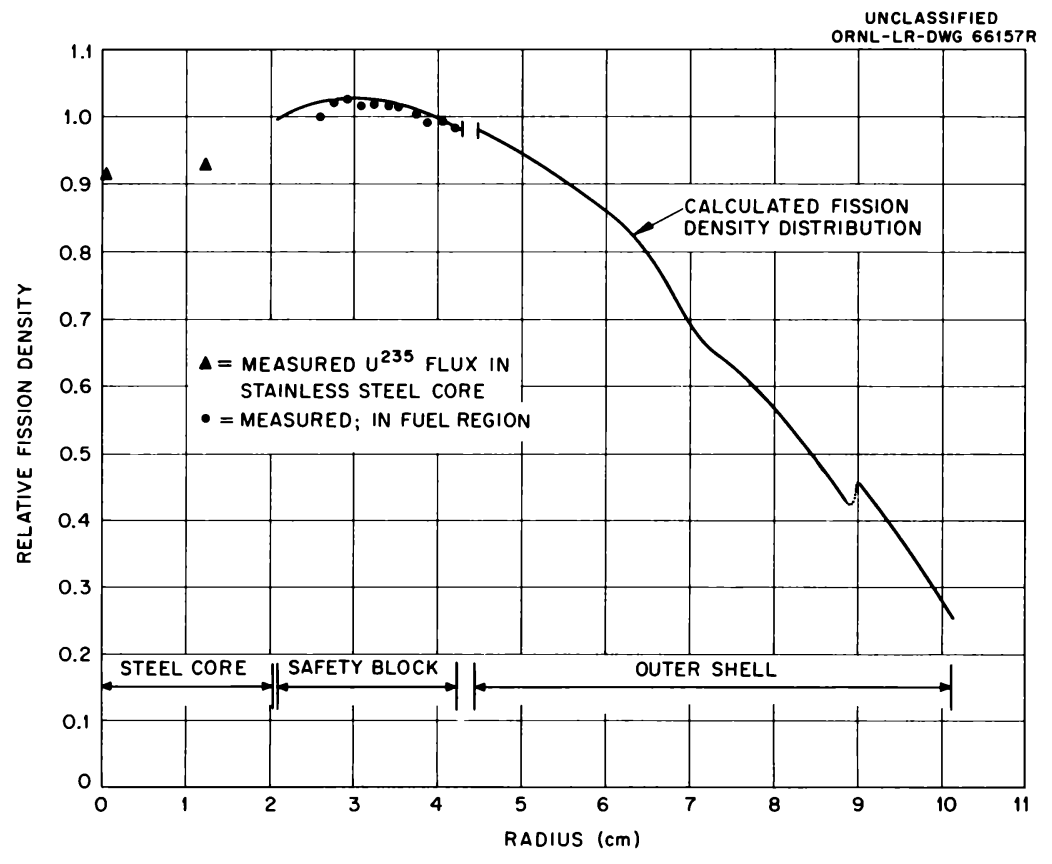

Fig. 3.17. Radial Fission-Density Distribution in HPRR. 
could be safely brought near the reactor during assembly. In the se experiments the lower 5-in. section of the main annular assembly, which was 8 in. in diameter, was constructed from disks with a 3.5-in.-diam central hole, while the remainder had a 2 in.-diam central hole. The critical heights, determined for nine different reflector conditions, are given in Table 3.4. The reflector material, Plexiglas, was placed

Table 3.4. Critical Parameters for an 8-in.-diam Annular Cylinder ${ }^{a}$ Under Various Conditions of Reflection

\begin{tabular}{|c|c|c|}
\hline Reflector Condition & $\begin{array}{c}\text { Critical } \\
\text { Mass } \\
\left(\mathrm{kg} \text { of } \mathrm{U}^{235}\right)\end{array}$ & $\begin{array}{l}\text { Critical } \\
\text { Height } \\
\text { (in.) }\end{array}$ \\
\hline \multicolumn{3}{|c|}{ No Cadmium Between Assembly and Reflector } \\
\hline $\begin{array}{l}\text { l-in.-thick layer of Plexiglas on all outer } \\
\text { surfaces; void in center }\end{array}$ & 67.5 & 6.8 \\
\hline $\begin{array}{l}\text { 1-in.-thick layer of Plexiglas on all outer } \\
\text { surfaces; Plexiglas in center }\end{array}$ & 52.8 & 5.46 \\
\hline $\begin{array}{l}\text { 2-in.-thick layer of Plexiglas on all outer } \\
\text { surfaces; void in center }\end{array}$ & 47.2 & 4.95 \\
\hline $\begin{array}{l}\text { 5.98-in.-thick layer of Plexiglas on bottom } \\
\text { only; Plexiglas in center }\end{array}$ & 69.4 & 6.96 \\
\hline $\begin{array}{l}\text { 6.0l-in.-thick layer of Plexiglas on bottom; } \\
\text { l-in.-thick layer of Plexiglas on top and on } \\
\text { the lower 3.25-in. section of lateral sur- } \\
\text { face; void in center }\end{array}$ & 75.3 & 7.5 \\
\hline \multicolumn{3}{|c|}{$\begin{array}{c}\text { 0.010-in.-Thick Layer of Cadmium Between Assembly } \\
\text { and Outer Reflector }\end{array}$} \\
\hline $\begin{array}{l}\text { l-in.-thick layer of Plexiglas on all outer } \\
\text { surfaces; void in center }\end{array}$ & 70.7 & 7.08 \\
\hline $\begin{array}{l}\text { l-in.-thick layer of Plexiglas on all outer } \\
\text { surfaces; Plexiglas in center }\end{array}$ & 56.2 & 5.77 \\
\hline $\begin{array}{l}\text { 2-in.-thick layer of Plexiglas on all outer } \\
\text { surfaces; void in center }\end{array}$ & 61.2 & 6.22 \\
\hline $\begin{array}{l}\text { 2-in.-thick layer of Plexiglas on all outer } \\
\text { surfaces; Plexiglas in center }\end{array}$ & 49.8 & 5.19 \\
\hline
\end{tabular}


around the assembly and within the central cavity, and, in four instances, 0.010-in.-thick cadmium sheets separated the assembly from the outer reflector.

In addition to these tests, a systematic investigation of the reactivity effects of various types of reflectors and experimental assemblies is planned. This information will be developed in critical experiments and as required during the operation of the DOSAR Facility.

\section{Core Lifetime}

The burnup of fissionable material in the core will not be a significant factor in determining the core lifetime. Rather, the buildup of fission products and the concomitant gamma rays will be the determining factor. The projected operating schedule for use of the HPRR, expressed in terms of power level and frequency, is the equivalent of one of the following:

$2 \mathrm{hr}$ per day for 5-day week at $1 \mathrm{kw}$

$6 \mathrm{hr}$ per day for 5-day week at 5 watts

2 bursts per day for 5-day week at $10^{17}$ fissions per burst
$10 \mathrm{kwhr} /$ week

$150 \mathrm{whr} /$ week

$8.7 \mathrm{kwhr} /$ week

It is conceivable that a period of intensive reactor operation may of necessity be followed by a cooling period.

\section{Nuclear Constants}

The nuclear constants, group structure and cross sections, used in the calculations for the critical experiments are listed in the appendices of ref. 6 .

\section{Thermal Design Features}

Adequate cooling is required for the reactor core for three modes of operation: (I) steady-state operation at powers up to $1 \mathrm{kw}$ for extended periods of time, (2) steady-state operation at $10 \mathrm{kw}$ for approximately $10 \mathrm{~min}$, and (3) afterburst operation. The principal requirement is to maintain temperatures in the reactor low enough to minimize phase 
transformation of the gamma-stabilized uranium-molybdenum alloy fuel material and thus minimize dimensional changes. The time for initial phase transformation is at a minimum of approximately $25 \mathrm{hr}$ at temperatures in the neighborhood of $880^{\circ} \mathrm{F} .{ }^{I}$ At lower temperatures, the time for initial transformation increases, becoming more than $2000 \mathrm{hr}$ at $600^{\circ} \mathrm{F}$ and essentially infinite at temperatures below $570^{\circ} \mathrm{F}$. Adequate cooling for normal operation at low power (i.e., up to $1 \mathrm{kw}$ ) or for individual bursts can be obtained with natural convection of air. Forced-convection cooling is required only for extended operation at a power of $10 \mathrm{kw}$ or at times when it is desired to minimize the cooling period following a burst.

\section{Natural-Convection Cooling}

It was decided to limit the maximum temperature in the reactor to $600^{\circ} \mathrm{F}$ during extended steady-state power operation to minimize phase transformation of the gamma-stabilized fuel alloy. Calculations for natural-convection air cooling of the reference core yielded a maximum internal temperature of approximately $600^{\circ} \mathrm{F}$ and a surface temperature of approximately $480^{\circ} \mathrm{F}$ at $1-\mathrm{kw}$ operation. ${ }^{1}$ Cooling of the reactor at a power of $1 \mathrm{kw}$ or less for extended periods of time is thus adequately provided by natural convection of air.

Steady-state operation of the reactor at $10 \mathrm{kw}$ with natural-convection cooling results in an equilibrium reactor surface temperature of approximately $1300^{\circ} \mathrm{F}$, which is too high for prolonged operation. For $10 \mathrm{~min}$ of operation at $10 \mathrm{kw}$, however, the reactor temperature rises only to approximately $800^{\circ} \mathrm{F}$. If it is assumed that the reactor starts at room temperature $\left(70^{\circ} \mathrm{F}\right)$, is brought quickly to power (10 kw), and is scrammed when the temperature reaches $600^{\circ} \mathrm{F}$, operation for 6 to $7 \mathrm{~min}$ is possible with only natural-convection cooling.

\section{Forced-Convection Cooling}

To extend the allowable operating time to $10 \mathrm{~min}$ or more at $10 \mathrm{kw}$ without exceeding a temperature of $600^{\circ} \mathrm{F}$ in the reactor, forced-convection cooling is used. A forced-air cooling system was installed for this purpose in the reactor building (see Section 6). By making a portable-hose 
connection from one of the air discharge nozzles to the reactor core, it is possible to provide 1500 to $2000 \mathrm{cfm}$ of room-temperature air for cooling. This air can maintain the reactor below $600^{\circ} \mathrm{F}$ for more than 10 min of 10-kw operation.

The cooling of the reactor after burst operation is required primarily to minimize the waiting time between bursts. No harm is done to the reactor if only natural-convection cooling is used following a burst, since the maximum temperature very quickly falls to 500 to $600^{\circ} \mathrm{F}$ with or without forced convection. The bulk of the cooling time is required to reduce the temperature from 200 to $300^{\circ} \mathrm{F}$ to room temperature. Calculations indicate that the total time required for natural-convection cooling after a burst is about $21 / 2 \mathrm{hr}$.

If it is desired to reduce this time to approximately $30 \mathrm{~min}$, it is necessary to utilize forced-convection cooling. The reactor can be positioned over a portable cooling manifold or placed in its storage pit, which is provided with a cooling manifold. Calculations indicate that the reactor can be brought to within $10^{\circ} \mathrm{F}$ of room temperature in 30 to $40 \mathrm{~min}$ by utilizing forced-convection cooling.

\section{Core Temperature Distributions}

Temperature distributions at the instant of pulse operation are essentially the same as the power (fission-density) distribution, since there is insufficient time for thermal diffusion to occur. Experimental information on fission distribution was presented above (see discussion and Figs. 3.16 and 3.17). Based on the experimentally determined core temperature rise, a factor of $4.6 \times 10^{14}$ fissions $/{ }^{\circ} \mathrm{C}$ is applicable for converting the power-distribution data to temperature-distribution values. The peak temperature rise, calculated from the flux distribution, is 1.9 times the average rise. This results in a core peak temperature rise of $230^{\circ} \mathrm{C}\left(414^{\circ} \mathrm{F}\right)$ for a burst yield of $1.05 \times 10^{17}$ fissions. ${ }^{5}$

These data indicate that a burst of $5.2 \times 10^{17}$ fissions would raise the peak temperature in the assembly to $1150^{\circ} \mathrm{C}$, the melting point of the fuel alloy. During low-power steady-state operation, the temperature distribution is "flatter" than indicated for bursts because thermal diffusion and conduction can take place. 
Stress Analysis

The reactor is subjected to inertial stresses as a result of the extremely rapid temperature rise of the core during a burst and to transient thermal stresses that are due to the nonuniform temperature distribution across the reactor. For bursts larger than approximately $5 \times 10^{16}$ fissions, inertial stresses become significant. For bursts of less than $5 \times 10^{16}$ fissions, the inertial stresses are practically zero, because the burst width $(\sim 100 \mu \mathrm{sec})$ is so large that the expansion of the reactor can almost exactly follow the temperature input.

The allowable design stress was set at $90 \%$ of the ultimate strength corresponding to the highest temperature expected in the given component. The ultimate strengths used were for static loading conditions; however, because of the very rapid loading to which the material is subjected, it is expected that the ultimate strengths will be much higher than those for static loading. In fact, based on experience with structural materials, such as steel, the ultimate strengths may be a factor of 2 to 3 higher than the design basis. Counteracting this favorable aspect, however, is the relatively low ductility of the fuel alloy at normal operating temperatures.

The calculated stresses for the various parts of the reference core ${ }^{1}$ are listed in Table 3.5 for bursts of $1.0 \times 10^{17}$ and $1.3 \times 10^{17}$ fissions. It can be seen that for a burst of $1 \times 10^{17}$ fissions, the maximum stress in every piece is at or below the allowable stress. Operation at this point should therefore be possible on a routine basis. For a burst that is $30 \%$ above the nominal operating point, it can be seen from the table that the maximum stress in the outer shell approaches the yield strength. This was not considered a serious situation, however, for two reasons: (1) the strength of the fuel alloy for dynamic loadings of this type is expected to be higher than predicted on the basis of static tests, and (2) the largest part of the stress is due to the nonuniform temperature distribution (transient thermal stress) which tends to be readily relieved by yielding of the material and which puts it in a favorable prestressed condition for withstanding subsequent bursts. For these reasons it was expected that the reactor could survive an accidental burst of at 
Table 3.5. Summary of Calculated Stresses and Temperatures As a Function of Burst Yield ${ }^{a}$

\begin{tabular}{|c|c|c|}
\hline Total burst yield, fissions & $1 \times 10^{17}$ & $1.3 \times 10^{17}$ \\
\hline Burst width, $\Delta t_{1 / 2}, \mu \mathrm{sec}$ & 38 & 34 \\
\hline \multicolumn{3}{|l|}{ Outer shell } \\
\hline $\begin{array}{l}\text { Average temperature rise, }{ }^{\circ} \mathrm{F} \\
\text { Maximum temperature rise, }{ }^{\circ} \mathrm{F} \\
\text { Stress, psi } \\
\text { Ultimate tensile strength, psi } \\
\text { Yield strength, psi }\end{array}$ & $\begin{array}{l}358 \\
750 \\
45,000 \\
74,000^{b} \\
68,000^{b}\end{array}$ & $\begin{array}{l}465 \\
960 \\
61,000 \\
63,000^{c} \\
62,000^{c}\end{array}$ \\
\hline \multicolumn{3}{|l|}{ Safety block } \\
\hline $\begin{array}{l}\text { Average temperature rise, }{ }^{\circ} \mathrm{F} \\
\text { Maximum temperature, }{ }^{\circ} \mathrm{F} \\
\text { Stress, psi } \\
\text { Ultimate tensile strength, psi } \\
\text { Yield strength, psi }\end{array}$ & $\begin{array}{l}643 \\
770 \\
16,000 \\
74,000^{b} \\
68,000^{b}\end{array}$ & $\begin{array}{l}835 \\
975 \\
22,000 \\
63,000^{c} \\
62,000^{c}\end{array}$ \\
\hline \multicolumn{3}{|l|}{ Bolts } \\
\hline $\begin{array}{l}\text { Diameter, in. } \\
\text { Number } \\
\text { Stress, psi } \\
\text { Ultimate tensile strength, psi } \\
\text { Yield strength, psi }\end{array}$ & $\begin{array}{l}0.750 \\
9 \\
33,000 \\
>87,000^{d} \\
>87,000^{d}\end{array}$ & $\begin{array}{l}0.750 \\
9 \\
48,000 \\
>75,000^{\mathrm{e}} \\
>73,000^{\mathrm{e}}\end{array}$ \\
\hline \multicolumn{3}{|c|}{ 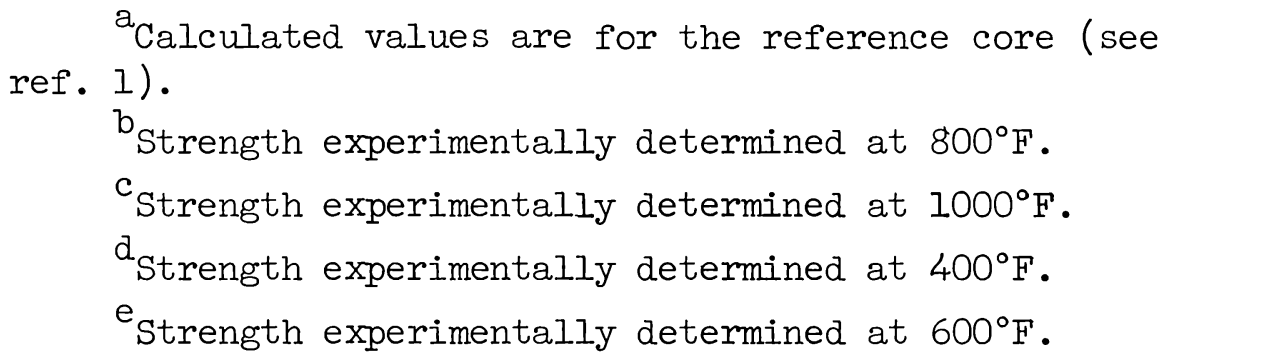 } \\
\hline
\end{tabular}

least $1.3 \times 10^{17}$ fissions without suffering mechanical damage, and in initial experiments ${ }^{5}$ the core did survive bursts of approximately $1.8 \times 10^{17}$ fissions with an associated maximum temperature rise of $720^{\circ} \mathrm{F}$. It must be noted, however, that large uncertainties remain as to the actual values of the stresses that will be encountered under burst conditions. 


\section{FACIITTY DESCRIPTION}

A plot plan showing the relationship of the control and reactor buildings is presented in Fig. 4.1. In order to increase the availability of "exposure" time, consideration was given in the design of the facilities to reactor handling and storage. A special area in the control building was provided for experimental assembly preparation. The experimental equipment can be built into racks and then transferred to the reactor building over a paved road by fork lift or truck without extensive loss of reactor availability time.

\section{Control Building}

The control building, shown in plan view in Fig. 4.2, is a one-story building approximately $133 \mathrm{ft}$ long and $56 \mathrm{ft}$ wide. This building houses the reactor controls, administrative offices, laboratories, counting room, toilet facilities, experimental assembly preparation area, and mechanical and electrical service rooms. The building floor is set slightly above finished grade. A l-ft-thick reinforced-concrete roof stmucture is provided for shielding building occupants from skyshine radiation (see the Appendix). The side of the building facing the reactor building is set into the hill separating the reactor and control buildings to provide additional radiation shielding. The cubicle walls and roof of the counting room consist of 2 -ft-thick boronated concrete for background radiation shielding to less than 1 neutron per square centimeter per burst of $10^{17}$ fissions in order to minimize activation of crystals. Access to the experimental assembly preparation area of the building is provided at a truck-unloading dock, which has a dock-leveling device and a ramp for fork lifts. The building provides space for five standard laboratories, including two physics, dosimetry, and electronics laboratories, one health physics laboratory, one chemistry laboratory, and one biology laboratory. It also houses the reactor control room, from which all reactor operations are controlled. In addition, facilities are available to permit observation and monitoring of experimental equipment in either the control room 
UNCLASSIFIED
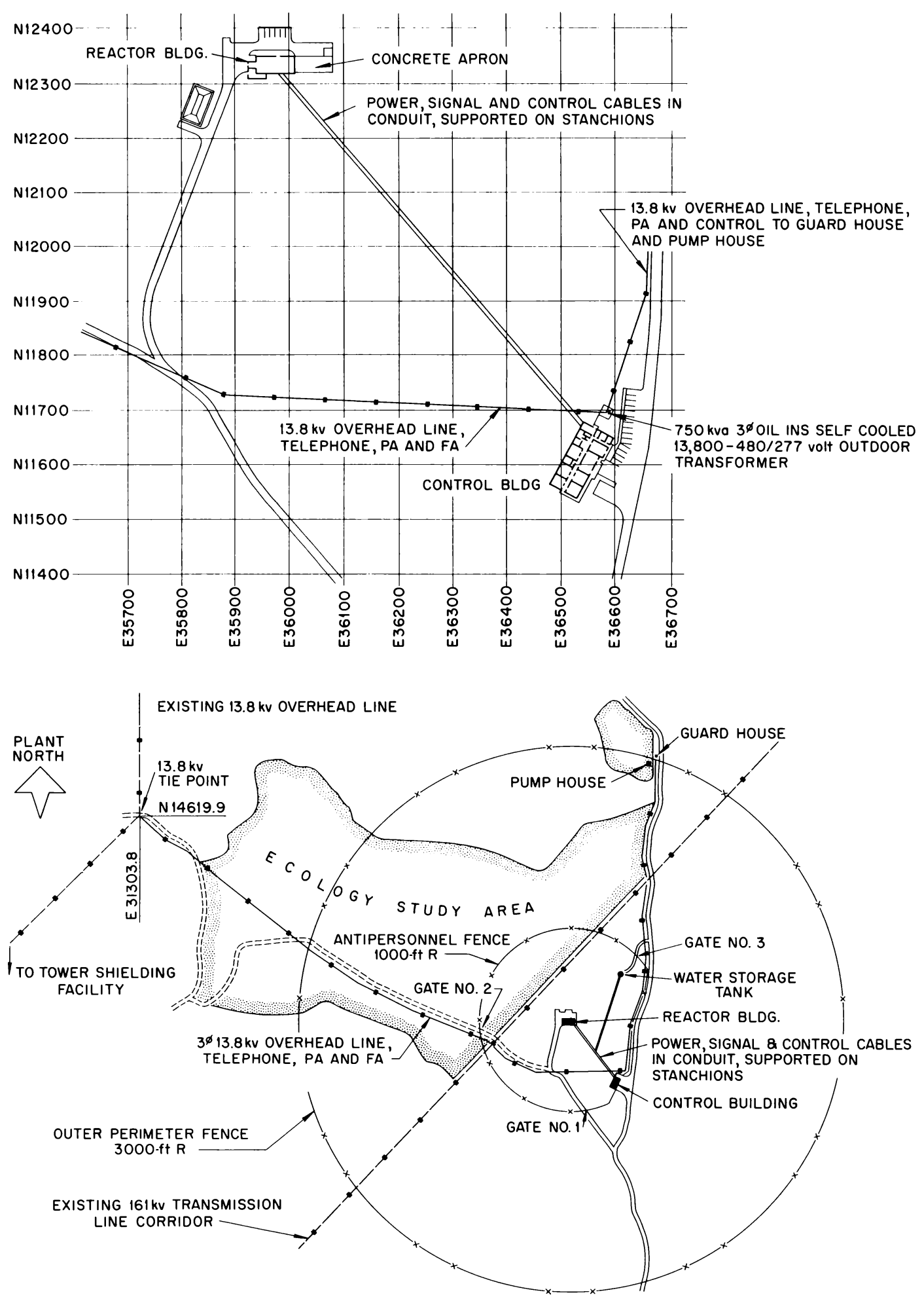

Fig. 4.1. Plot Plan of Health Physics Research Reactor Facility. Note that the 3000-ft-radius fence may be replaced by an extension of the existing TSF perimeter fence. 


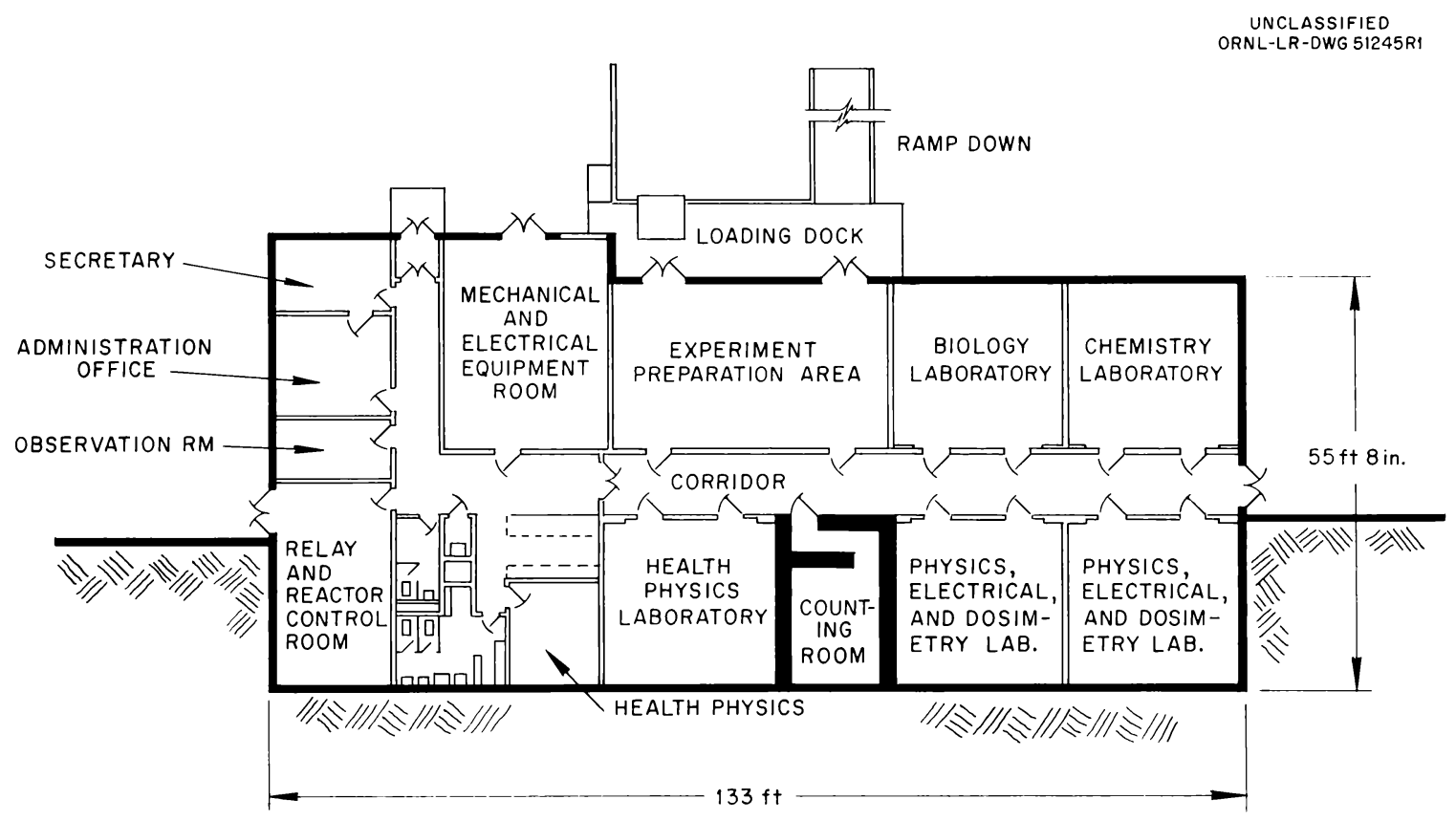

Fig. 4.2. Plan View of Control Building.

or in the laboratories, as desired. A trailer lot adjoins the control building to provide a parking area for trailers containing auxiliary equipment necessary for the operation of the experimental equipment under test. Outdoor electrical receptacles are provided for servicing the experimenter's trailer vans. The parking area also has space for 14 passenger vehicles.

\section{Reactor Building}

The reactor building, shown in Figs. 4.3 and 4.4 , is intended to provide protection from weather for the reactor, certain equipment, experimental assemblies, and basic utilities. The working area of the building is approximately $72 \mathrm{ft}$ long and $32 \mathrm{ft}$ wide. A bridge crane of 5-ton capacity spans the 32-ft width and travels along the 72-ft length. The low point of the bridge crane is $40 \mathrm{ft}$ above the floor to permit the reactorpositioning device to elevate the reactor midpoint $30 \mathrm{ft}$. The floor of the building is set slightly above grade. The building has insulated aluminum siding and is provided with filtered and controlled-circulation air-conditioning and exhaust systems. The interior wall and roof surfaces 
ORNL-LR-DWG 51249R1

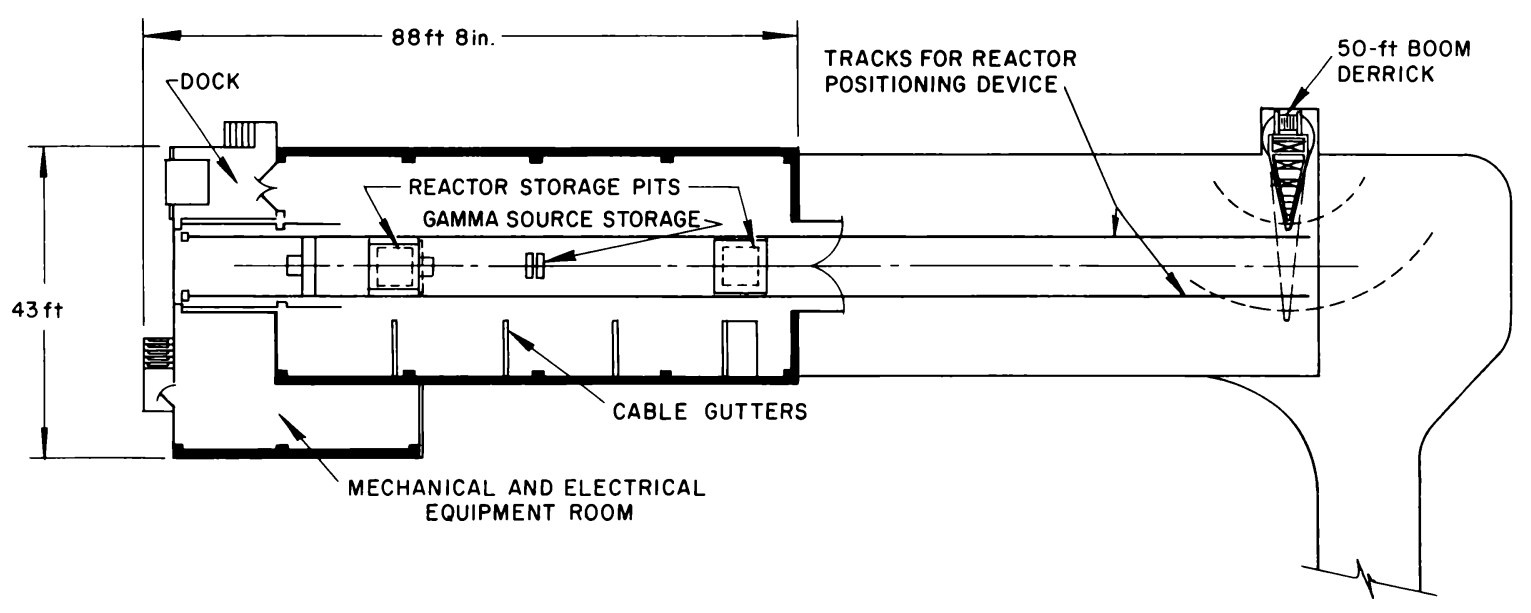

Fig. 4.3. Plan. View of Reactor Building.

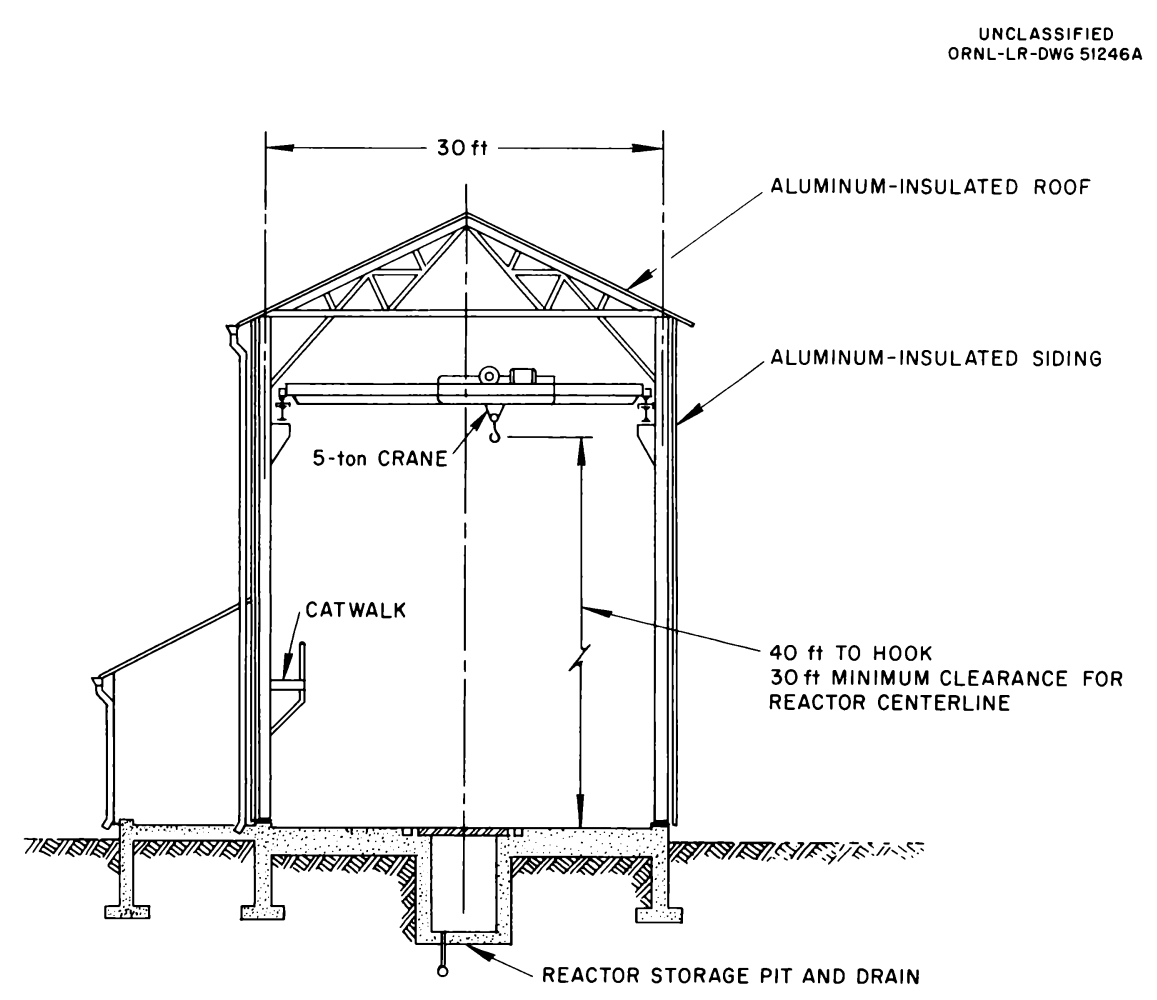

Fig. 4.4. Elevation View of Reactor Building. 
of the building are sealed so that the building can be maintained at a negative pressure of 0.3 in. of $\mathrm{H}_{2} \mathrm{O}$.

An auxiliary air-circulation system will supply air to a duct manifold for above-the-floor hose connections and to an underground duct system that discharges through nozzles into the reactor storage pits. A pressure-type blower recirculates building air. The capacity of this system is sufficient to dissipate within a 30- to 40-min period the maximum heat released from the reactor after a burst of $10^{17}$ fissions.

Two concrete pits are located along the centerline of the building for operational convenience in storage of the reactor when not in use. A set of tracks for the reactor-positioning device is located along the centerline of the building and extends the length of the building and the outdoor concrete pad. One additional pit is located between the tracks and at the center of the building. This pit will contain four gamma-capsule facilities for use in the experimental program planned for the DOSAR Facility.

At one end of the building there is a 12-ft-wide, 15-ft-high double door opening to the outside concrete pad which is $30 \mathrm{ft}$ wide and $70 \mathrm{ft}$ long. At the other end of the building there is a 6-ft-wide, 8-ft-high double door opening onto a truck-unloading dock provided with a dockleveling device. Service rooms for electrical equipment, the emergency generator set, and the heating, ventilating, and air-conditioning equipment are located adjacent to the unloading dock and on the outside of the building. Conduit and cable connections between the reactor building and the control areas for the reactor and experimental equipment control and instrumentation systems pass through the wall of the reactor building and over stanchions to the control building. A paved parking area for six vehicles is provided at the reactor building.

\section{Reactor-Handling Facilities}

The reactor, when not in use, is normally stored in one of two concrete pits located along the centerline of the building. A set of tracks extends the length of the building and the length of the outside concrete 
pad for the reactor-positioning device, which is used to remove the reactor from the storage pit, position it as required for an experiment, and return it to the pit after completion of the experiment. In addition a boom derrick is available at the outside pad for special experiments.

Reactor Storage Pits

Two concrete-lined pits, approximately $5 \mathrm{ft} \times 5 \mathrm{ft} \times 7 \mathrm{ft}$ deep, are located between the tracks along the centerline of the building for storage of the reactor when not in use. The concrete is lined with a protective coating of Amercoat paint. An electromechanically actuated 7-in.-thick steel door that is operable from the control room or from either of two remote stations in the reactor building is used to cover the pit. This door provides sufficient personnel shielding to permit immediate access to experiments in the reactor building with the reactor stored in the pit after use in the burst mode. Each pit is provided with a support and positioning rack for storage of the reactor. The support and positioning rack is designed to provide the required orientation and accuracy in location needed to permit remotely controlled withdrawal and replacement of the reactor by the reactor-positioning device during an experiment cycle. The possibility of immediate access provided by the shielded storage system will result in good utilization of the building for experiments.

The pits are drained by a 3-in.-diam untrapped drain line through a monitoring basin to an asphalt-lined retention pond located below the bottom of the pits (see Fig. 4.5). Each pit has a monitor for detecting any accumulation of water.

Reactor-Positioning Device

A reactor-positioning device that is operable from the control room or from control panels in the reactor building is provided for moving the reactor from either of the two storage pits, positioning it at its operating location, and then returning it to either of the two storage pits after an experiment has been completed. The device (see Fig. 4.6) is capable of raising the midpoint of the reactor to any desired elevation up to $30 \mathrm{ft}$ above the reactor building floor and to any position along the centerline 


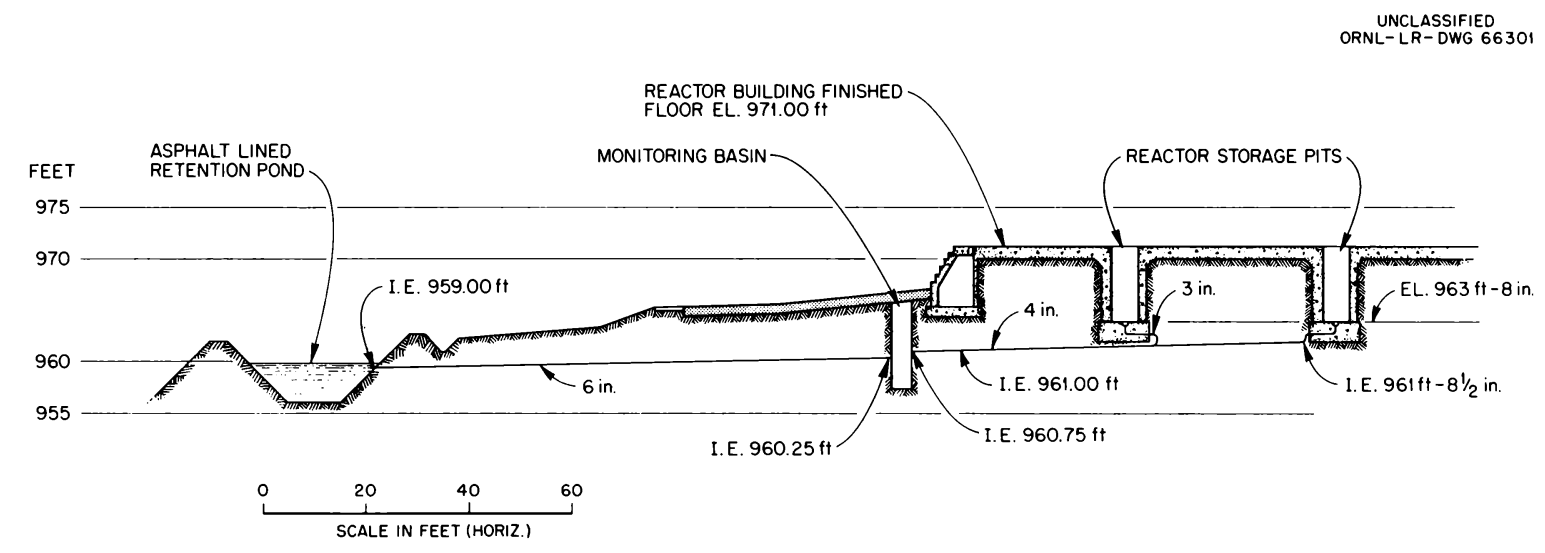

Fig. 4.5. Reactor Storage and Drain System.

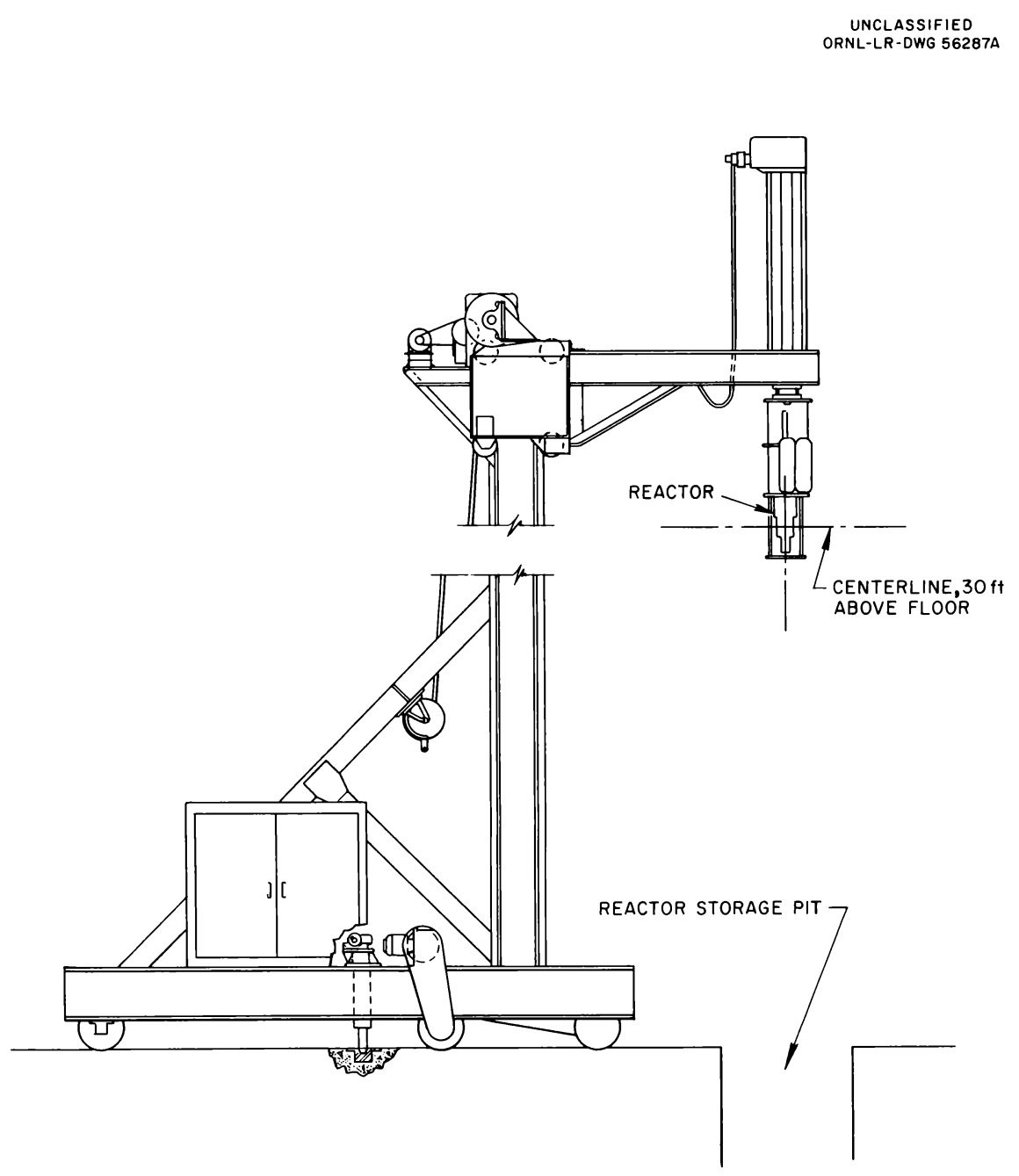

Fig. 4.6. Reactor Positioning Device. 
of the reactor building and the outside concrete pad. The device has a positioning accuracy of $\pm l \mathrm{~cm}$ over its operating range. In a typical operating sequence, a dummy reactor is used to set up an experiment by direct measurement from its centerline. Position stops are set for the desired vertical movement of the boom and the horizontal movement of the positioning truck. The storage-pit doors are remotely opened, and the reactor lifting device is clamped by remote control to the reactor in the pit. Electrical interlocks indicate when the lifting device is clamped to the top plate of the reactor holding structure. The reactor building and inner exclusion area are evacuated. After suitable checkout of the interlocks and an administrative check of entry into the area, the gates are closed and the reactor startup procedure is initiated, with the first step being the positioning of the reactor at the location previously occupied by the dummy reactor by remote operation from the control room. After operation the reactor can be returned to the storage pit by remote operation from the control room. Electrical interlocks are provided on the reactor-positioning device to prevent hazardous operations. A schematic control diagram of these interlocks is shown in Fig. 4.7. Movement of the reactor-positioning device will be possible only if the reactor is in the scrammed condition.

$\underline{\text { Boom Derrick }}$

A 5-ton-capacity boom derrick that is operable from a control panel in the reactor building is located at the end of the outside concrete pad. This device provides for remote handling of the reactor and materials and equipment for uncontained-reactor experiments outside the reactor building. The hook has a clear vertical movement of $56 \mathrm{ft}$ above the concrete slab at a distance of $10 \mathrm{ft}$ from the vertical centerline of the derrick. The derrick is capable of rotating 270 degrees.

Specific hazards associated with these special outdoor experiments will be separately analyzed and reported to the appropriate ORNL Review Committee for approval prior to operations. 


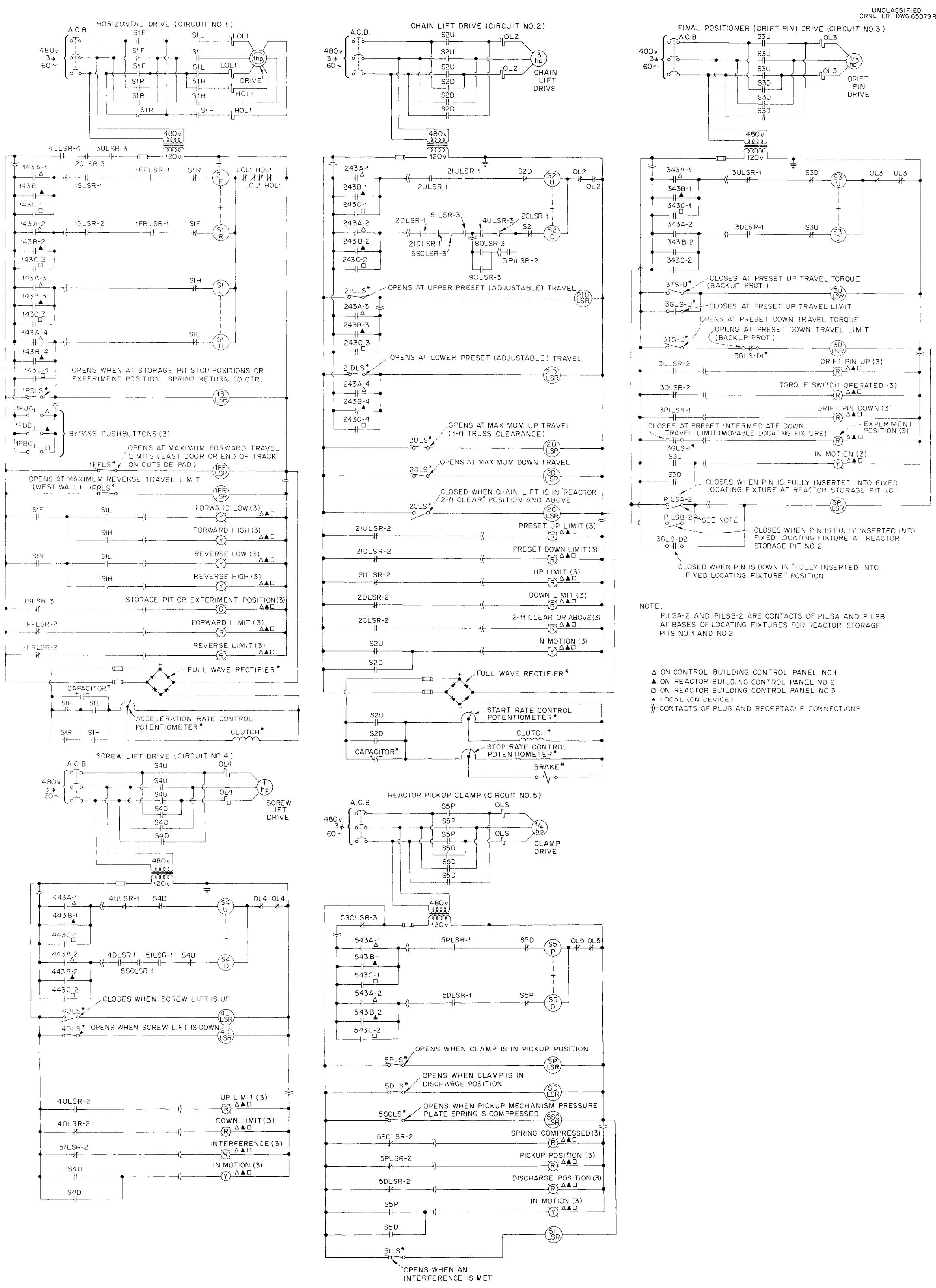

Fig. 4.7. Schematic Diagram of Control System for Reactor Positioning Device. 


\section{Water Systems}

Potable water is furnished underground from the main HFIR water loop in Melton Valley through approximately $5300 \mathrm{ft}$ of cast-iron pipe and a pumping station located near the guard house at the outer perimeter fence to a ground-level 30,000-gal-capacity storage tank located at an elevation of approximately $1095.5 \mathrm{ft}$ inside the 1000-ft fence. At this tank, part of the water becomes a primary fire-protection supply of 25,000 gal, which is fed to a yard hydrant, hose cabinets, and the sprinkler system at the control building and to a yard hydrant and hose rack at the reactor building. The remainder is available as a potable water supply for the control and reactor buildings.

At each of the buildings the potable supply is split into domestic (sanitary hot and cold) water and process water. The process water is prevented from backing up into the domestic water by an air break. Process water can be supplied to hose bibs in the reactor building for use in decontamination operations. Normally the line to these hose connections is valved off and drained.

\section{Sanitary Sewers}

Sanitary sewage is collected by the building sewers and run to separate septic tank and leaching field installations for the control and reactor buildings.

\section{Other Utilities}

Gas for laboratory service use is distributed to each of the laboratory areas of the control building from a liquid-petroleum gas-receiving and storage station located on the loading dock. Compressed air is distributed to the laboratory and shop areas of the control building and along the side of the reactor building and outside concrete pad from individual compressorreceiver stations located in the service equipment room at each building.

The electrical, ventilation, and waste-disposal systems are discussed in Section 6. 


\section{INSTRUMENTATION AND CONTROLS}

The instruments of the HPRR provide for safety, startup, and regulation of two modes of operation: (1) steady-state operation at any desired power level in the range from $1 \mathrm{mw}$ to $1 \mathrm{kw}$ or limited operation at higher powers up to $10 \mathrm{kw}$ and (2) pulsed operation of the order of $10^{17}$ fissions. For steady-state operation, the applicable control techniques are similar to those used for small reactors of the pool type. For pulsed-operation an entirely different approach must be made.

\section{Control Logic}

Control of the reactor is effected by positioning the safety block, the mass adjustment rod, and the regulating rod. The drives and reactivity worth of these elements, or rods, were discussed in Section 3. For normal control of the reactor, the rods are moved on demand at a slow, continuous speed to effect the desired change in reactivity. All rod motion is supervised by the safety system and interlocks shown in block diagram form in Fig. 5.1. Before increasing reactivity, all exclusionarea interlocks must be satisfied and a 3-min blast of a warning horn must be sounded to permit personnel in the exclusion area to reach safety or a conveniently located manual scram button. If delayed critical operation is desired, the safety block may be inserted subject to the following interlocks:

1. Log $\mathbb{N}$ amplifier calibration switch in the use position.

2. Log $\mathbb{N}$ period longer than 5 sec.

3. Log count-rate meter calibration switch in the use position.

4. Log count rate greater than 2 counts/sec.

5. Source at insertion limit or $\log \mathbb{N}>10^{-5} \mathbb{N}_{f}$, where $\mathbb{N}_{f}$ is the value for full power.

6. Regulating rod, mass adjustment rod, and burst rod all at withdrawn limit.

7. Delayed critical mode selected by means of a switch.

After the safety block is driven to its insertion limit, the mass adjustment and regulating rods may be moved in any sequence chosen by the 


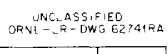

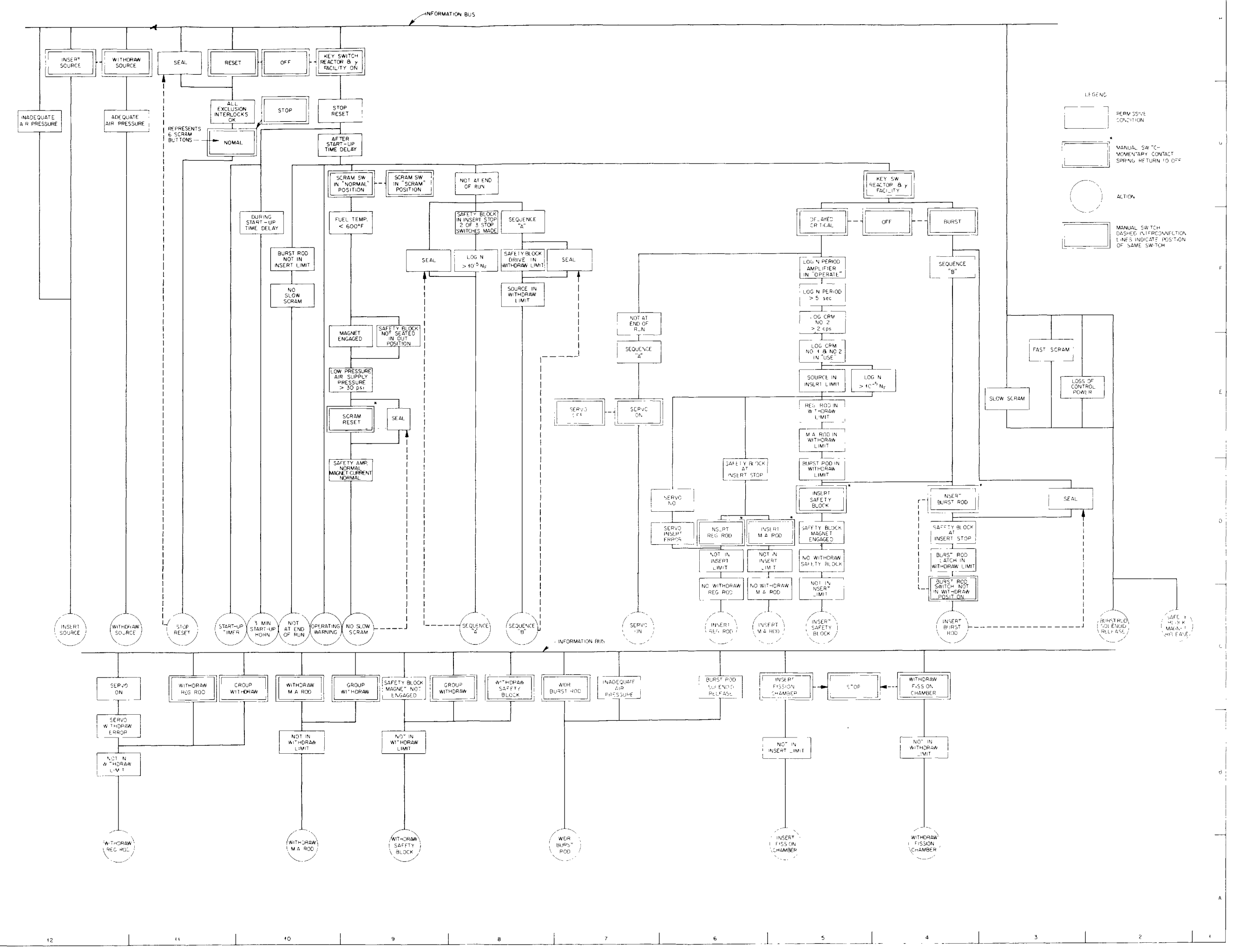

Fig. 5.1. Operational Block Diagram, 
operator. After attaining criticality, the reactor may be operated at any desired power up to $I \mathrm{kw}$, either manually or by using the servo system.

For burst operation, the reactor is first operated at delayed critical, as described above, and then it is necessary that a proper sequence be established to complete the burst, for example, sequences $A$ and $B$. When the power reaches $10^{-5} \mathbb{N}_{f}$, as indicated by the log $N$ system, and the safety block is inserted to its limit, the conditions needed to obtain sequence A are satisfied. Sequence A implies that the reactor is critical. The incremental value of the burst rod has been shown to be approximately 100 cents, but it may vary by a few cents because of changes in environment. The reactivity addition needed to obtain the target yield is higher than the incremental value of the burst rod. Excess reactivity is therefore added to the core by means of the mass adjustment rod. The amount to be added is ascertained by period measurements during the delayed-critical operation prior to disassembling the core by withdrawing the safety block to start the sequence of operations for accomplishing a burst. In order for excess reactivity not to be added inadvertently after the proper core reactivity is established, the mass adjustment and regulating rods are electrically interlocked to prohibit insertion after sequence $\mathrm{A}$ is obtained and the safety block is withdrawn from the insertion limit. When both the source drive and safety block are at the withdrawn limit, sequence $B$ is obtained. The operator may then select the burst mode. After an arbitrary waiting time to permit the neutrons to decay to a suitable low level, the operator proceeds to reassemble the core to its previously determined supercritical position by driving the safety block to its insertion limit. The burst is then accomplished by inserting the burst rod.

Nuclear information is transmitted to the operator from several channels, as shown on Fig. 5.2 and described below:

1. Level safeties. Two RD-300 dual-section ion chambers supply current to two level-safety channels.

2. Period. One section of one of the above ion chambers supplies current to a $\log \mathbb{N}$ period channel.

3. Linear. One section of the other of the above ion chambers supplies current to a micromicroammeter. 


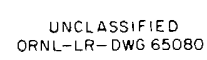
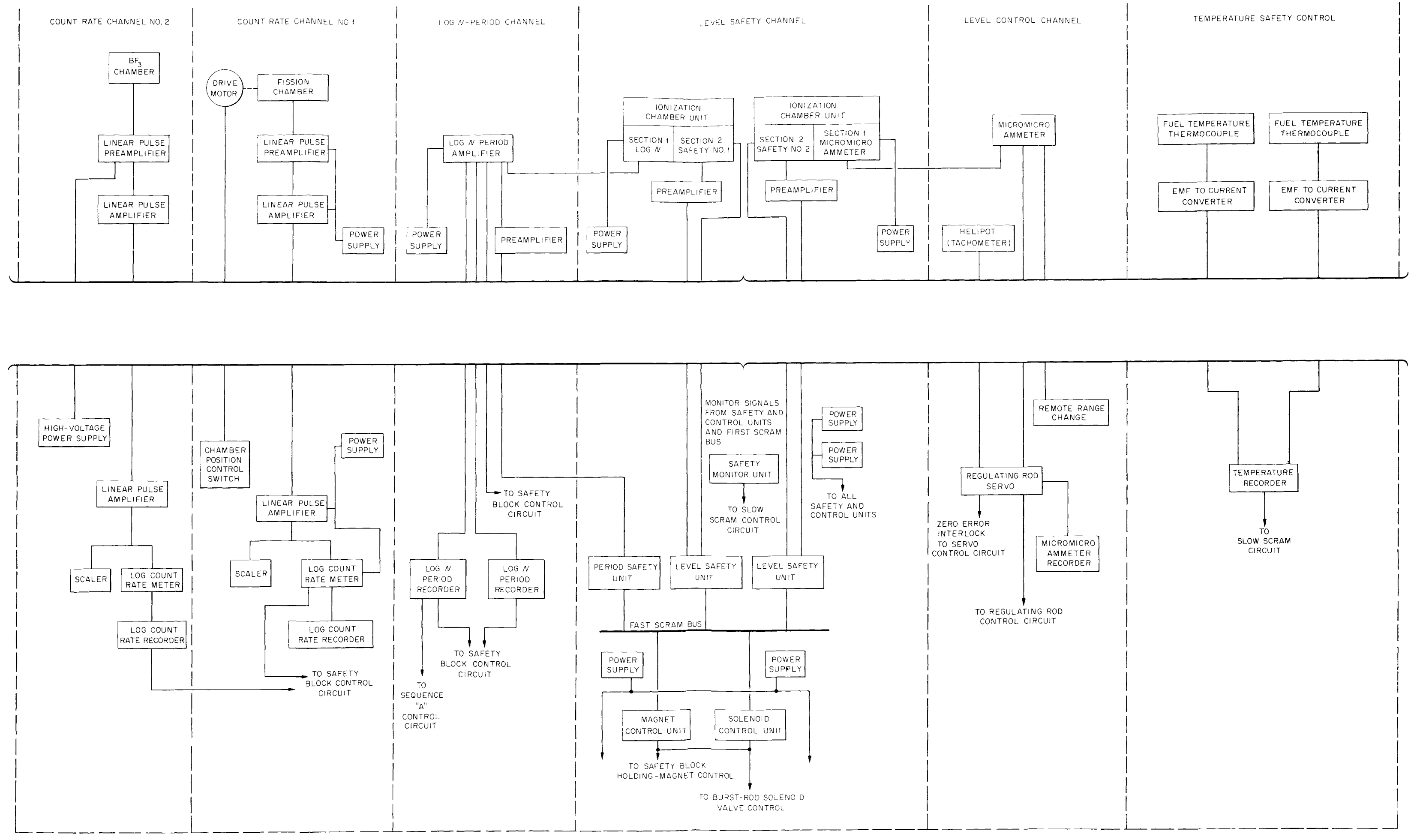

Fig. 5.2. Instrument Block Diagram. 
4. Counting rate. One fission chamber supplies pulses to a countingrate channel. A second counting-rate channel is provided that uses a $\mathrm{BF}_{3}$ chamber permanently mounted on the reactor support structure.

5. Neutron pulse-shape (burst) detector. A scintillation phosphor and phototube supplies current to an oscilloscope to map the pulse shape.

The ion chambers used in the level, period, and linear channels are dual purpose and are surrounded with polyethylene plastic to thermalize the fast neutrons emitted from the core to the sensitivity range of the chamber. The counting-rate channel used for startup is supplied with pulses from a Westinghouse fission chamber that can be moved from a polyethylene moderator to an absorber to provide a range adequate to span from the source level to the lowest level of the $\log N$ channel. The use of the second counting-rate channel provides added sensitivity at low counting rates during startup. This ensures a complete coverage of the steady operating range from source to full power.

As a convenience when operating at constant levels, a servo system will be employed. The regulating rod will be the control element and will change $\delta \mathrm{k}$ at a rate of less than $0.003 \% / \mathrm{sec}$. The motion of the regulating rod will be controlled by a servo amplifier that receives its signal from the micromicroammeter and matches its output against the set point.

A neutron pulse-shape detector will be used during pulse operation to give visual indication of pulse height and width. The detector consists of a scintillator that drives a phototube, the output of which is applied directly to an oscilloscope. The resulting trace may be photographed.

\section{$\underline{\text { Nuclear Safety }}$}

Two primary nuclear safety mechanisms exist: (1) self limiting by the temperature coefficient and (2) electromechanical level safeties. Since the reactor routinely operates at periods as short as $18 \mu \mathrm{sec}$, the selflimiting safety must be depended upon because no conceivable mechanical system has sufficiently fast response to be an effective power limiter. The self-limiting safety mechanism (i.e., the temperature coefficient) is effective only against additions of a limited amount of reactivity. 
Although the maximum change in reactivity available from the burst rod as a step addition is limited to approximately $\$ 1$, environmental effects may raise the effective reactivity above this value. Administrative controls will assure that the operations do not add more than a safe amount of reactivity.

When reactivity is added slowly, the power is limited to approximately $1.5 \mathrm{kw}$ in order to avoid excessive temperatures. Therefore for steadystate power operation, the level-safety system is required. A second function of the safety system is to minimize the objectionable production of neutrons immediately following a burst (the afterburst plateau). ${ }^{1}$ For this requirement a fast safety response (fast scram) is provided. This system consists of two ionization chambers which supply current to amplifiers whose output form an autioneering circuit. The largest signal governs the response of the system. When the thermalized flux at the chamber indicates that the reactor power has exceeded $1500 \mathrm{w}$ the sigma-bus voltage will vary so as to cause a decrease in the current in the electromagnet and the safety block will be driven out of the core. Also the current to the burst rod solenoid will be reduced and will cause venting of the pneumatic cylinder which ejects the burst rod when operating in the burst mode. ${ }^{1}$ The release magnet and solenoid are connected to the reactor safety system as in the MMR. ${ }^{2}$

The ultimate safety of this type of reactor is strongly dependent on administrative control. For example, when the safety block is driven out of the core during the delayed-critical check prior to each burst operation sequence, the operator must note the core temperature. When the safety block is reinserted immediately prior to inserting the burst rod, the operator must again note the temperature and, if it has decreased, he

\footnotetext{
${ }^{1}$ Experimental information from the critical experiments indicates that sufficient "bounce effect" exists to cause the electromagnet to release the safety block and initiate shutdown approximately $225 \mu \mathrm{sec}$ after the burst peak. See J. T. Mihalczo, Superprompt Critical Behavior of an Unreflected, Unmoderated Uranium-Molybdenum Alloy Assembly, ORNL-TM-230 (in press).

2T. E. Cole et al., The MPR Safety System and its Components, ORNL-1139 (April 4, 1952).
} 
must compensate for the effect of the temperature coefficient to prevent an excessively large burst.

\section{Non-Nuclear Instrumentation}

Temperature protection is provided by two iron-constantan thermocouple assemblies, located in the core as shown in Fig. 3.1, which indicate core temperatures and are connected to a dual-pen recorder on the reactor control console. Excessive temperatures sensed at either of the thermocouples initiate a slow scram. The temperature scram is the only safety against a slow meltdown at $10 \mathrm{kw}$, since the core cannot operate indefinitely at this power without forced cooling. During operation at $10 \mathrm{kw}$ the nuclear safety is set to protect the core against power overshoots; thus only the core temperature sensors are effective against overheating because of blower failure.

"Reactor-On" lights are located at the guard portal in the outer perimeter fence, at the water storage area, at gate 1 of the exclusion area, at the main doors of the control building, and at the reactor building doors. They are turned on when the reactor key switch is turned to "on." A level switch is provided to show the presence of water in the storage pit.

A third temperature channel consisting of an iron-constantan thermocouple (and spare, both located in the drilled-out bolt shanks) and a 0 to $100^{\circ} \mathrm{C}$ recorder are installed to monitor small changes in core temperature during the time interval between the delayed-critical operation preceding each burst and the insertion of the burst rod.

\section{$\underline{\text { Scram Actuation }}$}

Fast scrams are initiated through highly reliable, well-monitored, electronic channels. The slow scram is initiated through a relay that controls the power supply to the safety-block electromagnet.

A fast scram is initiated by the following:

1. Power greater than $1500 \mathrm{w}$ (or greater than 15,000 w for highpower operation). 
2. Reactor period less than 1 sec.

A slow scram is initiated by:

1. Insufficient air pressure for operation of source and burst-rod drives.

2. Loss of electric power.

3. Core temperature greater than $600^{\circ} \mathrm{F}$.

4. Manual scram request.

5. Reactor building doors opened.

6. Exclusion-area gates opened.

7. Manual scram buttons "depressed."

8. Certain safety system failures.

\section{Annunciators}

Visible and audible alarms will attract the operator's attention to the following conditions:

1. Safety monitor indicating trouble.

2. Stop reset open, indicating an exclusion-area gate has been opened or a manual scram button has been depressed.

3. Log $\mathrm{N}$ period less than 5 sec.

4. Fast scram.

5. Core temperature greater than $600^{\circ} \mathrm{F}$.

6. High-pressure air-tank pressure less than 150 psi.

7. Low-pressure air-tank pressure less than 60 psi.

8. Slow scram.

9. Control building doors open.

\section{Radiation Monitors}

Instrumentation of the types listed below will be provided for use by the health physicist and operators in monitoring the facility:

1. Continuous air monitors.

2. Laboratory beta-gamma background monitor of the GM type with endwindow and Esterline-Angus recorder located to measure background and to detect activity on smear samples and air samples. 
3. Cutie Pie beta-gamma monitors.

4. GM survey meters to be used as low-level background monitors and monitors for beta surface contamination.

5. Portable scintillation type alpha detectors to be used to detect surface alpha contamination, activity on smears, and activity on air samples.

6. Portable thermal-neutron survey meters.

7. Fast-neutron survey meters.

8. Monitrons to provide reading of direct gamma radiation. 


\section{AUXILIARY SYSTEMS}

There are no normal processes or operations contemplated that would produce radioactive wastes or result in dissemination of contaminated materials. In addition, the design of the reactor and its controls is such that automatic shutdown occurs during emergencies, such as electrical power failures. The auxiliary systems discussed herein are provided to permit easy handling of the results of the emergencies that may occur.

\section{Control Building Ventilation Systems}

Conditioned air (electrically heated in winter and cooled in summer) is provided in all areas of the control building, except the service equipment room. Laboratory air flow is on a "once through" basis, with each laboratory zoned individually for maximum ambient control. Exhaust air from the office areas is recirculated, with the related corridor serving as a return air plenum.

Supply air is obtained from an outside louver through roughing and final air filters. Pressure levels in the various areas of the building are maintained at values that assure controlled movement of air, with any leakage from the offices or control room into the laboratory and work areas. An exhaust system for the laboratories maintains the desired pressure-level differences. High-efficiency filters are provided for the counting room and provision has been made for future installation of highefficiency filters for the laboratory exhaust systems.

The supply and exhaust systems are provided with controls to automatically shut down both systems if radiation levels rise to above preset tolerance levels. The exhaust system is interlocked with the supply system to prevent its startup when the supply system is shut down.

\section{$\underline{\text { Reactor Building Ventilation Systems }}$}

The reactor building and its ventilation systems are designed to maintain a controlled negative pressure of 0.3 in. $\mathrm{H}_{2} \mathrm{O}$ below atmospheric within the main building when the doors are closed. Air-conditioning 
designed to handle the sensible and latent heat gains encountered is provided for the space within the building that is below a level of $8 \mathrm{ft}$ above the floor.

Supply air is filtered and recirculated through a duct distribution system. A separate exhaust system having two systems in parallel consisting of blowers and roughing and high-efficiency filters is provided. Pressure-relief and alarm devices are provided for limiting the negative pressure in the building or for indicating a higher than normal pressure.

A forced-air cooling system, utilizing recirculated building air, is available for rapid cooling of the reactor after a burst or for extending operating time during high-power runs. This system supplies air, as required, to either an above-the-floor duct manifold or to the reactor storage pits. It can provide up to $2000 \mathrm{cfm}$ of air at any of the discharge nozzles.

The reactor cooling and building exhaust systems can be operated on emergency power in case of power outages. A schematic air flow diagram is presented in Fig. 6.1.

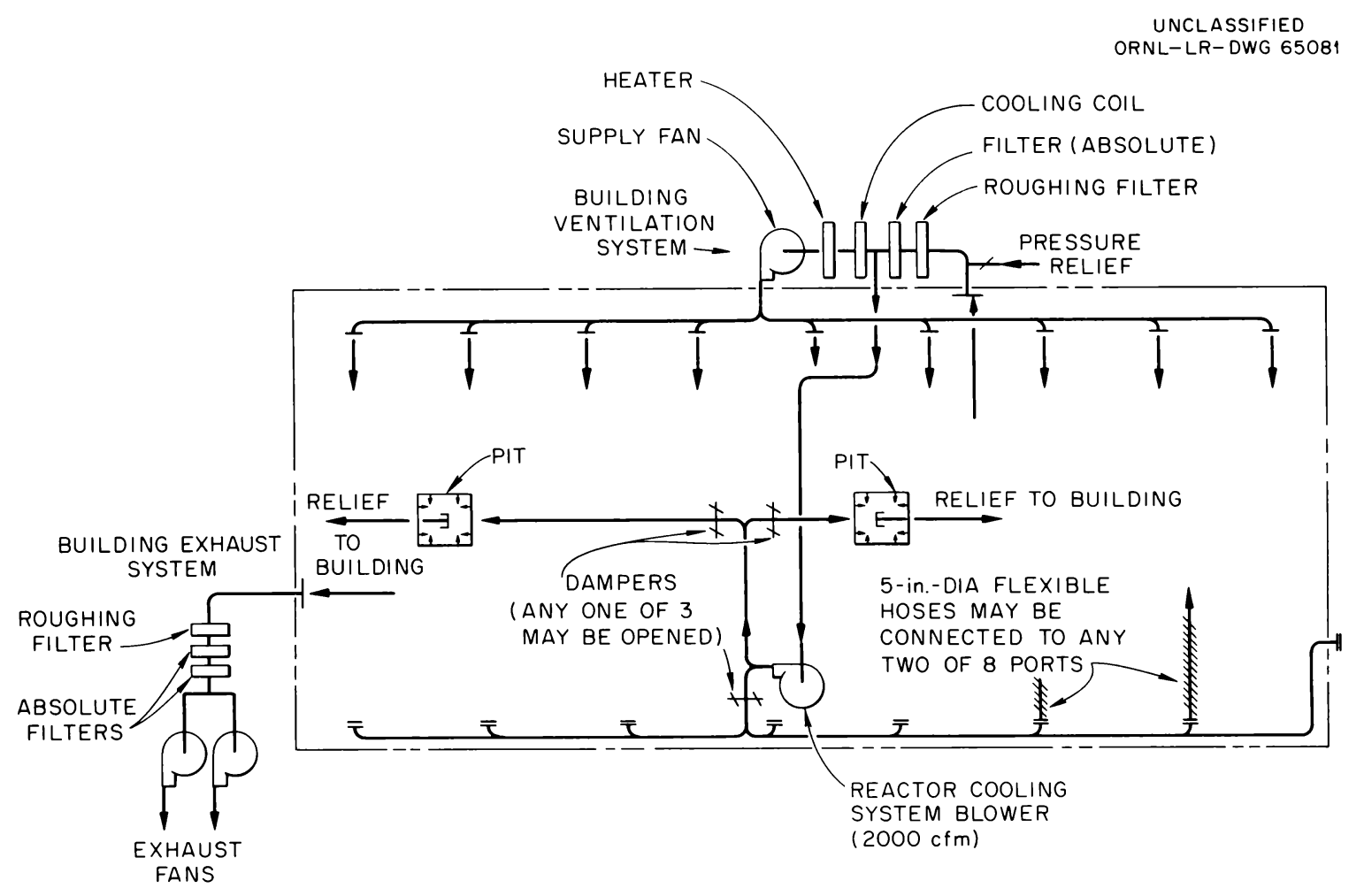

Fig. 6.1. Schematic Diagram of Air Flow in Reactor Building. 
Television Monitors

Three closed-circuit television systems will be installed for use as required in monitoring the reactor and the interior of the reactor building during experiments. Control of these monitors will be from the reactor control room. Receivers will be located in the reactor control room and monitor screens can be placed in the experimental laboratories. The three television pickups will be located as follows: one at the end of the building that is capable of wide-angle operation, with remote focus control, to monitor the entire building; one along the side of the building at the center that is capable of remote control of pan, tilt, and focus adjustment for monitoring an experiment or the reactor; a third portable unit, located on a movable tripod, that is capable of remote control of pan, tilt, and focus and can be placed at a critical position to monitor the experiment or the reactor.

\section{Communications Systems}

Intercommunication System

A master all-call type of intercommunication system is provided for communication between the reactor building, reactor control room, experimental laboratories, and the guard station at the outer perimeter fence. The circuits between the reactor building and the control room are available at all times.

\section{Public Address System}

A public address system is provided for the control building, reactor building, and outside areas. This system ties into the ORNL plant emergency system and is operable from the control room or from the master public address system controls at the Oak Ridge National Laboratory.

\section{Electrical Systems}

Electrical power to service this area is furnished from a connection to the existing $13.8-k v$ overhead line serving the Tower Shielding Facility. 
The power is transformed to $480 \mathrm{v}$ by a 1000-kva transformer located outside the control building. The transformer secondary is run underground to an indoor 480- $\mathrm{v}$ substation and distribution center in the control building.

A 25-kw emergency diesel generator set is provided to permit an orderly shutdown of experimental operations in case of a power outage. This emergency power will be available for operation of the reactor-positioning device, the boom derrick, the storage-pit doors, the reactor-building exhaust fans, the reactor forced-air cooling system, intercommunication sysems, the fire alarm, and the reactor control console. Individual batteryoperated emergency-lighting units are provided for use during a power outage.

\section{Waste-Disposal System}

Although no liquid radioactive wastes are normally generated in the facility, a 25,000-gal capacity asphalt-lined retention pond is located adjacent to the reactor building to provide for the retention of radioactive waste that would drain from the reactor building during emergency decontamination following a reactor incident. Following such an event, the waste would be collected and transferred by truck to the ORNL wastetreatment facility. Likewise the process drain systems in the control building include provisions for the installation of monitoring equipment for use in the event of radioactive leakage or contamination. Normally these process wastes are diluted, chlorinated, and discharged to the storm sewers. 


\section{SITE DESCRIPTION}

The reactor and its associated laboratories and facilities is located along Copper Ridge approximately 2 miles south-southeast of the ORNL main laboratories and approximately $13 / 8$ miles east of the Tower Shielding Facility. A site plan for the facility is shown in Fig. 7.1. The reactor building is located within a hollow and is surrounded by hills at least 50 ft high to provide natural shielding and to prevent "line-of-sight" viewing of the reactor installation from all directions.

\section{Site Characteristics}

The meteorology, seismology, geology, hydrology, and surrounding population distribution involved have been thoroughly studied in connection with the operation of the various installations in this area. Extensive summaries were prepared for previous reactor installations at ORNL. 1-6 The study for the Experimental Gas-Cooled Reactor ${ }^{3}$ presented a comprehensive summary of available information applicable to the DOSAR facility site.

\section{$\underline{\text { Restricted Areas }}$}

The reactor building is located in a hollow surrounded by a 1000-ftradius chain-link type of antipersonnel fence. The control building,

${ }^{1}$ A Meteorological Survey of the Oak Ridge Area, ORO-99 (Dec. 23, 1953).

${ }^{2}$ Climatology and Meteorology of the TSF Site, U. S. Weather Bureau Office, Oak Ridge, Tenn. (November 1958).

${ }^{3}$ Experimental Gas Cooled Reactor Preliminary Hazards Summary Report, ORO-196 (May 1959).

4J. H. Buck and W. B. Cottrell, ARE Hazards Summary Report, ORNL-1407 (November 1952), classified. $1953)$.

${ }^{5}$ Tower Shielding Facility Safeguard Report, ORNL-1550 (Del.) (June 9,

${ }^{6} \mathrm{C}$. E. Winters, Report on the Safety Aspects of the Homogeneous Reactor Experiment, ORNL-731 (June 7, 1950). 


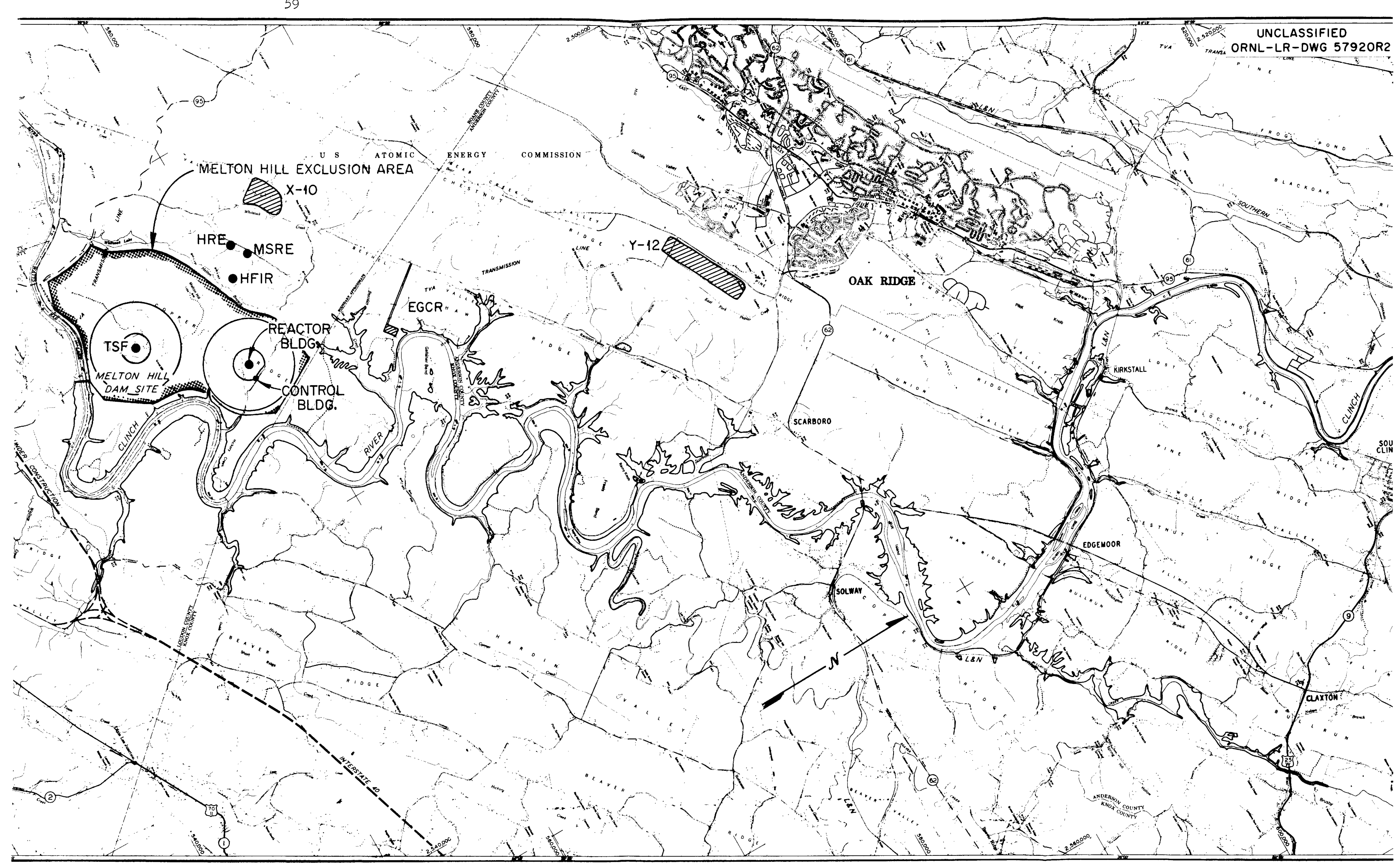

Fig. 7.1. Site Plan. 
which houses the administrative offices and the laboratories in addition to the facility controls, is located at the perimeter of this area and will be further isolated from the ORNL area by a Melton Hill area perimeter fence posted with radiation warnings (see Fig. 7.I). A guard house will be provided where the main access road enters the area. A gate (Gate No. I) is provided where the access road enters the looo-ft-radius exclusion area (see Fig. 4.1 of sec. 4). Additional gates in the l000-ftradius exclusion-area fence are provided for access to the water storage area and for the TSF patrol road (Gates Nos. 2 and 3). The personnel exclusion fence for the Melton Hill area is to be built by the Tennessee Valley Authority to restrict the entry of unauthorized personnel from the recreational area development of the Melton Hill Dam to the reactor areas of the Oak Ridge National Laboratory. ${ }^{7}$

\section{Nearby Installations}

The DOSAR facility is approximately 2 miles from the Melton Hill Dam now being constructed on the Clinch River by the Tennessee Valley Authority. At its closest point the Melton Hill Lake will be a little more than 3000 ft from the facility site. The Clinch River is a navigable stream and it is anticipated that river traffic and commerce will increase following the completion of construction of the dam. The embayment of large bodies of water above the dam will result in more extensive use of the Clinch River for recreational purposes.

Other installations within a radius of 2 miles from the DOSAR Facility are shown on Fig. 7.1 and described below:

\begin{tabular}{|c|c|c|}
\hline Facility & $\begin{array}{l}\text { Approximate } \\
\text { Distance } \\
(f t)\end{array}$ & $\begin{array}{l}\text { Direction } \\
\text { from DOSAR }\end{array}$ \\
\hline $\begin{array}{l}\text { Tower Shielding Facility (TSF) } \\
\text { Experimental Gas-Coled Reactor (EGCR) } \\
\text { High-Flux Isotope Reactor (HFIR) } \\
\text { Molten-Salt Reactor Experiment (MSRE) }\end{array}$ & $\begin{array}{r}6,800 \\
10,000 \\
6,000 \\
7,200\end{array}$ & $\begin{array}{l}\text { West } \\
\text { Northeast } \\
\text { Northwest } \\
\text { Northwest }\end{array}$ \\
\hline
\end{tabular}

7U. R. Cain, Additional Fencing and Radiation Monitoring Required for 5 Mw Operation of the TSR-II, CF 60-8-7, Aug. 1, 1960. Note: This, Melton Valley exclusion fence is
with completion by September 1962 . 


\section{REACTOR OPERATION}

The organization and procedures to be initially used for operation of the HPRR in the DOSAR Facility are described below. At the present time the procedures and criteria must be regarded as preliminary and subject to improvement as proper perspective is obtained during initial checkout of the reactor and operation of the facility.

\section{Operating Staff}

Organization

The initial startup and calibration of the HPRR was accomplished in the ORNL Critical Experiments Facility under the direction of experienced physicists and engineers qualified in the handling of critical assemblies. For routine operation of the DOSAR Facility, the functional organization shown in Fig. 8.1 is proposed. Responsibility for the safe operation of the HPRR is vested in the persons and committees shown on the chart of Fig. 8.1, which also defines the lines of authority.

\section{Responsibilities}

All operations and experiments in the DOSAR Facility will be under the direct supervision of the Facility Supervisor. He will be responsible for the establishment and control of procedures for the safe efficient operation of the facility, for all experiments run within the facility, and for handling any emergencies that may arise.

The supervision of the reactor and its associated facility operations will be the responsibility of the Reactor Supervisor. He will be responsible for the safety and continuity of these operations. He will be required to have appropriate operating experience, technical background, and training.

The reactor operators will be individuals who are trained and checked out in the operation of the reactor by the reactor supervisor. At least two trained persons will be on duty in the control room at all times that the reactor is operating. 


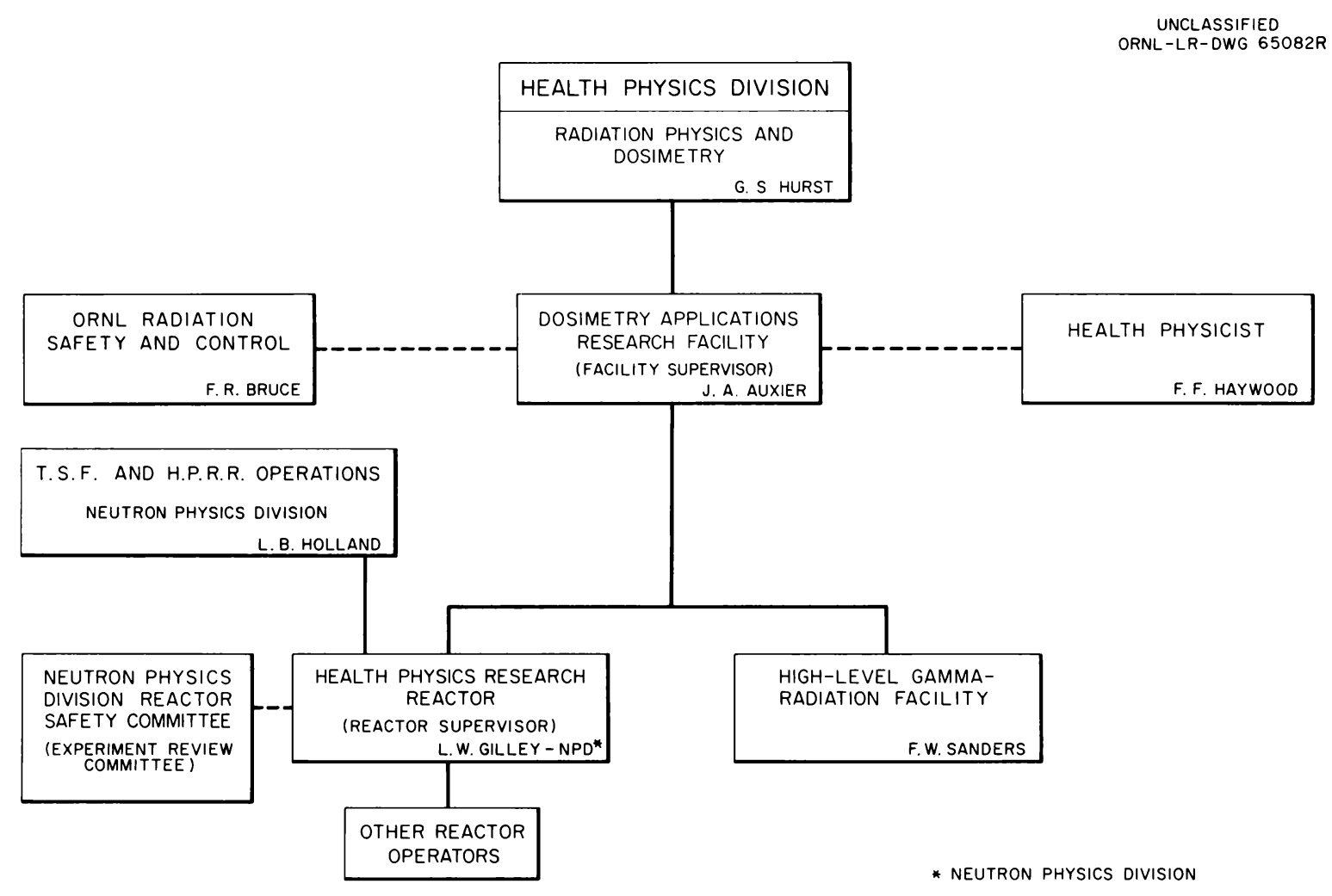

Fig. 8.1. Facility Organization Chart.

It will be the duty of the health physicist at the facility to set allowable time limits for work involving radiation exposure. All exposures will be kept below approved plant tolerance limits (see Table 9.5, sec. 9).

The reactor supervisor will have over-all responsibility for all reactor inspection and maintenance operations and may exclude all unnecessary personnel from the reactor building and control room during these operations. He will be responsible for the instruction and supervision of the workmen to ensure that the work is being carried out with approved procedures.

Experiments will be reviewed by the appropriate Laboratory Committee. The Neutron Physics Division Reactor Safety Committee (Experiment Review Committee), which will be composed of senior members of the Neutron Physics Division staff and representatives of the groups that will use the reactor, will review and approve the limits within which the reactor supervisor can normally operate. The over-all operation of the facility from a 
nuclear safety point of view will also be reviewed by the Laboratory Director for Radiation Safety and Control.

The ORNL Reactor Review Committee, responsible to the Laboratory Director for Radiation Safety and Control, will periodically review the reactor operating experience and will set new review dates and approve experiment limits based on the hazards involved. This procedure is similar to that now followed for other experimental reactors in the ORNL area.

\section{Critical Experiments}

Critical experiments of the types indicated below have been performed. These tests were preceded by a series of mechanical and electrical checkouts and tests of the equipment. The reactor control panel and interlock system was tested; the instruments were calibrated; the speed of the rod drives was measured; and the accuracy with which the mass adjustment and regulating rods and the safety block could be positioned was determined.

Preliminary Critical Experiment

Prior to the final machining of the core pieces, subcritical assemblies were tested and critical experiments were conducted at the ORNL Critical Experiments Facility. ${ }^{1}$ The subcritical assemblies simulated the final parts, and the test results were useful in establishing the anticipated critical mass of the reactor core.

The experiments provided preliminary information on void-coefficient and fission-rate distributions and on the effects of Plexiglas reflectors of various thicknesses. The data obtained for the Plexiglas reflectors were extrapolated to determine the effects of personnel and experimental samples in the vicinity of the core during both experiments and maintenance operations.

\footnotetext{
${ }^{I}$ W. E. Kinney and J. T. Mihalczo, ORNL Fast Burst Reactor: Critical Experiments and Calculations, ORNL CF 61-8-7I (August 24, 1961).
} 
Critical Experiment with Machined Assembly

After criticality was achieved with the machined assembly, calibration curves were obtained for the reactivity worth of the mass adjustment, regulating, and burst rods and for the safety block (see sec. 3 and Figs. 3.5 and 3.6).2 During the experiments, bursts with yields up to a maximum of approximately $1.8 \times 10^{17}$ fissions were generated to learn the characteristics of the reactor. ${ }^{3}$

Calibration Experiments for Reflectors

Experimental apparatus used in the DOSAR Facility experiments may have two types of effect on the reactor. First, reflection of neutrons would alter the critical mass and necessitate adjustment in the positioning of the mass adjustment or regulating rods or, in some cases, actual removal of fuel from the assembly, and, second, reflected neutrons would distort the normal neutron distribution and might thereby alter the calibration of the various movable components of the assembly. Procedures similar to the following will be utilized for determining the reactivity effect or in making a conservative estimate of the reactivity effect of the apparatus to be used in a proposed experiment.

During initial assembly of the reactor core, the neutron multiplication was determined as a function of height without reflecting material near the assembly and with a reflector consisting of an $8 \times 8 \times 1$-in.thick curved piece of Plexiglas placed against the core and a paraffin reflector $18 \mathrm{in.}$ wide by $12 \mathrm{in.} \mathrm{thick} \mathrm{by} 48 \mathrm{in.} \mathrm{high} \mathrm{placed} \mathrm{symmetrically}$ 10 in. away from the core. ${ }^{2}$ Count rates were taken for each of these reflector conditions at each fuel loading, and the data were extrapolated as a guide to obtaining the critical conditions. At critical conditions, the reactivity worth of the Plexiglas reflector was determined as a function of distance from the core. These data are presented in Fig. 8.2.

${ }^{2}$ J. T. Mihalczo, Reactivity Calibrations and Fission Rate Distributions in an Unmoderated, Unreflected Uranium-Molybdenum Alloy Research Reactor, ORNL-TM-189 (in press).

${ }^{3} \mathrm{~J}$. T. Mihalczo, Superprompt Critical Behavior of an Unreflected Unmoderated Uranium-Molybdenum Alloy Assembly, ORNL-TM-230 (in press). 


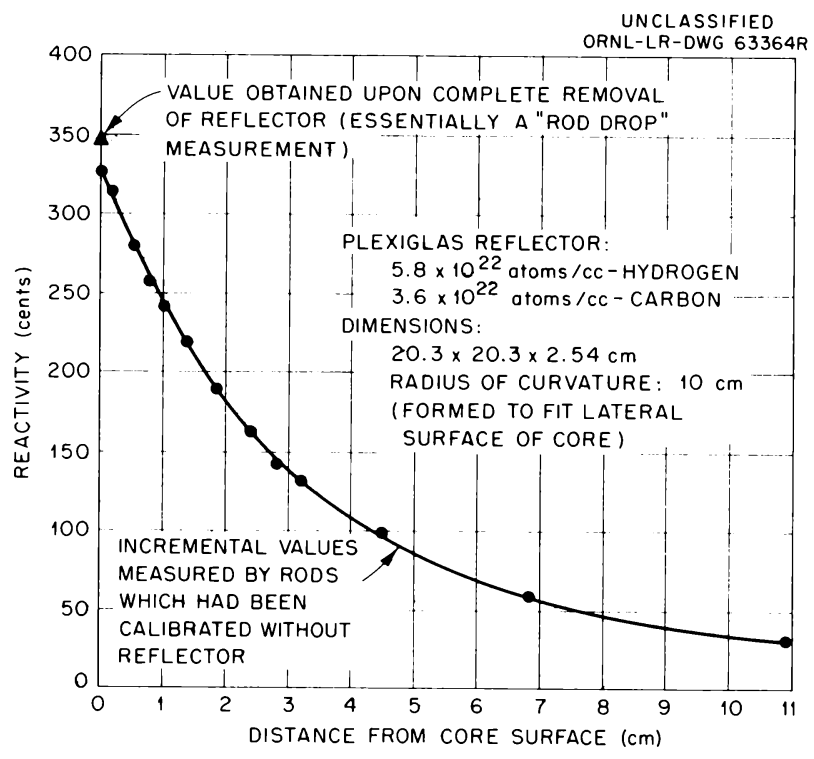

Fig. 8.2. Reactivity Worth of Plexiglas Reflector as a Function of Separation Distance from Core.

Similar experiments with reflectors of various sizes will be performed, as required, to provide data for making evaluations of the reactivity effects of proposed experimental apparatus.

\section{Normal Operation}

$\underline{\text { Reactor and Experimental Assembly Positioning }}$

It is planned that the majority of the experimental objects will be fabricated and installed on racks at the experiment preparation area of the control building and brought to the reactor building when required. In performing an experiment it will be first necessary to position the reactor and the objects of the experiment (instruments, samples, animals, etc.) in proper relationship to each other. This can be done in either of two ways: ( 1 ) by placing the reactor in the desired location in the reactor building, using the reactor-positioning device, and then placing the objects of the experiment around the reactor and (2) by setting up the experimental objects around a dummy reactor and then moving the reactor into the desired location. The latter procedure will be useful when the radiation level near the reactor (from fission-product gammas) 
is high and it is necessary to leave the reactor in its storage pit while personnel are in the reactor building. This flexibility in setting up an experiment is made possible by having controls for the reactor-positioning device located both in the reactor building and in the control building.

It is of utmost importance to maintain control over any relative motion of the reactor and experimental objects. To this end it is planned that the reactor-positioning device will be interlocked with the reactor controls so that the reactor can be moved only if it is in a safe condition. No movement of the reactor will be permitted during an experiment. Deliberate movement of experimental objects will be permitted only after careful review of the potential hazards by the appropriate Laboratory Committee. For burst-type operation, all objects of the experiment must be constrained so that there can be no movement of mass towards the reactor. The operating procedures will require that the reactor operator in charge of a given experiment examine the experimental setup and approve it from a nuclear safety standpoint before continuing operation.

\section{Prestartup Check}

A check list will be prepared and utilized during the operations preliminary to reactor startup.

$\underline{\text { Personnel Check }}$

The reactor cannot be operated unless certain safety requirements are satisfied to ensure that no personnel are in the exclusion area. Interlocks prevent reactor operation unless the reactor building doors and vehicle gate No. 1 in the exclusion fence are closed. Warning devices to notify personnel in the area of a reactor startup include "Reactor-On" lights in the control building, at the guard portal, and at gate No. I; a flashing light on a pole at the top of the hill between the reactor building and the control building; a 3-min blast from a horn at the top of the hill; and Klaxons at the reactor building. Manual scram buttons are located in the reactor building, at the water storage area, and at gate No. 1. Actuation of these buttons by anyone still in the 
exclusion area will prevent reactor startup. Television cameras located in the reactor building permit observation of this area from the control building. Proposed operating procedures require that the guard at the outer antipersonnel fence identify each person entering the area by name or code number. At the initiation of the startup procedure, the reactor supervisor or reactor operator in the control room will, through the "intercom" or public address system, ascertain the location and safety of each individual who has passed the outer-perimeter gate. Keys which lock gates Nos. 2 and 3 in the personnel exclusion fence must be brought back to the control building and placed in their proper position on the control panel before the reactor startup procedure can be initiated. If gate No. I or any of the reactor building doors are opened, the reactor will be automatically scrammed. Opening any control room doors during reactor operation will give an alarm and annunciation in the control room.

Steady-State Operation

Low-Power Operation. If no manual scram buttons have been depressed, startup operations can continue when the preliminary procedures described above have been satisfactorily completed. In order to obtain a condition of delayed critical, the safety block and the mass adjustment and regulating rods are inserted in sequence in the presence of a neutron source until a small excess reactivity is obtained. The safety block and both control rods have continuous position indicators attached to them. When the desired power is reached, the source is removed and the regulating rod is used to maintain the delayed-critical condition. In order to go through the above procedure the operation mode switch must be in the "delayed critical" position.

The electrical interlock sequence described in Section 5 must be satisfied before the safety block is inserted. Electrical interlocks prevent insertion of the mass adjustment or regulating rods unless the safety block is fully inserted. At this time, if automatic operation is desired and the proper interlocks are satisfied, the level demand signal on the servo amplifier can be set to match the actual power and the servo switch turned to "on." At the end of the run, the reactor is 
shut down with a group withdrawal switch, which withdraws the safety block and the two control rods.

High-Power Operation. When it is desired to operate the reactor at a high steady-state power, that is, from 1 to $10 \mathrm{kw}$, the operating procedure is similar to that outlined for lower power operation. A requirement for sustained high-power operation is that the reactor must be cooled by the forced-convection system (see secs. 3 and 6) in order to avoid scrams resulting from an excessive core temperature.

A core temperature in excess of $600^{\circ} \mathrm{F}$, as measured by the two thermocouples in the fuel plates (see Fig. 3.1), will initiate a scram. In operating from room temperature to $600^{\circ} \mathrm{F}$ it will be necessary to add approximately $90 \phi$ of reactivity to compensate for the negative temperature coefficient of the reactor core.

\section{Burst Operation}

For burst operation, a condition of delayed critical is obtained using the same procedure as that for low-power operation, and the reactivity is adjusted to give the desired yield (as described in Section 5). The safety block is then withdrawn for a sufficient time to allow the delayed-neutron population to effectively decrease to background. This requires approximately $20 \mathrm{~min}$. Closed-circuit television systems will be available to permit visual inspection of the reactor and experimental area. This will provide an added precaution against otherwise unobserved movement of experimental objects that might increase reactivity. When the neutron population has decreased to background, the operation mode switch is turned to "burst." Electrical interlocks then prevent the addition of reactivity by means of either the mass adjustment rod or the regulating rod.

Electrical interlocks, sequences $A$ and $B$ (see sec. 5), must be satisfied before the safety block can be reinserted. When the safety block has been reinserted, the operator will then trigger the burst by inserting the burst rod. During the burst, scram circuits are tripped and the safety block ${ }^{4}$ and the burst rod are withdrawn automatically.

\footnotetext{
${ }^{4}$ See ref. 1 of Section 5 for note regarding "bounce effect."
} 


\section{Basic Operating Regulations}

All reactor operations, maintenance work, and experimental assembly installation will be in compliance with limitations approved by the appropriate review committee, and previously prepared check lists will be utilized. Since all controls for reactor operation are centralized in the reactor control room, there can be no operation of the assembled reactor from any other location. The reactor control room will be manned by at least two qualified persons at all times when the key switch is turned on for reactor operation. The reactor power supply will be locked in the "off" position at other times.

Television monitors will be available as required for observation of the reactor room from the control room. Personnel entry to the reactor building will not be permitted without prior approval of the reactor supervisor. The reactor supervisor will check with the health physicist to ensure that radiation levels being encountered are within safe limits.

Inspection, testing, and maintenance of protective devices and critical operating equipment will be done in accordance with specified schedules and written procedures. The reactor area will be monitored with proper radiation detection instruments at all times when maintenance or other work is being done. A continuous log of all experiments, maintenance, and operations; modifications and repair of instrumentation and interlocks; adjustments to critical mass; and all other pertinent information will be kept by the reactor operator. This log will be kept up-to-date to make the status of the reactor available at any time.

\section{Special Operations}

It is recognized that some experiments will require certain special operations. Operating procedures following the established safety rules will be written and enforced for all such special operations.

All operations involving exposures to radiation sources will be monitored by the facility health physicist. He will set allowable time limits for work on the reactor to ensure that the exposures are kept below tolerance. In addition to the normal safeguards, strict administrative control will be maintained to minimize hazards during these operations. 
Reactor Handling and Transportation

In order to avoid the inadvertent addition of reactivity, all reactor movements will be carefully planned and programmed in advance of any experiment. The reactor will be in the fully scrammed condition during movement; that is, the safety block will be withdrawn and the control rods retracted. In this condition the reactor is approximately $\$ 23$ below the delayed-critical configuration.

When experimental objects are installed, the position stops for vertical movement of the horizontal boom on the reactor-positioning device and for horizontal movement of the truck will be set and checked out as described in Section 4.

If reactor movements are controlled from one of the control panels in the reactor building, the health physicist will be in attendance to monitor the operation with the proper instrumentation. If the reactor handling is to be remotely controlled from the control room, all movements of the positioning device can be monitored by means of the closed-circuit television systems provided for this purpose. When it is necessary to ship the uranium core to other sites, the core will be dismantled as discussed below. The uranium parts will be shipped in approved individual fissionable material containers ("bird cages") of the type used by the Y-12 plant.

\section{Inspection Procedures}

In addition to daily checks of the safety instrumentation and controls, periodic inspections of the reactor and its associated equipment will be carried out on a regular schedule, with additional inspections permissible at the discretion of the operator and manager of the facility. Check lists will be utilized for these inspections.

Core Maintenance and Disassembly

A complete series of preoperational critical experiments was run at the ORNL Critical Experiments Facility to provide basic information for evaluating the reactivity worth of various types of reflectors under different subassembly conditions. Maintenance procedures will be written 
with safety standards based on these experiments. All maintenance and inspection operations will be under the direct supervision of the reactor supervisor. At least two persons will be present during all such operations. In addition, proper radiation monitoring equipment will be used when any work is done on the core.

A set of jigs and fixtures will be provided, as required, to simplify core maintenance operations. These fixtures will include devices for support and assembly of the core. Approved, written procedures will be followed for assembly and disassembly of the core.

\section{Emergency Procedures and Disaster Plans}

The reactor and its instrumentation and controls were designed to shut the reactor down automatically without need for operator action in case an unsafe condition develops. In the event such a condition develops and an automatic shutdown occurs, the reactor supervisor will assess the situation and initiate whatever additional actions may be required. The objective of the emergency procedures in all cases will be to minimize hazards to personnel and bring the reactor to as safe a condition as possible as soon as possible. In general, the local emergency procedures in the ORNL Plant Radiation Safety and Control Manual will be followed. In addition, specific emergency procedures applicable to the DOSAR facility will be put into effect. Typical items that will be incorporated into these procedures include:

1. A supply of decontamination equipment and contamination-zone clothing will be stocked in the control building.

2. The reactor supervisor will be responsible for warning building personnel if a reactor incident occurs. All personnel will assemble immediately in the control building counting room.

3. Although the control building ventilation system will automatically shut down on a signal of excessive radiation at the reactor building, the facility health physicist will be responsible for checking that the ventilation system has actually shut down. 
4. The facility health physicist, with the assistance of the reactor supervisor, will, as soon as possible, conduct a survey to determine the extent of the incident and the nature and location of any radiation hazards. 5. Decontamination will start as soon as radiation levels permit. 


\section{HAZARDS AND SAFEGUARDS}

The potential accidents to the reactor can be grouped in two major categories. First, a failure of the safety circuits or controls to scram the reactor after an operating sequence could cause an accident, and, second, the addition of excess reactivity at an inopportune moment could result in excessive fission yields during an operating sequence. The hazards, their consequences, and the safeguards are discussed below.

\section{Activity Levels}

\section{Fission-Product Inventory and Exposure Doses}

The buildup of fission products in the core and the possible exposure doses that would result from their release to the atmosphere following accidents such as meltdown or excessive fission yield were analyzed previously in connection with site selection.1,2 The results of the calculations are presented in Tables 9.1 through 9.4.

Table 9.1 presents an estimate that, rather than being the total actually released, is in excess of the maximum $I^{131}$ equivalent available for release in case of a meltdown of the core because of failure of the control system to scram the reactor. If the total shown were released, the estimated resultant dose would amount to $0.2 \mu \mathrm{c}$ at $3.6 \times 10^{-2} \mu \mathrm{c}$ inhaled per curie released, with a total resultant internal exposure to the thyroid of $295 \mathrm{mrad}$ for a person at a distance of approximately $3000 \mathrm{ft}$ from the reactor. This estimate is considered to be high because total meltdown of the core is not likely to occur and because total release of the iodine inventory does not occur on meltdown.

Similar calculations for a burst yield of $10^{19}$ fissions, that is, the maximum credible accident, give a total equivalent $I^{13}$ inventory, as given in Table 9.2, of 70 curies one minute after the burst, which

\footnotetext{
${ }^{I_{F}}$. W. Sanders et al., Operation Plan and Hazards Report - Operation BREN, pp 91-101, CEX-62.02 (January 1962).

${ }^{2}$ M. I. Lundin, ORNL Fast Burst Reactor and Facilities, ORNL CF-60-8-116 (Aug. 29, 1960).
} 
Table 9.1. Total Equivalent $I^{131}$ Inventory for Meltdowna

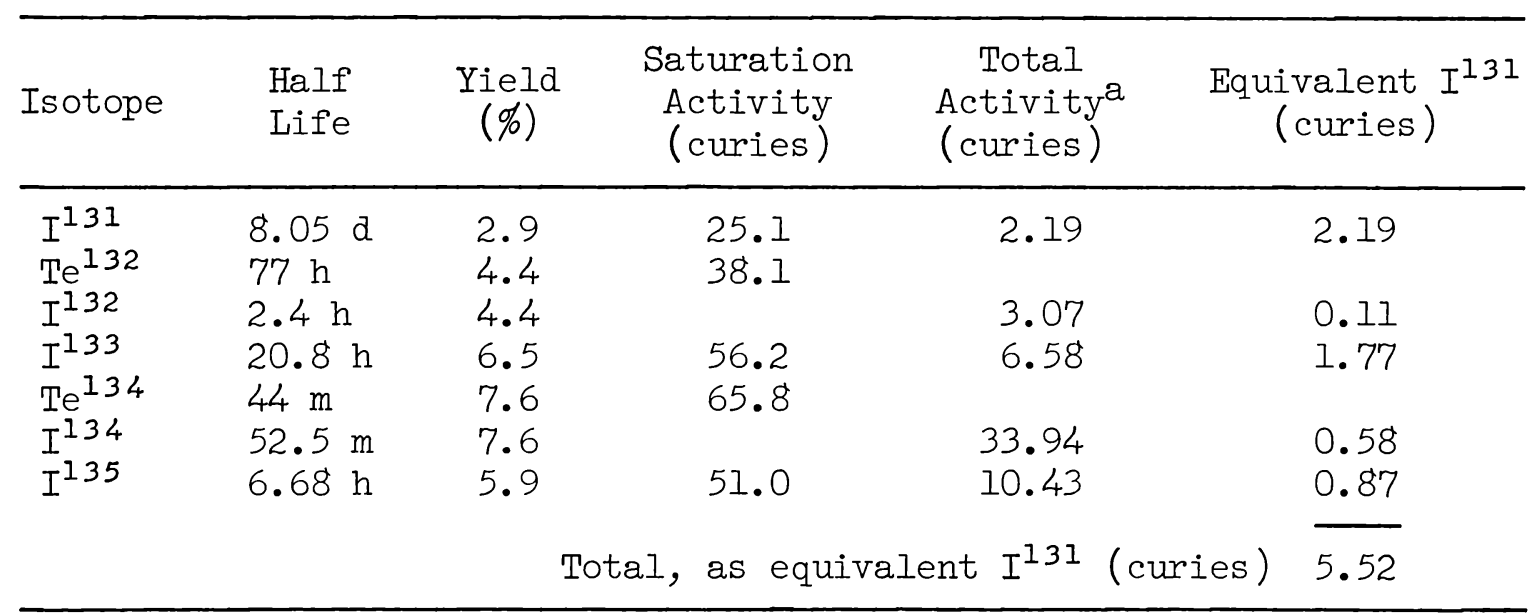

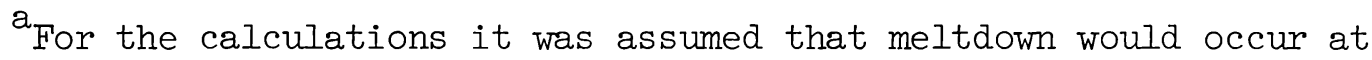
the end of a 2-hr run at $1 \mathrm{kw}$ following a long sequence of previous daily runs of like operation.

Table 9.2. Total Equivalent $I^{131}$ Inventory for MCA Burst Yield of $10^{19}$ Fissions

\begin{tabular}{|c|c|c|c|c|}
\hline \multirow{2}{*}{ Isotope } & \multicolumn{2}{|c|}{$\begin{array}{c}\text { Activity Inventory (curies) } \\
1 \text { min After Burst }\end{array}$} & \multicolumn{2}{|c|}{$\begin{array}{c}\text { Activity Inventory (curies) } \\
\text { 1.12 hr After Burst }\end{array}$} \\
\hline & Total & Equivalent $I^{131}$ & Total & Equivalent $I^{131}$ \\
\hline$I^{131}$ & 0.05 & 0.05 & 4.38 & 4.38 \\
\hline$I^{132}$ & 43.3 & 1.56 & 38.1 & 1.37 \\
\hline$I^{133}$ & 37.0 & 9.96 & 102.5 & 27.57 \\
\hline$I^{134}$ & 1301 & 22.13 & 1730 & 29.41 \\
\hline$I^{135}$ & 438 & 36.36 & 397.3 & 32.98 \\
\hline Total & & 70.06 & & 95.71 \\
\hline
\end{tabular}

rises to a maximum of approximately 96 curies in $1.12 \mathrm{hr}$ and decreases thereafter. The larger inventory results in a total thyroid exposure dose of $5.19 \mathrm{rad}$, which does not exceed the permissible quarterly adult occupational exposure.

The strontium isotopes present after a burst of $10^{19}$ fissions are listed in Table 9.3. It should be noted that the bone exposures from 
Table 9.3. Strontium Isotope Inventory for MCA Burst of $10^{19}$ Fissions

\begin{tabular}{|c|c|c|c|c|c|}
\hline Isotope & $\begin{array}{l}\text { Times of } \\
\text { Maximum }\end{array}$ & $\begin{array}{l}\text { Maximum } \\
\text { Inventory } \\
\text { (curies) }\end{array}$ & $\begin{array}{c}\text { Exposure Dose } \\
\text { per } \mu \mathrm{c} \text { of } \\
\text { Strontium } \\
\text { (mrem) }\end{array}$ & $\begin{array}{l}\text { Estimated } \\
\text { Strontium } \\
\text { Inhaleda } \\
\quad(\mu \mathrm{c})\end{array}$ & $\begin{array}{c}\text { Estimated } \\
\text { Maximum Ex- } \\
\text { posure Dose } \\
(\text { mrad })^{b}\end{array}$ \\
\hline $\mathrm{Sr}^{89}$ & $3.52 \mathrm{hr}$ & 1.65 & 418 & 0.0594 & 24.8 \\
\hline $\operatorname{Sr}^{90}$ & $\begin{array}{l}31.2 \mathrm{~m} \text { to } \\
9.82 \mathrm{~d}\end{array}$ & 0.0152 & 44,550 & $5.47 \times 10^{-4}$ & 24.4 \\
\hline $\mathrm{Sr}^{91}$ & $1.12 \mathrm{hr}$ & 265 & 7.44 & 9.54 & 71.0 \\
\hline \multirow[t]{2}{*}{$\mathrm{Sr}^{92}$} & $2.15 \mathrm{~m}$ to & 1103 & 2.59 & 39.7 & 102.8 \\
\hline & & & & Total & 223.0 \\
\hline
\end{tabular}

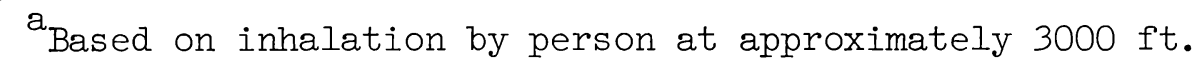

$\mathrm{b}_{\text {Based on } \mathrm{RBE}}=1$ for converting beta and gamma doses from rem to rad.

Table 9.4. Total Fission Products in MCA Burst of $10^{19}$ Fissions

\begin{tabular}{lcc}
\hline $\begin{array}{c}\text { Time After } \\
\text { Burst }\end{array}$ & $\begin{array}{c}\text { Activity at } \\
\text { Indicated Time } \\
\text { (curies) }\end{array}$ & $\begin{array}{c}\text { Submersion } \\
\text { Exposure Dose } \\
\text { (rad) }\end{array}$ \\
\hline $19 \mathrm{sec}$ & $7.44 \times 10^{6}$ & 207.7 \\
$1 \mathrm{~min}$ & $1.70 \times 10^{6}$ & 47.5 \\
$3.15 \mathrm{~min}$ & $5.16 \times 10^{5}$ & 14.4 \\
$9.92 \mathrm{~min}$ & $1.69 \times 10^{5}$ & 4.72 \\
$31.2 \mathrm{~min}$ & $6.27 \times 10^{4}$ & 1.75 \\
$1.12 \mathrm{hr}$ & $2.87 \times 10^{4}$ & 0.80 \\
\hline
\end{tabular}

strontium isotopes would be less than the thyroid exposures from iodine isotopes by a factor of over 20.

The postulated $10^{19}$ fissions, neglecting probable attrition from deposition and condensation in transit to the point of exposure, result in the submersion-exposure doses listed in Table 9.4. It would take approximately $200 \mathrm{sec}$ for the air-borne material to travel to the nearest access point (3000 ft), and the external dose would not be greater than 15 rad at that point. 


\section{Radiation from Core}

Normal Operation. The fast-neutron dose from a pulse of $10^{17} \mathrm{fis}-$ sions (or operation at $10 \mathrm{kw}$ for $10 \mathrm{~min}$ ) is shown in Fig. 9.1. The doses shown at 900 and $3000 \mathrm{ft}$, that is, 40 and $0.25 \mathrm{mrad}$, respectively, should in practice be reduced by a factor of 2 to 3 to account of the presence of ground cover and hills.

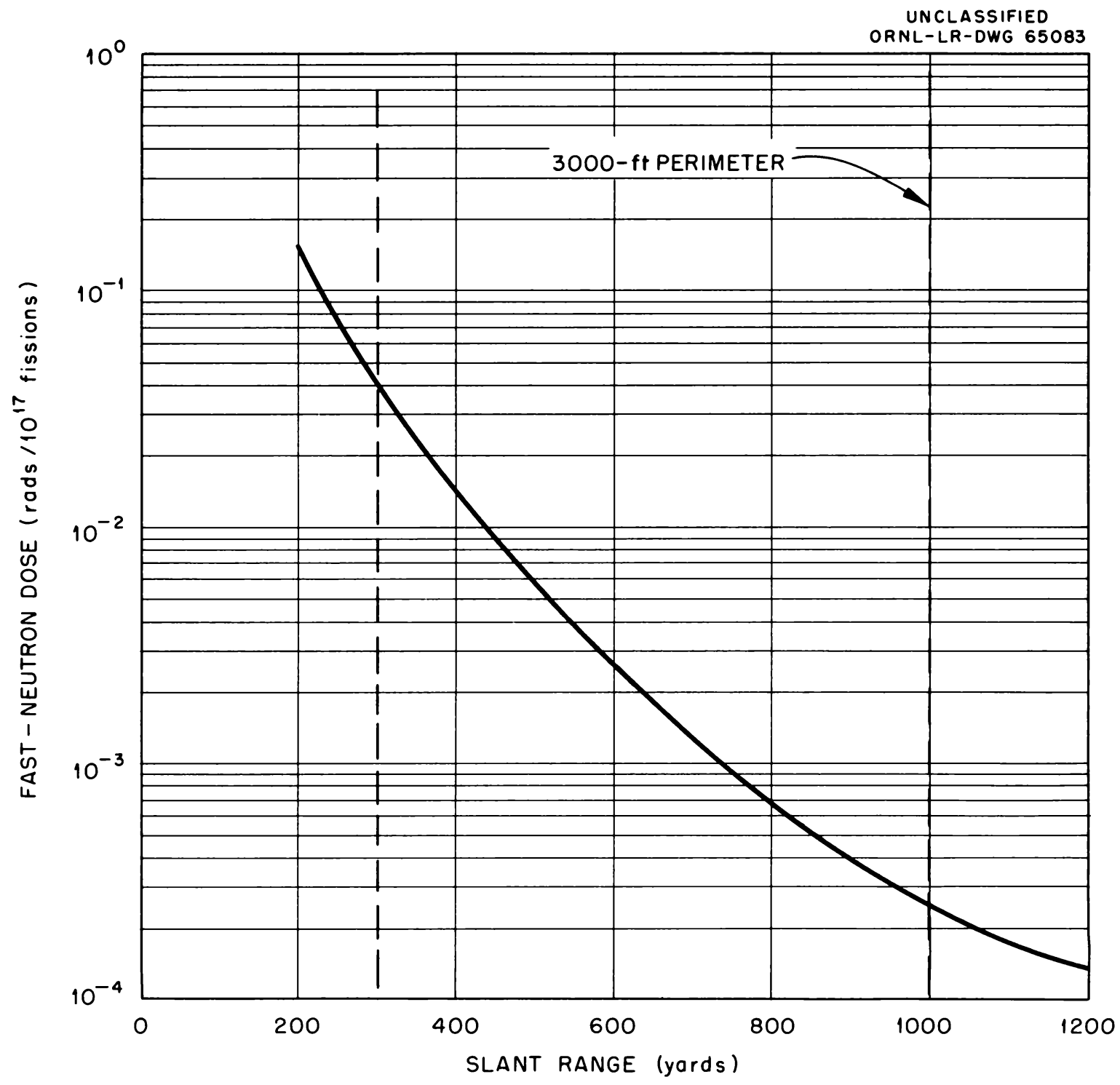

Fig. 9.1. Fast Neutron Dose vs Distance from Core. [Based on data of R. L. French and M. B. Wells, Health Physics, ㅌ, 108-18 (1961).] 
A conservative calculation of the gamma dose at a distance of $10 \mathrm{ft}$ from the core is shown as a function of time after a burst in Fig. 9.2. Calculations indicate that the exposures per burst within the control building will be $0.3 \mathrm{mrad}$ in the counting room and $2 \mathrm{mrad}$ in the remaining portion of the building.

Abnormal Performance. An excursion of $10^{19}$ fissions would result in a neutron dose of $25 \mathrm{mrad}$ at $3000 \mathrm{ft}$.

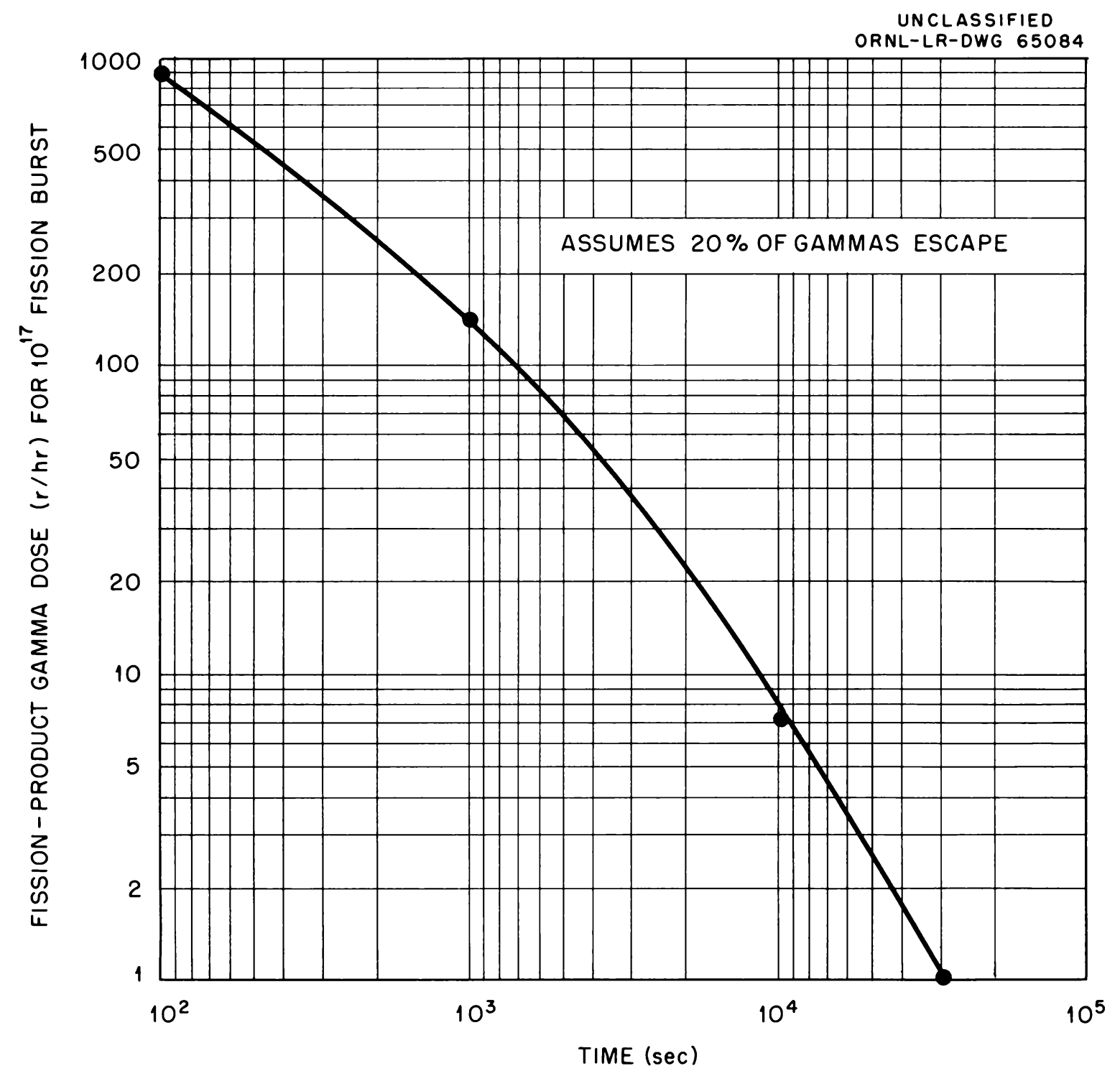

Fig. 9.2. Fission Product Gamma Dose vs Time at Distance of $10 \mathrm{ft}$ from Core. 
Radiation from Activated Materials

It is anticipated that activation of structural materials, such as concrete or stainless steel, will be negligible for the expected exposures. The radiation field at the surface of the safety tube mounted beneath the core was $7 \mathrm{mrad} / \mathrm{hr} 29 \mathrm{hr}$ after a series of bursts, including one with a yield of approximately $1.8 \times 10^{17}$ fissions, with the total number of fissions in the series in excess of $10^{18},{ }^{3}$ over a period of approximately 12 days.

Calculations of concrete activation from a fission burst indicate that the activation will be primarily due to $2.3-\mathrm{min} \mathrm{Al}^{28}$ and $15-\mathrm{hr} \mathrm{Na}{ }^{24} \cdot{ }^{4}$ Immediately following a burst of $1 \times 10^{17}$ fissions, the surface field on a concrete slab at a distance of $10 \mathrm{ft}$ from the core would be approximately $4000 \mathrm{mr} / \mathrm{hr}$ from the 2.3-min $\mathrm{Al}^{28}$ and approximately $14 \mathrm{mr} / \mathrm{hr}$ from the $15-\mathrm{hr} \mathrm{Na}^{24}$.

\section{Nonoperating Periods}

\section{Experimental Assembly Installations}

Hazards may arise during installation of experimental apparatus and samples because of the possibility of the addition of reactivity by the actions of the personnel making the installation. The reactor is normally more than $\$ 23$ below delayed critical at the time of experimental assembly installation because the safety block and the regulating, mass adjustment, and burst rods are withdrawn. It is conceivable, however, that reactivity in excess of \$23 could be added by "hugging" the core physically or with a highly reflective assembly, but such reactivity additions are considered unlikely if there is strict adherence to approved procedures.

Before installation, all experimental assemblies must be approved by the appropriate review committee, as indicated in Section 8. For guidance in analyzing proposed experiments, the preliminary operations at the

\footnotetext{
${ }^{3}$ Personal communication, J. T. Mihalczo.

${ }^{4}$ Final Report on the Conceptual Design and Initial Radiological Safety Study for a Pulse Nuclear Reactor, NP-10495, AN-176 (Apr. 18, 1960).
} 
DOSAR facility will provide data for the compilation of information on reactivity increments for various types of reflectors. If the reactivity worth of a particular experimental assembly is not determinable with any degree of accuracy in advance, it will be necessary that it be "calibrated," utilizing approved procedures, before it can be put into its final position. If the reactivity worth is known, the experimental assembly can be installed around a dummy reactor or around the actual core, depending upon the previous operating history of the core, and normal operations can proceed as described in Section 8.

All installation operations will be monitored, using appropriate dosemeasuring instruments, and working times will be set within permissible exposure limits. Adherence to the approved procedures and limitations, as outlined in Section 8, during experimental assembly installation should preclude hazards to either operating personnel or the general public.

\section{Maintenance and Inspection}

The potential hazards of maintenance and inspection work are similar to those to be encountered during experimental assembly installation. Allowable working times during maintenance operations or during work on the unshielded core following operation are listed in Table 9.5. The doserate data tabulated ${ }^{1}$ are based on the penetrating gamma radiation from the fission products in the core following the mode of operation listed. The allowable working times are based on a maximum weekly accumulated dose not to exceed $300 \mathrm{mrad}$, with exposure limits of 3 rad per quarter. It is evident from the data of Table 9.5 that shielding of the core during maintenance and inspection work may be a necessary precaution. Special tools and shields will be provided to minimize exposures.

It must be noted also that, although the reactor is more than $\$ 23$ below delayed critical during these operations, enough reflective material could conceivably be added to make the core critical. Thus, the procedures to be followed in maintenance and inspection work must be specified, in advance, to prohibit the inadvertent addition of excess reactivity. The established procedures must be adhered to and the work must be monitored. Proper monitoring and administrative control will minimize the hazards to personnel. 
Table 9.5. Estimated Dose Rates 5 ft from Center of Core

\begin{tabular}{|c|c|c|}
\hline $\begin{array}{l}\text { Cooling } \\
\text { Time } \\
(\mathrm{hr})\end{array}$ & $\begin{array}{l}\text { Dose Rate } \\
\text { (rad/hr) }\end{array}$ & $\begin{array}{l}\text { Working Time } \\
\text { Based on } 300 \\
\text { mrad per week } \\
\text { (min) }\end{array}$ \\
\hline
\end{tabular}

Following Operation at $1 \mathrm{kw}$ for $5 \mathrm{hr}$

$\begin{array}{ccc}0.5 & 5.0 & 3.6 \\ 6.0 & 0.90 & 20 \\ 12.0 & 0.50 & 36\end{array}$

Following Operation at $1 \mathrm{kw}$ for $10 \mathrm{hr}$

$\begin{array}{rcc}0.5 & 6.50 & 2.8 \\ 6.0 & 1.50 & 12 \\ 12.0 & 0.85 & 21\end{array}$

Following a Burst of $10^{17}$ Fissions

$\begin{array}{rrr}0.5 & 30.0 & 0.6 \\ 4.0 & 2.0 & 9.0\end{array}$

Reactor Movement

Hazards during movement of the nonoperating reactor, as in the operations discussed above, involve the potential for addition of large amounts of reactivity by moving the reactor toward a reflector. The procedures for control of the motion of the reactor-positioning device must be carefully planned in advance of operation. The rates of motion of the reactorpositioning device are such ( $6 \mathrm{ft} / \mathrm{min}$ vertically, 5 and $10 \mathrm{ft} / \mathrm{min}$ horizontally) that, in the presence of a source, reactivity additions could result in operation at power and possible damage to the reactor. In such an incident, the danger to the general public and to the operators would be no more than that discussed below for the maximum credible accident.

\section{Reactor Storage}

When not in use, the reactor will normally be stored in the scrammed condition in one of the storage pits. These pits are provided with doors having a minimum of 7 in. of steel as shielding above the reactor storage 
location. The anticipated dose rate directly above a storage-pit door $15 \mathrm{~min}$ after shutdown of the reactor is less than $1 \mathrm{rad} / \mathrm{hr}$.

Unobstructed drains (i.e., without valves or traps) in the storage pits minimize the possibility of flooding (see sec. 4). The reactor is expected to be critical in the scrammed condition if immersed in water. In the unlikely event of flooding with the source inserted, the reactor would operate at power with possible resultant damage to the reactor, but the hazard to personnel or to the general public would be no more than that discussed for the MCA.

\section{Abnormal Operation}

Various abnormalities in operation have been postulated. These situations have been analyzed in terms of likelihood of occurrence and potential effects.

Positioning of Safety Block

A potential hazard could be created by the malpositioning of the safety block. If the block were incompletely inserted during the delayed-critical determination and later inserted more fully prior to burst operation, the excess reactivity so added could significantly increase the resultant burst.

The control system logic diagram (see sec. 5) provides electrical interlocks to prevent out-of-sequence insertion of the safety block. In addition, the safety block positive stop has contact switches electrically interlocked into the operating sequence to show that the block is fully inserted into the core, as mentioned in Section 3.

As shown in Fig. 3.6, Section 3, it would take an error of 0.005 in. in positioning to result in a reactivity addition of $1 \phi$. Since the safetyblock insertion position is reproducible to an accuracy of better than 0.001 in., a variation of $0.005 \mathrm{in}$. in the position of the safety block will be seen at the control console. The operating procedures will require that any burst run be terminated if such a discrepancy in repositioning occurs. It must be emphasized that the ultimate safety of the reactor depends on rigid administrative control and adherence to the detailed operating procedures. 
Jamming of Movable Fissionable Materials

Jamming could conceivably occur during insertion or withdrawal of any movable fissionable component, and the mechanical design (i.e., clearances, loading on motors and gear trains, etc.) was conservatively chosen to minimize such difficulties and the likelihood of occurrence. Jamming of any two of the three movable components on initial insertion would result in operating difficulties that would require maintenance to correct but would not present a hazard. Jamming of the burst rod during insertion would lead to a lower than expected burst yield.

Failure of the burst rod and the safety block to withdraw after a burst would result in continued operation of the reactor at some power, but the core would have thermally expanded to a point where it would be below prompt critical.

The effect of continued operation at a high power level was calculated ${ }^{5}$ to result in average temperatures in excess of $1000^{\circ} \mathrm{C}$, with eventual equilibrium at $550^{\circ} \mathrm{C}$. The temperatures as a function of time are shown in Fig. 9.3 for the reference core. The high average temperature would most likely be accompanied by local melting of the fuel. This would result in destruction of the reactor core but should not present a serious hazard to operating personnel or to individuals outside the exclusion area. Fission-product release as a consequence of a meltdown following a burst was discussed above.

\section{Control System Failures}

Failure of the safety circuits to scram the burst rod and safety block can result in overheating and possible meltdown of the reactor core. The consequences of this type of failure would, at the worst, be the same as the consequences of jamming of fissionable components (see above).

\section{Steady-State Mode}

When operating in the steady-state mode, abnormal operations such as failures of the scram or safety systems could result in reactor meltdown,

\footnotetext{
${ }^{5}$ Preliminary Design of the ORNL Fast Burst Reactor, NDA-2136-1 (July 30, 1960).
} 


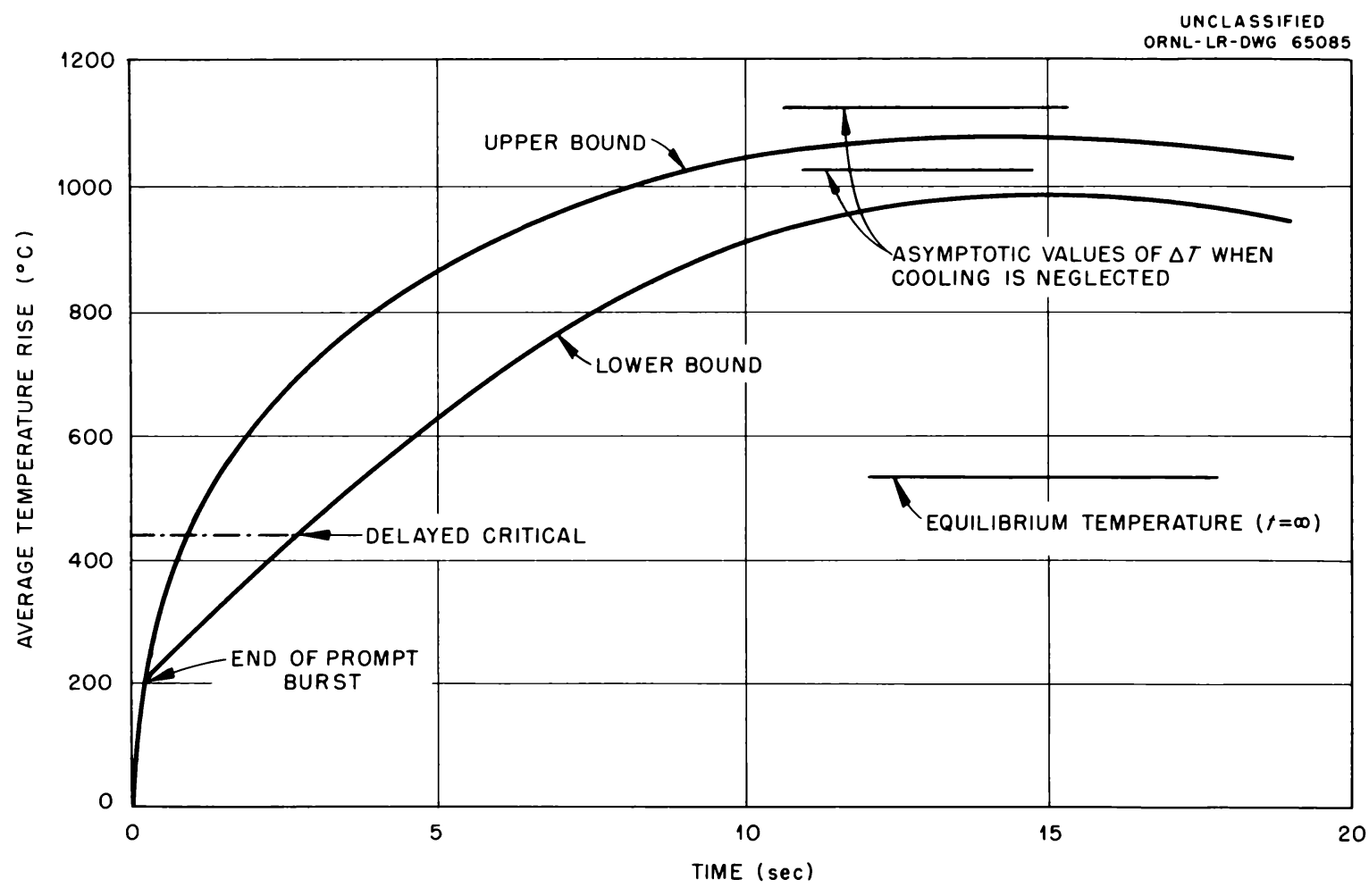

Fig. 9.3. Calculated Average Temperature Rise vs Time Following a Burst of $10^{17}$ Fissions and Scram Failure. (Based on NDA Report 2136-1.)

as mentioned above. Additions of excess reactivity during steady-state power would be ramp additions, and, if the addition were small or slow or both small and slow, the power level would rise until thermal expansion compensated for the reactivity addition or a scram took place. Rapid and large reactivity additions could result in a fission spike similar to the spikes shown for Godiva in Fig. 9.4. It should be noted that addition rates in excess of $\$ 1000 / \mathrm{sec}$ are required to result in a burst significantly in excess of $2 \times 10^{17}$ fissions.

Burst Mode

Two major categories of accident can occur during burst-mode operation. The first, failure of the safety system to scram the reactor, was considered above. The second, the addition of excess reactivity at an inopportune moment could result in greater than target yields. Small increments of reactivity beyond that required for the target yield of $10^{17}$ 


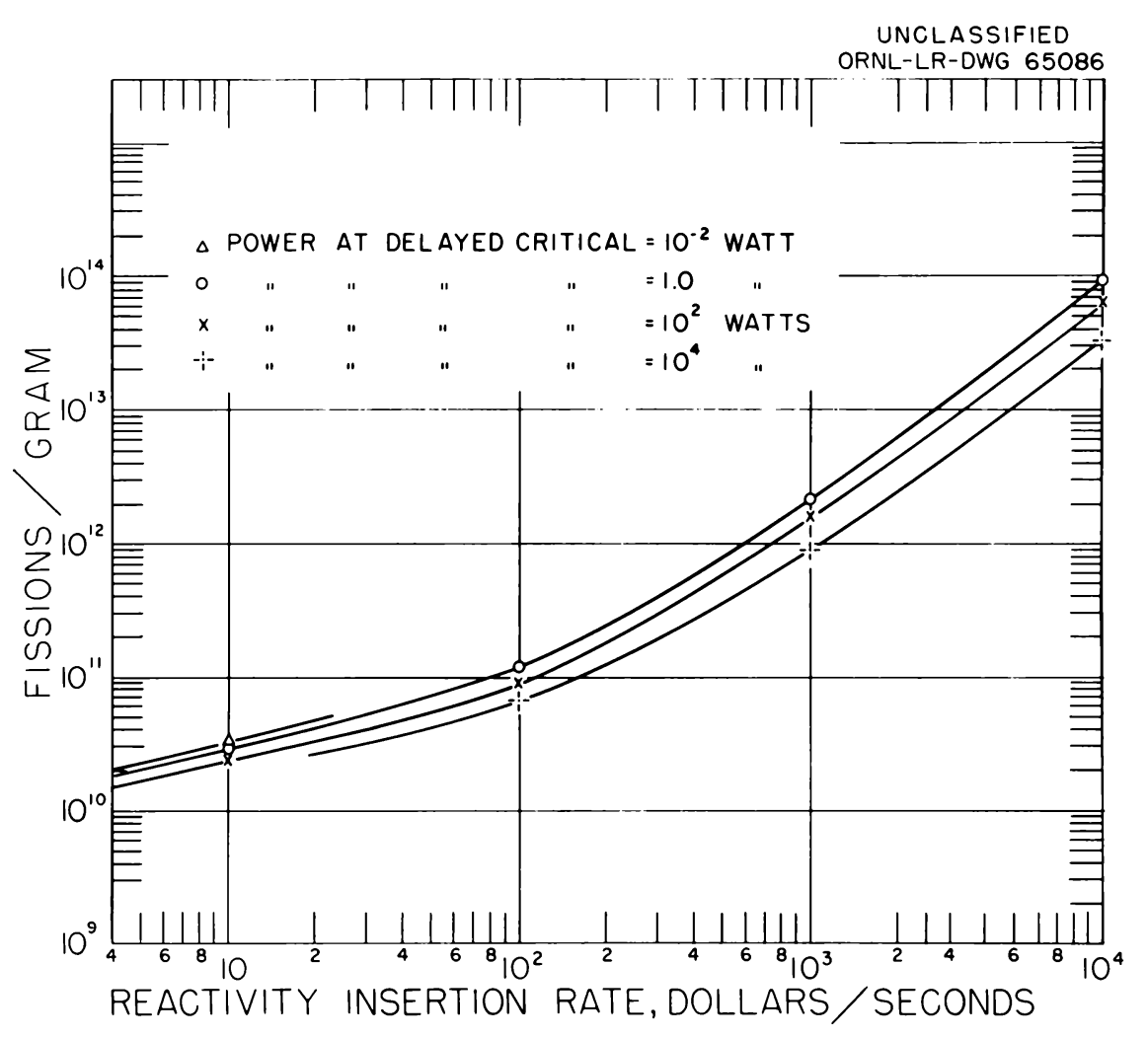

Fig. 9.4. Computed Fission Yield per Gram of Godiva as a Function of Reactivity Insertion Rate for Several Initial Power Levels at Delayed Critical. [Reprinted, with permission, from Nuclear Science and Engineering, 8(6), 705 (1960).]

fissions could possibly result in damage and disruption of the core, depending upon the magnitude of the excursion. The potential for larger excursions and the results of such excursions are discussed below in detail for the maximum credible accident.

\section{Other Hazards}

Flood

A severe flood at the reactor building location is considered extremely unlikely because of the natural topography of the site. ${ }^{6}$ The

\footnotetext{
${ }^{6}$ Experimental Gas Cooled Reactor Preliminary Hazards Summary Report,
} ORO-196 (May 1959). 
reactor building is located at an elevation of $971 \mathrm{ft}$, which is to be compared with a maximum anticipated flood level for the Clinch River of 800 ft.

\section{Weather}

The reactor building was designed to withstand the wind and snow loads anticipated for this area. ${ }^{7}$

$\underline{\text { Fire }}$

The buildings were constructed in accordance with the Southern Standard Building Code and are classified as Group G, Industrial Occupancy Type IV, Noncombustible. The control building is furnished with a fire-protection system consisting of fire-hose cabinets strategically located in the hallways and local $\mathrm{CO}_{2}$ fire extinguisher stations, and the entire building is protected with an automatic sprinkler system. There is an outside fire hydrant and Siamese pumper connection.

The reactor building has a hose station and standpipe, local $\mathrm{CO}_{2}$ stations, and an outside fire hydrant. There is a heat-detection system within the reactor building, but there is no sprinkler system. The heat-detection system operates in conjunction with the facility fire-alarm system. In case of fire the responsible supervisor in attendance will evaluate the safety and desirability of using water in the particular situation.

\section{Earthquake}

The earthquake history of the eastern portion of Tennessee, including the Oak Ridge area, is one of comparative freedom from shocks. ${ }^{8}, 9$ The area does not have a history of any major earthquakes or of frequent

7Preliminary Proposal for Fast Burst Reactor Facility, Bldgs. 7709, 7710, \& 7711, ORNL Area, Contract AT-(40-1)-2511, Giffels and Vallet, Inc., Detroit, Mich.

${ }^{8}$ Letter from J. Lynch to M. Mann, November 3, 1948, quoted in A Report on the Safety Aspects of the Homogeneous Reactor Experiment, $0 \overline{\mathrm{RNL}}-73 \mathrm{I}$ (June 20, 1950).

${ }^{9}$ B. C. Moneymaker, private communication to W. B. Cottrell, October 27, 1952. 
minor ones, reflecting the general stability of the earth's crust in the Southern Appalachians. In the design of facilities at ORNL and in the design of dams and power houses by TVA in East Tennessee, no special allowances for earthquake forces above those required by the structure itself have been made. It is concluded that no major damage would be incurred by the reactor or the DOSAR facility in the event of an earthquake of the severity predicted for this area.

\section{Maximum Credible Accident}

Any discussion of the maximum credible accident (MCA) for a reactor of the type described in this report eventually devolves to the question of how much excess reactivity can be added to the reactor after it has been reassembled to delayed critical following the period of neutron decay. All operations in the initial assembly are accomplished in the presence of a source, with reactivity addition rates limited to safe amounts assessed on the basis of the speed of response of the controls system and the possible effects as predicted by the work of Hansen ${ }^{10}$ and stratton et al. 11

Following reassembly, the burst rod is immediately fired into the reactor. There is a period of time (wait time, see Fig. 9.5) in which the neutron population is low and the behavior of the reactor is described, not by kinetic equations, but by statistical fluctuations. During this time, chains of fission reactions occur but terminate by leakage of neutrons from the core. Inevitably, the neutron population will build up through the establishment of nonterminating fission chains to the point where the kinetic equations are again valid. It is during this waiting time, while the neutron population is low, that the potential exists for the possible hazardous addition of reactivity to the system.

${ }^{10} \mathrm{G}$. E. Hansen, Burst Characteristics Associated with the Slow Assembly of Fissionable Materials, LA-1441 (1952).

${ }^{11_{W}}$. R. Stratton, T. H. Calvin, and R. B. Lazarus, Analysis of Prompt Excursions in Simple Systems and Idealized Fast Reactors, Second United Nations International Conference on the Peaceful Uses of Atomic Energy, Geneva, 1958, United Nations, Vol. 12, p. 196. 


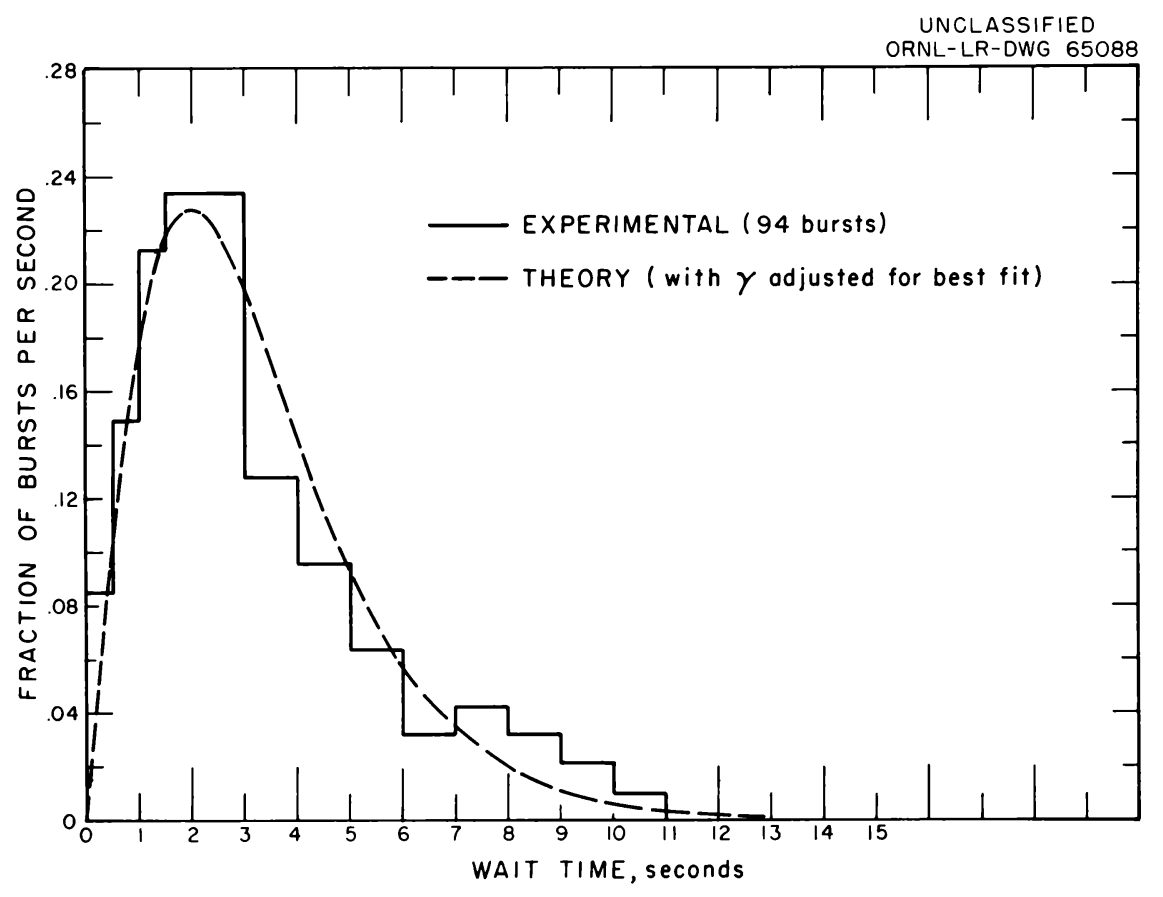

Fig. 9.5. Distribution of Burst Wait Times in Fraction per Second vs Wait Time. [Reprinted, with permission, from Nuclear Science and Engineering, 8(6), $703(1960)$.

Positive mechanical stops ensure that only the desired amount of reactivity is added with the burst rod. It is conceivable that changes in external configuration that would cause an increase in reactivity could have occurred during the period following the initial criticality calibration. Since access to the operating area is not permissible during this time it is considered unlikely that any such change would have occurred. Furthermore, all experimental equipment will be suitably designed and secured to prevent movement toward the reactor. Nevertheless, if a major increase in reactivity, equivalent to 50 cents, should occur during this period, it can be seen from Fig. 9.6 that potential yields in the order of approximately $10^{19}$ fissions appear possible for a core of $10^{5} \mathrm{~g}$. An example of the magnitude of change required can be seen from Fig. 8.2. The $8 \times 8 \times 1$-in.-thick curved piece of Plexiglas would have to be moved from a position $0.8 \mathrm{in}$. away from the core to one $0.5 \mathrm{in}$. away. Correspondingly greater movements would be required if the reflector were further away initially. 


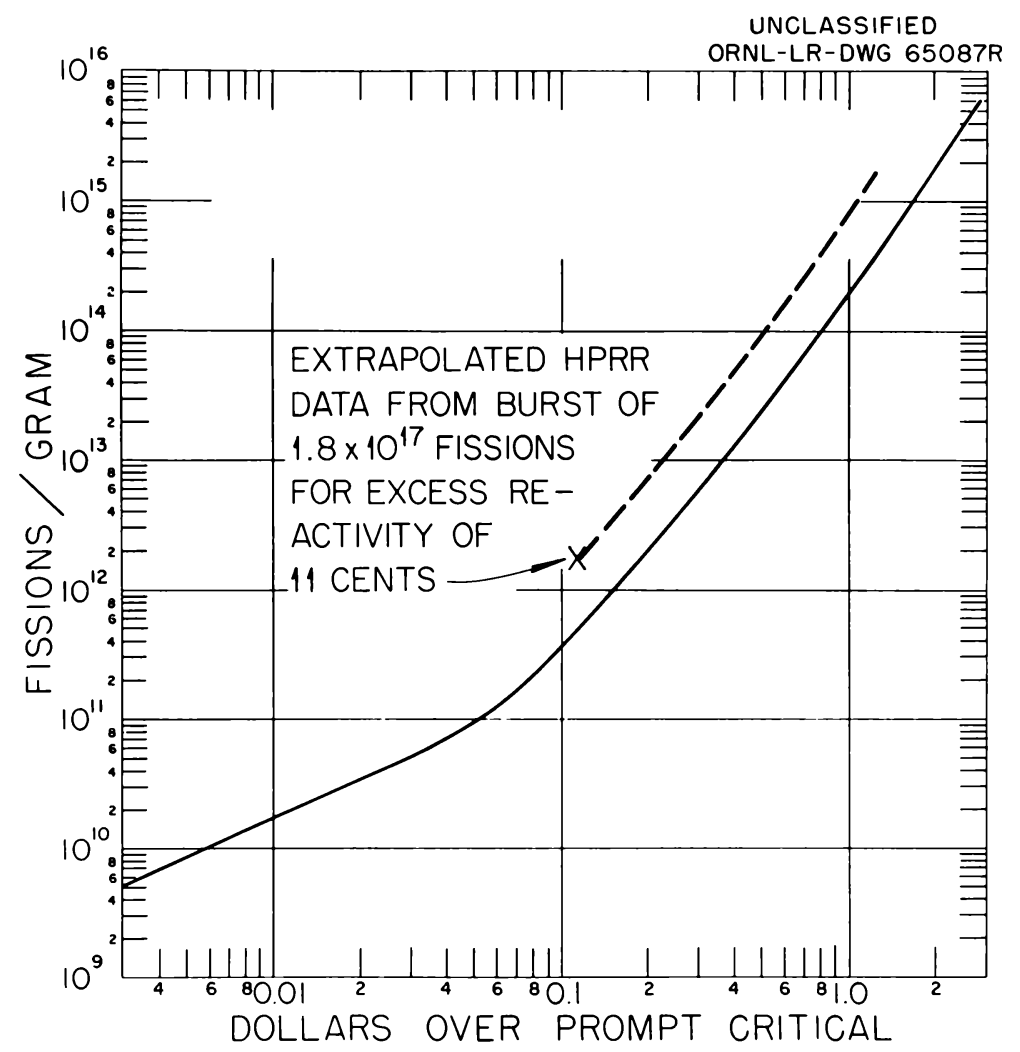

Fig. 9.6. Computed Fission Release in Godiva for a Wide Range of Initial Excess Reactivities. [Reprinted, with permission, from Nuclear Science and Engineering, 8(6), 705 (1960).]

It is highly unlikely that such a change in external configuration would go undetected since all equipment is rigidly mounted. In addition, three remotely controlled television sets will be available to permit observation of the experiment and the reactor.

Other provisions to limit reactivity increments include the tube placed around the volume into which the safety block is scrammed, the crash plate that can be installed on the reactor-holding structure, and the safety cage that can be installed around the core. These provisions will be utilized as dictated by the requirements of specific experiments. With these provisions it is considered highly unlikely that an undetected reactor addition as high as 50 cents could occur. Even though 
Table 9.6. Criticality Accidents of Metal Systems in Air

\begin{tabular}{|c|c|c|c|c|c|}
\hline Incident & $\begin{array}{l}\text { Active } \\
\text { Material }\end{array}$ & Geometry & $\begin{array}{l}\text { Total } \\
\text { Fissions }\end{array}$ & Cause & $\begin{array}{l}\text { Physical } \\
\text { Damage }\end{array}$ \\
\hline $\begin{array}{l}\text { Pu core reflected with } \\
\text { tungsten carbide; } \\
\text { August } 21,1954\end{array}$ & $\begin{array}{l}\text { 6.2-kg 8-phase } \\
\mathrm{Pu}\end{array}$ & $\begin{array}{l}\text { Spherical core, tungsten- } \\
\text { carbide reflected }\end{array}$ & $\sim 10^{16}$ & $\begin{array}{l}\text { Hand stacking of } \\
\text { reflector }\end{array}$ & None \\
\hline $\begin{array}{l}\text { Pu core reflected with } \\
\text { beryllium, May 21, } \\
1946\end{array}$ & $\begin{array}{l}\text { 6.2-kg } \delta \text {-phase } \\
\mathrm{Pu}\end{array}$ & $\begin{array}{l}\text { Spherical core, beryllium } \\
\text { reflected }\end{array}$ & $\sim 3 \times 10^{15}$ & $\begin{array}{l}\text { Hand stacking of } \\
\text { reflector }\end{array}$ & None \\
\hline $\begin{array}{l}\text { Jemina; a cylindrical, } \\
\text { unreflected, U⿱235 as- } \\
\text { sembly; April 18, } \\
1952\end{array}$ & $\begin{array}{l}\text { 92.4-kg uranium } \\
\text { metal, } 93 \% \mathrm{U}^{235}\end{array}$ & Cylindrical, unreflected & $1.5 \times 10^{16}$ & Computation error & None \\
\hline $\begin{array}{l}\text { Godiva; a bare U } U^{235} \\
\text { sphere; February } 3 \text {, } \\
1954\end{array}$ & $\begin{array}{l}\text { 53-kg uranium } \\
\text { metal, } 93 \% \mathrm{U}^{235}\end{array}$ & Spherical, unreflected & $5.6 \times 10^{16}$ & $\begin{array}{l}\text { Incorrect posi- } \\
\text { tioning of fuel }\end{array}$ & $\begin{array}{l}\text { Slight warping of } \\
\text { core pieces }\end{array}$ \\
\hline $\begin{array}{l}\text { Godiva; a bare } U^{235} \\
\text { sphere; February } 12, \\
1957\end{array}$ & $\begin{array}{l}\text { 54-kg uranium } \\
\text { metal, } 93 \% \mathrm{U}^{235}\end{array}$ & $\begin{array}{l}\text { Spherical, unreflected } \\
\text { except for experimental } \\
\text { objects }\end{array}$ & $1.2 \times 10^{17}$ & $\begin{array}{l}\text { Shift of experi- } \\
\text { mental objects }\end{array}$ & $\begin{array}{l}\text { Warping, oxidation, } \\
\text { near melting close } \\
\text { to core center }\end{array}$ \\
\hline
\end{tabular}


its occurrence is improbable, the resultant excursion of approximately $10^{19}$ fissions is considered the maximum credible accident. While it is true that the reactor would be destroyed, it has been shown herein that its destruction does not represent danger to operating personnel or to persons outside the restricted area.

A review of criticality accidents for metal systems in air ${ }^{12}$ is presented in Table 9.6. The maximum accidental excursion for fast systems is listed as $1.2 \times 10^{17}$ fissions. It must be emphasized, however, that operation of a bare metal assembly is hazardous unless potential sources of reactivity additions are carefully controlled. In the last analysis, this depends on rigid administrative control and strict adherence to safe operational procedures.

${ }^{12}$ Based on data reported by W. R. Stratton. "A Review of Criticality Accidents" in Progress in Nuclear Energy, Ser. IV: Technology, Engineering and Safety, Vol. 3, Pergamon Press, New York, 1960. 


\section{ACKNOWLEDGMENTS}

It is with sincere appreciation that I acknowledge the cooperation and assistance of many members of the staff of the Oak Ridge National Laboratory in the preparation of information for inclusion in the various sections of this report. In particular, I wish to thank W. B. Cottrell and his group for comprehensively reviewing the drafts and outlining the requirements for a hazards summary, L. C. Oakes for material for the Instrumentation and Controls section, P. H. Pitkanen for material for the Hazards and Safeguards section, J. T. Mihalczo and L. W. Gilley for the results of the critical experiments which were copiously utilized in this writeup, and J. A. Auxier for his guidance in establishing project goals and design specifications. 
APPENDIX

Shielding Considerations

The shielding factors on which the concrete thicknesses for the roof and walls of the control building and counting room are based were taken from the following letter:

To: M. I. Lundin, Bldg. 9204-1

From: J. A. Auxier, Bldg. 2001

Subject: Shielding Considerations for Fast Burst Reactor Control Building

At LASL Godiva II, crystal activation after a 30-min. exposure at $6 \mathrm{mrad} / \mathrm{hr}$, i.e. $3 \mathrm{mrad}$, presented a serious problem for several days afterward. Consequently, we should keep the integrated exposure at the FBR Counting Room to not greater than $0.3 \mathrm{rad} /$ exposure; for experiments where several high level exposures per day are absolutely necessary, individual counter shields could be increased. This level is arbitrary, but should be a reasonable assumption.

The walls and roof of the Counting Room should be 12 in. minimum thickness regardless of the neutron shielding considerations. Then, assuming three high level exposures per day, on occasion, the maximum dose to any point in the Control Building should not exceed 2 mrad per exposure.

Therefore, using Ritchie's calculations of angular distribution and dose as a function of distance, the table attached was constructed. It should be noted that for the thicker roof slabs, 6 in. of concrete should be sufficient to support enough soil to furnish the remainder of the shielding. By placing the building immediately adjacent to the hill at about $800 \mathrm{ft}$ (by utilizing some excavating and a retaining wall as high as the building, long side near hill) "geometry" would provide adequate shielding on that side, and this would also decrease the roof thickness slightly. Such an arrangement also keeps the cables between the reactor and Control Building shorter; this will be an overall, long-range advantage, electronically and economically.

The addition of a boron compound to the concrete is recommended to decrease further thermal neutron activations.

J. A. Auxier 
To: M. I. Lundin

Attachment 1

August 25, 1960

Reduction Factors and Inches of Concrete Equivalent

Shielding for F'BR Control Building

\begin{tabular}{cccccc}
\hline $\begin{array}{c}\text { Distance } \\
\text { From } \\
\begin{array}{c}\text { Reactor } \\
(\mathrm{ft})\end{array}\end{array}$ & $\begin{array}{c}\text { Dose - rad } \\
10 \mathrm{~min}, \\
10 \mathrm{kw}\end{array}$ & $\begin{array}{c}\text { Reduction } \\
\text { Factor } \\
\text { C. } \text {. }^{*}\end{array}$ & $\begin{array}{c}\text { Inches } \\
\text { Concrete } \\
\text { C. } \text { R. }^{*}\end{array}$ & $\begin{array}{c}\text { Reduction } \\
\text { Factor } \\
\text { Personnel }\end{array}$ & $\begin{array}{c}\text { Inches } \\
\text { Pencrete }\end{array}$ \\
\hline 800 & $42-30 * *$ & $140-100^{*}$ & $20-18.5 * *$ & $21-15^{* *}$ & $12-11^{* *}$ \\
1000 & 18 & 60 & 16 & 9 & 9 \\
1200 & 11 & 37 & 14.5 & 5.5 & 7 \\
1400 & 5.5 & 18 & $12(\mathrm{~min})$ & 2.8 & 4 \\
\hline
\end{tabular}

*Counting Room.

**Denotes values corrected for angular distribution when placed near hill. 

ORNL-3248

UC-80 - Reactor Technology

TID-4500 (17th ed., Rev.)

\section{Intermal Distribution}

1. S. I. Auerbach

2-11. J. A. Auxier

12. S. E. Beall

13. M. Bender

14. E. P. Blizard

15. A. L. Boch

16. R. B. Briggs

17. F. R. Bruce

18. T. H. J. Burnett

19. A. D. Callihan

20. T. E. Cole

21. W. B. Cottrell

22. N. E. Dunwoody

23. E. P. Epler

24. A. P. Fraas

25. J. H. Frye

26. W. R. Gall

27-28. L. W. Gilley

29. R. H. Guymon

30. F. F. Haywood

31. J. R. Hill

32. A. Hollaender

33. L. B. Holland

34. G. S. Hurst

35. W. H. Jordan

36. P. R. Kasten

37. W. E. Kinney

38. J. A. Lane

39. M. I. Lundin
40. R. N. Lyon

41. H. G. MacPherson

42. W. D. Manly

43. J. T. Mihalczo

44. K. Z. Morgan

45. W. L. Morgan

46. G. Morris

47. L. C. Oakes

48. J. S. Olsen

49. A. M. Perry

50. P. H. Pitkanen

51. F. W. Sanders

52. A. W. Savolainen

53. H. E. Seagren

54. M. J. Skinner

55. I. Spiewak

56. W. S. Snyder

57. H. F. Stringfield

58. J. A. Swartout

59. A. Taboada

60. A. M. Weinberg

61. J. P. Witherspoon

62. M. Witkamp

63-102. Laboratory Records Department

103. Laboratory Records Department, ORNL-F

104-106. Central Research Library

107-109. ORNL - Y-12 Technical Library

Document Reference Section

110-112. Reactor Division Library

\section{External Distribution}

113. E. O. Baicy, U. S. Army Ordnance Ballistics Laboratory, Aberdeen Proving Ground, Maryland

114. H. D. Bruner, M.D., Division of Biology and Medicine, USAEC, Washington, D.C.

115-116. David Cope, Reactor Division, USAEC, ORO

117. R. L. Corsbie, Director, Civil Effects Tests Operations, DBM, USAEC, Washington, D.C.

118. K. O. Donelian, United Nuclear Company, Development Division, NDA, White Plains, New York 
119. C. L. Dunham, M.D., Chief, DBM, USAEC, Washington, D.C.

120. Glen E. Elder, White Sands Missile Range, White Sands, New Mexico

121. Marvin Fox, Nuclear Electronics Laboratory, Engr. Div., Hughes Aircraft Company, Los Angeles, California

122. H. E. Grier, Edgerton, Germeshausen \& Grier, Inc., Las Vegas, Nevada

123. Arthur L. Kaplan, Defense Systems Department, General Electric Company, Syracuse, New York

124. Albert Kirschbaum, Lawrence Radiation Laboratory, Berkeley, California

125. Ralph F. Lumb, Western New York Research Center, Univ. of Buffalo, New York

126. Hugh C. Paxton, Group N-2 - Los Alamos Scientific Laboratory, Los Alamos, New Mexico

127. Col. J. E. Pickering, USAF, Aerospace Center, School of Aviation Medicine, San Antonio, Texas

128. J. E. Reeves, Ass't. Mgr. for Field Operations, USAEC, Albuquerque, New Mexico

129. H. M. Roth, Division of Research and Development, USAEC, ORO

130. C. S. Shoup, Biology Division, USAEC, ORO

131. S. C. Sigoloff, Edgerton, Germeshausen \& Grier, Inc., Goleta, California

132. Anthony Stathopolos, United Nuclear Company, Development Division, NDA, White Plains, New York

133. William R. Stratton, Group N-2 - Los Alamos Scientific Laboratory, Los Alamos, New Mexico

134. B. Stephens, Aerojet-General Nucleonics, San Ramon, California

135. G. E. Thoma, Jr., M.D., St. Louis University Hospital, St. Louis, Missouri

136. J. B. Williamson, CETO, Mercury, Nevada

137. T. F. Wimett, Los Alamos Scientific Laboratory, Los Alamos, New Mexico

138. David Wood, USAEC, Albuquerque, New Mexico

139-741. Given distribution as shown in TID-4500 (17th ed., Rev.) under Reactor Technology Category (75 copies - OTS) 



